\title{
THE GREEN ROOM METHOD: INCORPORATING GREEN FAÇADES INTO WHOLE BUILDING ENERGY MODELS
}

\section{By}

\section{Francis Laparé}

\author{
Bachelor of Arts, Strategic Studies \\ Royal Military College of Canada, 2002
}

\author{
A Major Research Project \\ presented to Ryerson University \\ in partial fulfillment of the \\ requirements for the degree of \\ Master of Building Science \\ in the Program of \\ Building Science
}

Toronto, Ontario, Canada, 2013

CFrancis Laparé, 2013 


\section{Authors Declaration}

I hereby declare that I am the sole author of this MRP. This is a true copy of the MRP, including any required final revisions.

I authorize Ryerson University to lend this MRP to other institutions or individuals for the purpose of scholarly research.

I further authorize Ryerson University to reproduce this MRP by photocopying or by other means, in total or in part, at the request of other institutions or individuals for the purpose of scholarly research.

I understand that my MRP may be made electronically available to the public. 


\begin{abstract}
The Green Room Method: Incorporating Green Façades into Whole Building Energy Models. Master of Building Science 2013

Francis Laparé

Program of Building Science

Ryerson University
\end{abstract}

This project proposes a technique, called the green room method, to enable incorporating a Green Façade into a whole building energy model using software from Integrated Environmental Solutions, called Virtual Environment (IES-VE). The technique sees a room created onto the exterior walls of a building. This room has geometry similar to that of a planned or actual Green Façade and sees thermal properties assigned to its walls which are also similar to the ones of the vegetative cover growing on the structure of Green Façades. In addition, a mechanical system is assigned to the void space of the green room (plenum) in order to dissipate the thermal gains from solar radiation through evaporative cooling, imitating plant transpiration and other biological functions. Results indicate that the Green Room Method is accurate in predicting the thermal behaviour of Green Facades. 


\section{Acknowledgements}

I would like to express my deepest appreciation to the many people who have supported my efforts in completing this project. In many ways, I found myself at the center of a support network which enabled me to complete a technical research paper, something I had very little background to do. First and foremost, without the assistance and guidance of Mr. Tristan Truyens from Dialog's Toronto Studio, this project would have been unachievable. His level of expertise with IES-VE and his patience in helping me understand its intricacies were instrumental to the successful development of the software based models. Of course, his assistance was available to me because of the support of Mr. Craig Applegath, co-founder and Principal at Dialog. In addition to providing access to his team of experts, Mr. Applegath offered the inspiration for this research project as well as sustained guidance and encouragement. I was introduced to Dialog by Mr. Alexander Hay, a British Army Veteran, Adjunct Professor at the University of Toronto and Infrastructure Resilience Leader at Dialog. In addition to initiating this chain of relationships, he has offered countless insights and much support as this project moved forward.

I also need to thank Mr. Applegath for introducing me to Mr. Reuben Freed from Greenscreen, a Green Façade manufacturer. Mr. Freed took time to share much of his expertise on Green Façades, to describe some of the most important installations in North-America and to provide me with valuable research documents. Mr. Freed was also kind enough to introduce me to Prof Liat Margolis from the University of Toronto's Daniels School of Landscape Architecture and director of the Green Roof Innovation Testing Laboratory. Prof Margolis was extremely welcoming to collaborate with this research and offered much more resources that I unfortunately could not use in this short research period. She also carefully reviewed the research proposal for this project and provided very specific feedback which has influenced much of this paper. In addition to providing continued insights over the course of my research and always exploring opportunities to assist my efforts, she was kind enough to introduce Prof David Tilley.

Prof Tilley from the Ecosystem Engineering Design Lab at the University of Maryland is the leading North-American researcher on Green Façades. In discussing with him, he provided very clear and concise insights into the thermal effects of Green Façades on buildings as whole 
systems. He also provided valuable guidance on research papers on this topic and also shared highly relevant documentation. Prof Tilley shared much more data and information then I was able to use for this project, but nonetheless contributed significantly to shape the direction of my research through his previous work and acumens.

It goes without saying that my supervisor, Prof Zaiyi Liao and my second reader Prof Ramani Ramakrishnan, both from Ryerson University's department of Architectural Sciences are the ones who allowed me to put all of the information and assistance I received into a coherent and rigorous research project. Both were very involved in my work and their patience, methodical focus and support they provided allowed me to create an original software based method which is scientifically sound and promises great applicability. Thanks to them and the Building Science Graduate Program faculty, I now have gained a science based perspective on the built environment.

Finally, while this project is the culmination of my graduate work, the year of academic effort preceding it and the intense months which saw it materialise where possible because of the steadfast support and encouragement of my wife, Natalie Laparé. This year saw her shoulder more than her fair share of work at home with our two very young children so that I could succeed in completing this degree. I can hardly express how thankful I am for her support in not only pursuing this academic endeavour but also in changing career path at a very challenging time in our lives. Thank you. 


\section{Table of Contents}

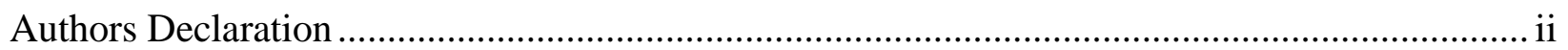

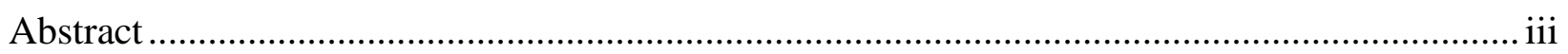

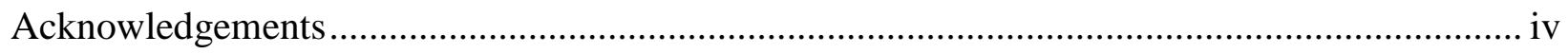

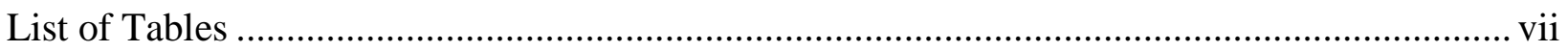

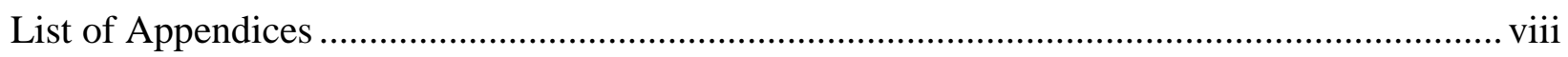

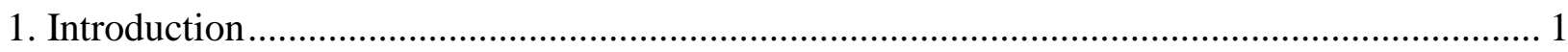

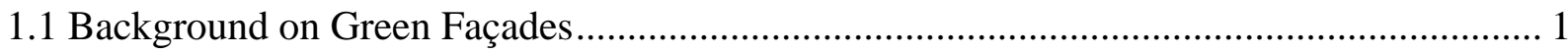

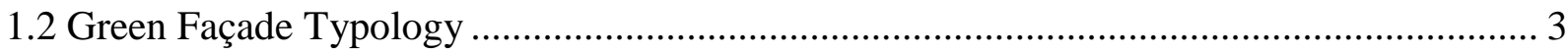

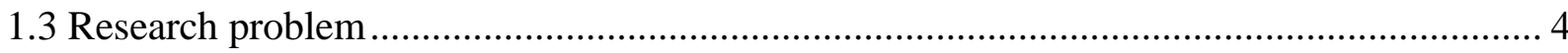

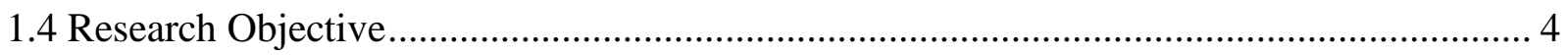

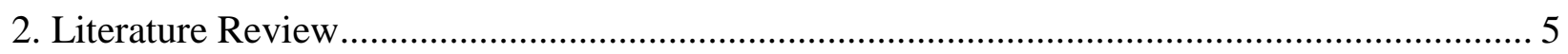

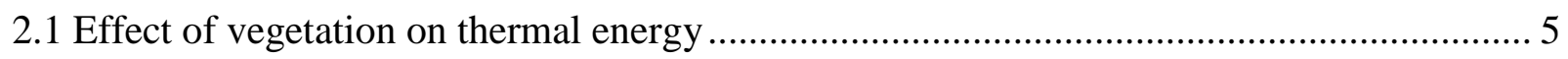

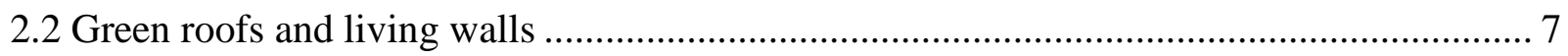

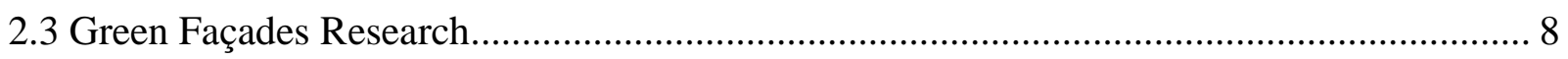

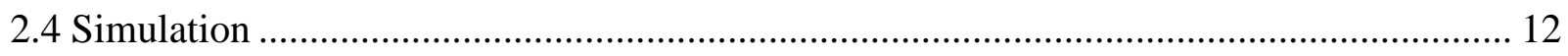

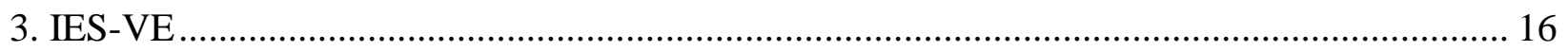

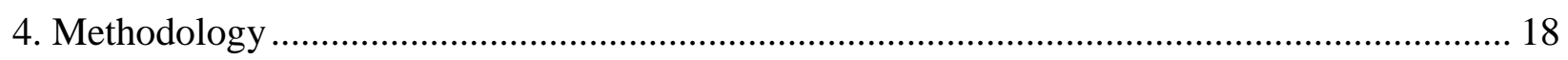

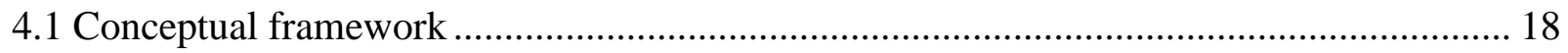

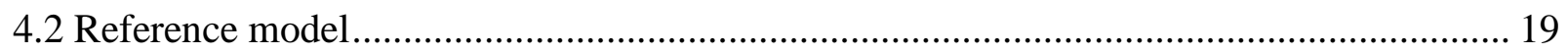

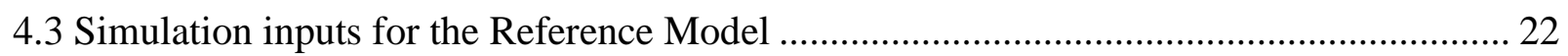

4.4 Result interpretation for the reference model............................................................... 23

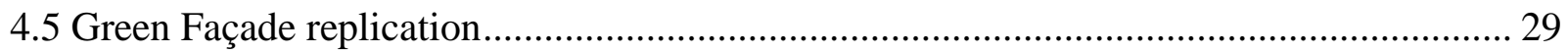

4.6 Enclosed Green Room Technique............................................................................. 32

4.7 Vented Green Room Technique ............................................................................ 33

4.8 Cooled models for energy consumption quantification .................................................. 35

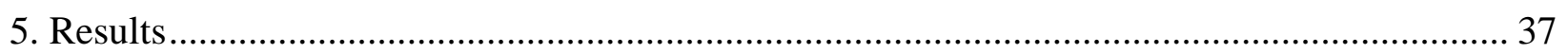

5.1 Reference building and vegetated building comparison ................................................. 37

5.2 Reference model and enclosed vegetated model comparison ............................................ 38

5.3 Reference model and vented vegetated model comparison .............................................. 39

5.4 Comparison between Enclosed and Vented Green Rooms .............................................. 40

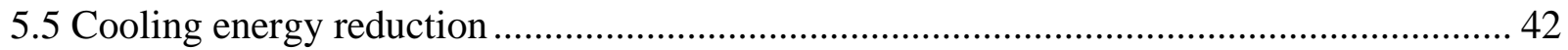

5.6 Thermal Dynamics and Green Facades...................................................................... 43 


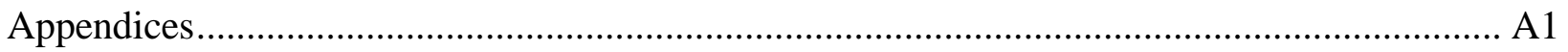

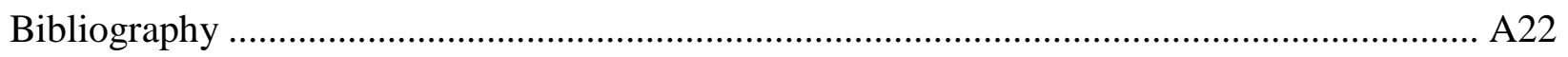

\section{List of Tables}

Table 1 Dimensions and construction details of the actual and model reference buildings ........ 20

Table 2 U-Value of building parts and solar absorptivity coefficient ..................................... 21

Table 3 Color-reflectivity classification for opaque building materials .................................. 21

Table 4 General Characteristics of the Green Room .......................................................... 31

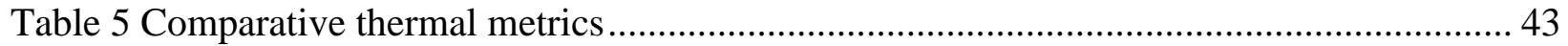

Table 6 Comparative conduction gains into main room, 11-17 July ....................................... 44

\section{List of Figures}

Figure 1 Vernacular Green Façade (Köhler, 2008) .............................................................. 1

Figure 2 perforated metal screen, CANMET Hamilton........................................................ 2

Figure 3 Indirect Green Façade system by Greenscreen ${ }^{\circledR}$.................................................... 3

Figure 4 Actual Reference Building (Tilley, Price, \& Marrow, 2012) \& Figure 5 Model

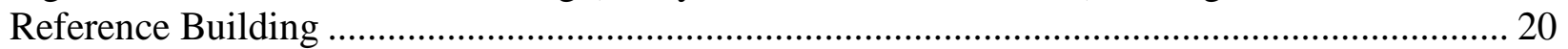

Figure 6 Exterior temperature fluctuations in ${ }^{\circ} \mathrm{C}$ over hours, 11-17 July................................ 24

Figure 7 Incident Solar Radiation on South Façade in Watts per square meters over hours, 11-17

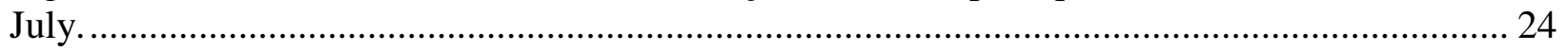

Figure 8 Interior temperature fluctuations in ${ }^{\circ} \mathrm{C}$ over hours, 11-17 July................................ 25

Figure 9 Integrated Deltas for thermal conditions, in ${ }^{\circ} \mathrm{C}$ and Watts per square meters over hours,

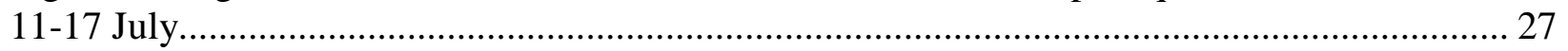

Figure 10 Tilley et al.'s vegetated experimental building with a Green Façades in 2011 ........... 28

Figure 11 Green room rendering, looking from the North-East. ......................................... 30

Figure 12 Effective temperature given local peak temperatures in Kansas City, ASHRAE 200732

Figure 13 Open loop ventilation and evaporative cooling system......................................... 33

Figure 14 Vented green room rendering, looking from the North-East. ................................. 34

Figure 15 Closed loop ventilation and evaporative cooling system ..................................... 35

Figure 16 Experimentally measured Interior temperature fluctuations in ${ }^{\circ} \mathrm{C}$ over hours, 11-17

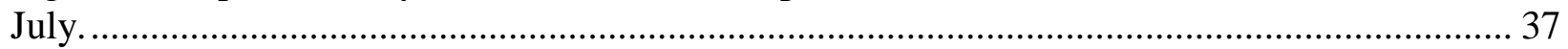

Figure 17 Enclosed technique, IES-VE generated interior temperature fluctuations in ${ }^{\circ} \mathrm{C}$ over

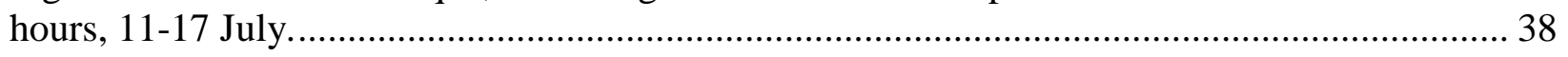

Figure 18 Vented techniques, IES-VE generated interior temperature fluctuations in ${ }^{\circ} \mathrm{C}$ over

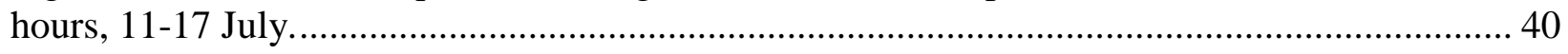

Figure 19 comparative graphs of interior temperature fluctuations for enclosed and vented green

room models in ${ }^{\circ} \mathrm{C}$ over hours, $11-17$ July................................................................... 41

Figure 20 Comparative graph of cooling load to maintain the main room of all models at set

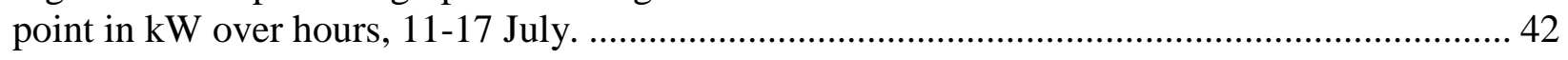


Figure 21 Relative contributions of different thermal pathways to the total heat gain of the main room, 11-17 July. 44

Figure 22 Relative contributions of different thermal pathways to the total heat gain of the vegetated main room, 11-17 July. 45

Figure 23 Comparative graph of heat transfer across the walls of the main room in $\mathrm{kW}$ over

hours, 11-17 July. 46

Figure 24 Hotel Stadthalle, Vienna. the world's first city centre hotel with a zero energy balance

\section{List of Appendices}

Description of Tilley et al.'s experimental building construction

Table A.1 Composite insulation of Tilley et al.'s experimental building

Table A. 2 Comparative exterior air temperature data, reference building and reference model A2

Table A. 3 Comparative solar radiation data, reference building and reference model A4

Table A. 4 Comparative interior temperature data for reference building and reference model. A7

Table A. 5 Difference between reference building and reference model condition ................. A10

Table A. 6 Cooling effect observed between reference building and vegetated building ......... A13

Table A. 7 Cooling effect observed between reference model and vegetated models

Table A. 8 Reduction in cooling energy between reference model and vegetated models A18

Table A. 9 Exterior wall specific conduction gain observed between reference model and vegetated models 


\section{Introduction}

This research is concerned about developing a simulation method to allow the integration of Green-Façades into Whole Building Energy Models. Because a feature to incorporate them in software used by design professionals does not yet exist, an indirect approach based on how the software works and on the fundamental thermal behaviour of Green Façades is currently the only effective avenue. Such a method would give designers and decision makers a way to quantify the impact of Green Façades on a given building. The impact can then be quantified in terms of cooling energy consumption reduction and reduced system capacity. More importantly, such a method can allow for comparison of Green-Façades to other energy management design strategies.

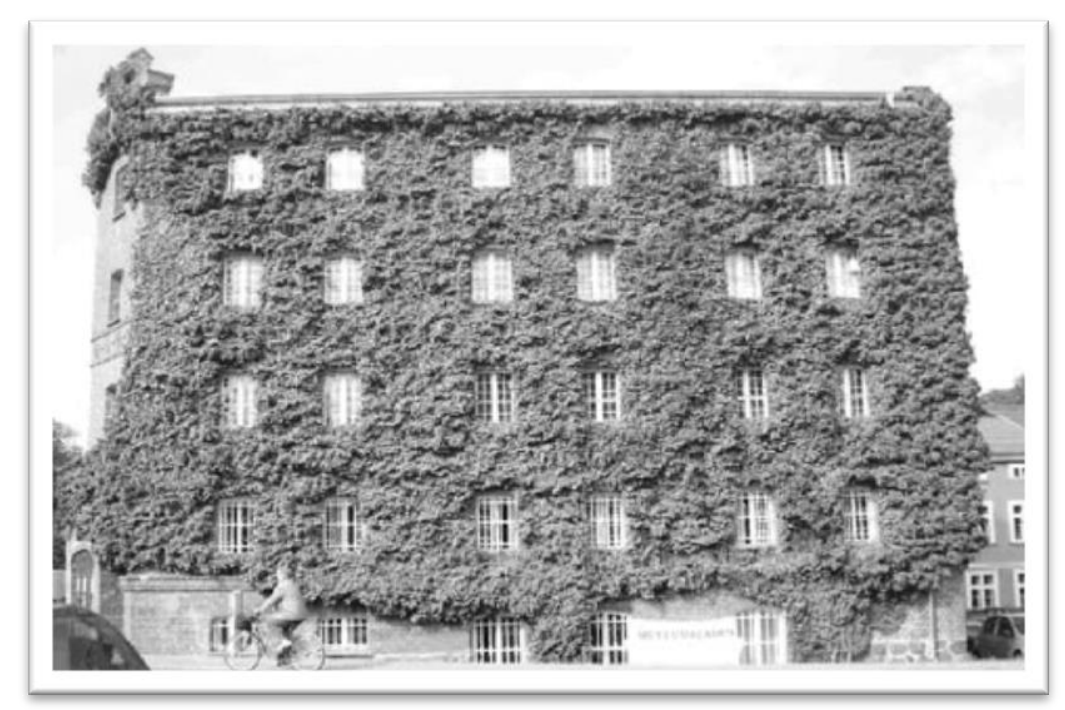

Figure 1 Vernacular Green Façade (Köhler, 2008)

\subsection{Background on Green Façades}

Green Facades have been used in traditional architecture because they allow the buildings underneath to be cooler in summer months, providing a more comfortable thermal environment for occupants and reducing cooling energy consumption. Their usefulness today can be seen in examples such as Figure 1, located in Germany, however their early use dates back more than 2000 years, to the Mediterranean basin (Köhler, 2008). Today, in addition to contributing to thermal comfort, they are increasingly finding relevance within a world where global warming 
and increasing energy costs are becoming more significant concerns. Given these two growing factors, the mitigation of heat gains in order to reduce building cooling load and urban heat island effect, becomes more urgent.

Green Façades have four main mechanisms that directly contribute to moderating heat gains (Pérez, Rincón, Vila, González, \& Cabeza, 2011). Firstly, the presence of a vegetated façade provides shading, thus reducing incident short wave solar radiation on its exterior surface. Secondly, the plants themselves convert solar energy through evapotranspiration, dissipating important amounts of energy as the water within them changes phase to become vapour. Thirdly, the plants' materials form a coherent layer with a very slight thermal insulation value. Lastly, the Green Façade disrupts wind patterns and flow around the building, creating a near-stagnant layer of air between itself and the wall it covers.

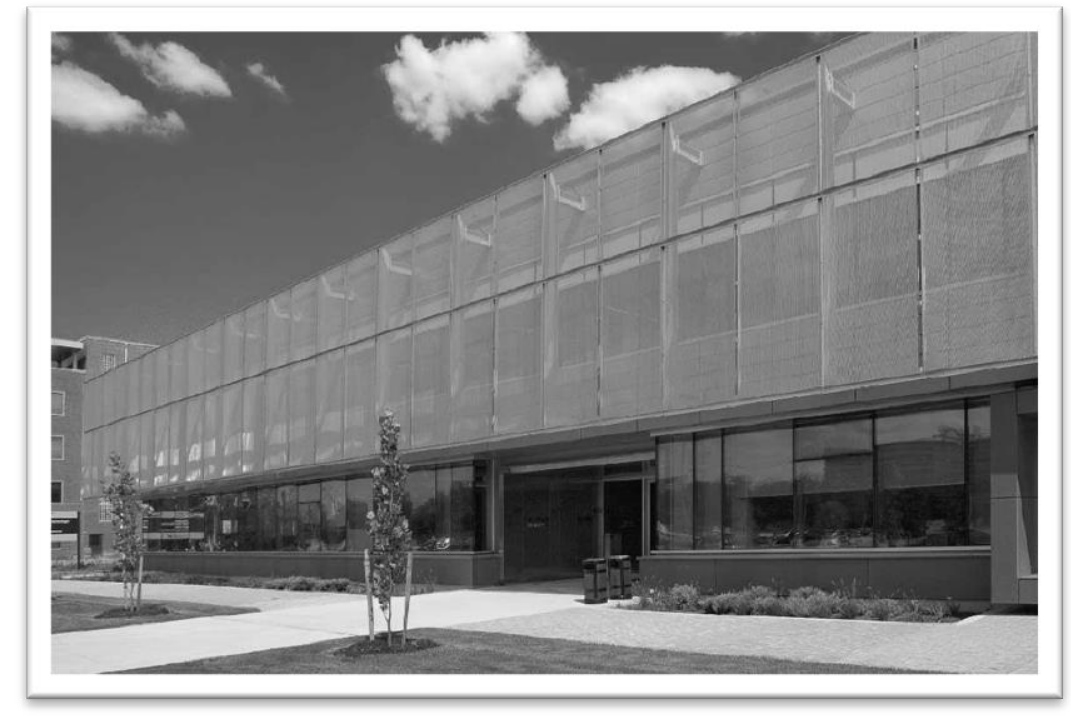

Figure 2 perforated metal screen, CANMET Hamilton

Moreover, Green Façades have been shown to offer slight insulation value even during the winter months (Köhler, 2008). For cities, while many factors interact to cause the urban island effect, the lack of vegetation greatly contributes to increased temperatures in dense urban settings, highlighting the large potential of green walls (Christen \& Vogt, 2004). As such, while other solutions for solar gain management are available, such as the perforated metal screen shown in Fig. 2 or exterior blinds, they do not offer evaporative cooling, carbon capture, 
reduction in air pollution and a number of other benefits offered by exterior green walls (Price, 2010).

\subsection{Green Façade Typology}

The image that most often comes to mind when thinking of vegetation on an exterior wall, is that of plants like climbing ivy on the exterior façade of buildings. While certainly not new, however, quite effective at reducing solar heat gain, this approach presents key drawbacks which have limited its adoption (Pérez, Rincón, Vila, González, \& Cabeza, 2011). They include damage to the wall surface, difficult maintenance and undesirable insect or animal presence. A number of architectural alternatives are widely used in Europe, particularly in Germany and have recently been slowly gaining visibility in North America, mostly on the heels of the growing prevalence of green roofs (Köhler, 2008).

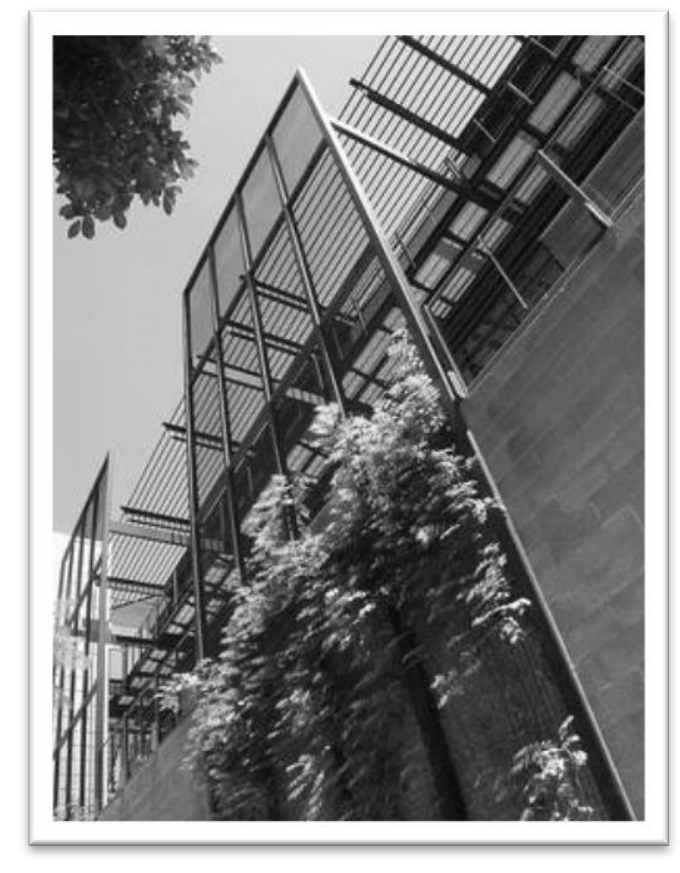

Figure 3 Indirect Green Façade system by Greenscreen ${ }^{\circledR}$

Of these alternatives, this research will explore in more depth indirect Green Facades, also referred to as Green Curtain Walls or Double Skin Green Façades. Those take the form of metal wire trellis modules which act as the support structure for the plants to grow on. Not fastened directly to the façade they provide cover for, such trellis are either slightly offset at a distance of $100 \mathrm{~mm}$ or they can be mostly free standing at a distance of $1000 \mathrm{~mm}$ from the façade. Fig. 3 is an example of such a system, manufactured by Greenscreen ${ }^{\circledR}$. It is important to 
distinguish this type of vegetated façade from a living wall, which is a system where soil is arranged vertically with the use of geotextile fabric to support the direct growth of plants along its surface.

\subsection{Research problem}

Using modular systems implies higher procurement and installation costs compared to direct wall vegetation. As such, even if experiments have determined that green facades can effectively reduce conduction thermal gain by approximately $43 \%$ (Tilley, Price, \& Marrow, 2012), in this period of value engineering and return on investment horizon, decision makers require precise quantitative information to support their design choices. Currently, Green Façades are not part of the standard and officially sanctioned energy saving methods (Eumorfopoulou \& Kontoleon, 2009). , likely attributable to the fact that the exact impact of Green Façades on a specific building are very difficult to quantify. While a number of quantitative experiments on Green Façades have been conducted, they have mostly been conducted via custom-built mathematical models or via custom-built models on software not designed for whole building energy assessment. This approach is neither convenient, nor economical nor efficient for decision makers and as such, pushes Green Facades to the sidelines.

Currently, in the building design industry, energy modeling is the tool used to help make informed decisions about different energy saving strategies or techniques. Energy modeling software such as IES-VE allows approximating global and specific energy use for a given building and allows quantifying the impact of different strategies. As previously highlighted and following some queries to IES, there is not yet a technique developed to quantify the effects of Green Façades in energy modeling software. Given the overwhelmingly positive impact that Green Façades can have on the built environment and its occupants, developing a technique to integrate Green Façades quickly and conveniently into an energy modeling software is not only advantageous, but necessary.

\subsection{Research Objective}

The primary objective of this research is to validate a technique allowing the effective integration of Green Façades into a whole building energy model in IES-VE. This technique will replicate the physical mechanisms of heat moderation inherent to Green Facades and will have to 
generate results indicating a cooling effect which is validated against the one observed in field experiments.

\section{Literature Review}

\subsection{Effect of vegetation on thermal energy}

In 1988 McPherson, Herrington and Heisler respectively from the University of Arizona, the State University of New York and the US Forest Service, explored the effects of trees and shrubs by way of simulation. While they did not directly focus on vegetated walls or Green Façades, they provided insight on the energy consumption impact of shadings and wind disruption. Their study provided a valuable macro level perspective on the effect of the previously mentioned factors over heating and cooling seasons in different climate zones. Highlighting the importance of climate-appropriate design, not all vegetation is beneficial to building energy management. They concluded that wind disruption was associated with higher cooling loads in warm climates while shading was associated with increased heating loads in cold climates.

Hoyano from the Tokyo Institute of Technology, also in 1988, investigated the thermal effects of vegetation. His took a more micro perspective, compared to McPherson et al. as he looked at strategies which saw the use of different plants in immediate contact or very close to the building. He considered the use of green roofs, evergreen shrubs, and climbing plants on buildings and pergolas. He outlined that the use of ivy growing directly on the façade of a building, while it did provide shading and cooling during the day, also presented a drawback. He found that the stagnant layer of air created by the ivy caused nighttime cooling to slow down.

In 1990, Alan Meier from the Lawrence Berkeley National Laboratory offered an overview of the body of knowledge and the different experimental approaches used to quantify the effects of plants on building cooling energy use. His research not only focused on vines, but also on the use of shrubs and trees. The factors he identified as the most difficult and also most important to represent accurately in simulation were: the heterogeneous nature of plant shading, the micro-climate created in the space between the plants and the building and, finally, the 
reduction in building air infiltration rates due to wind flow disruption. He concluded that with the combined use of trees, shrubs and vines, one could expect cooling energy use to be reduced by 25-50\%. Meier stresses that those reductions are achievable in different climates and relies on the combined and locally appropriate use of plant species.

In 1997 Taha, also from the Lawrence Berkeley National Laboratory identified the 3 main factors influencing the Urban Heat Island Effect. Of interest, he identified that evapotranspiration from both the soil and vegetation can effectively moderate urban temperature gain. The soil required for the growth of vegetation, stores moisture instead of allowing it to run-off rapidly like impervious surfaces would. The greater the proportion of impervious surface, the less water can be retained and, obviously, less vegetation could be grown and sustained. Also, surfaces such as gravel and asphalt had much smaller albedo then vegetation and much greater specific heat capacity, which further amplified the effect of solar radiation. Equally, those materials increased the intensity of long-wave thermal radiation incident on nearby buildings.

In 2003 Dimoudi and Nikolopolou from the Center for Renewable Energy Sources, a European Union funded research center in Greece, aimed at simplifying the parameters used in quantifying the effect of vegetation, highlighting the mechanisms by which plants mitigate heat gain on both a micro and macro scale. They underlined the fact that plants don't actually cool, but more precisely, they greatly moderate the rise of ambient air temperature. While the mechanism of shading and evaporative cooling are taken into account in a similar fashion to many other papers, this article quantified the effect of a vegetated park within a city. It does so by using computational fluid dynamics and comparing a number of different park sizes and orientations. While the influence on the parks varied with size, the cooling effect could extend to, with a clear line of sight, a distance of about 120 metres on the downwind side of the park. At a distance of 70 metres, the park had a cooling effect of up to $10{ }^{\circ} \mathrm{C}$ on hot, dry, high solar radiation days.

In 2004, Christen and Vogt from the University of Basel studied the energy balance of a European city. This study aimed at creating a model accurately representing the macro scale 
thermal dynamics. To do so, they examined in great detail and measured with sophisticated instrumentation the parameters of albedo, evapotranspiration and anthropogenic heat of an urban center and compared it to a rural setting. In effect, the urban centers absorbed much more energy due primarily to lower albedo and to greatly reduced evapotranspiration. While the paper presented detailed and quantifiable results through measurement energy balance equations for both city and rural settings, the conclusion highlighted interesting facts. Once the sun set, the flux of nocturnal releases of heat stored in the city was typically twice as much as what was observed in rural areas. While lower albedo and heat storage capacity had an impact, the most important factor altering the energy balance for cities was the reduced evaporative cooling. On average, low evaporative cooling caused cities to gain $6.1 \mathrm{MJ} / \mathrm{m}^{2} \cdot$ day compared to the country. The local magnitude of this extra gain is completely correlated to total vegetative cover.

\subsection{Green roofs and living walls}

In 2007 Hien, Yok and Yu from the National University of Singapore extensively studied green roofs. They used an existing building about to be retrofitted with a green roof, to measure and document a number of thermal parameters. Once the green roof was installed and established, they measured the same parameters. Infrared camera imagery presented in the paper illustrated very clearly the general effect of green roofs. Overall, well vegetated green roofs had lower surface temperature then similar uncovered roofs, to a maximum of $18{ }^{\circ} \mathrm{C}$ on a densely vegetated roof portion. Interestingly, a portion of the green roof where the vegetation was sparse saw increased temperatures compared to the bare roof surface. Densely vegetated portions had higher albedos and greater moisture storage capacity compared to sparse sections.

In her MSc Thesis completed in 2009 at the Portland State University, Castillo-Garcia focused his research on the effects of evaporative cooling on a green roof using a wind tunnel and sponge material. While the experiment is not directly applicable to Green Facades, it nonetheless allows understanding of the significant role of phase change from water to vapour in solar radiation dissipation. Her results indicated that the evaporative cooling reduced the heat flux going through a roof by 45-49\% and reduced surface temperatures between 3-7 ${ }^{\circ} \mathrm{C}$. Given that shading or other biological mechanism are not considered, these results are consistent with a number of the previously mentioned reports. 
In 2010 Cheng et al. studied living walls in Hong Kong. While the panels used to contain the growing media had notable differences in thermal properties, compared with a trellis structure, the results offer similar results with regards to surface temperature. The study found that at its peak, the difference between bare wall surface temperature and vegetated wall surface temperature was approximately $14{ }^{\circ} \mathrm{C}$, which corresponded to the peak values obtain by Tilley in his 2012 study. The effects of wall growth vegetation on surface temperature are similar regardless of the configuration, be it a living wall, a Green Façade or direct growth. The physics of evaporative cooling, solar radiation reflection and shading were the fundamentals at play and behave consistently regardless of the plant medium.

In 2012 Fernandez-Canero, Urrestarazu and Salas from the University of Seville assessed the cooling potential of an indoor living wall using different substrates in warm climate. While the parameters of the experiment where very different, since the wall studied was indoors and was a living-wall configuration vice trellis-grown vines, the effects of the wall were remarkably similar to those obtained by Tilley (2012). In this experiment, the indoor living wall offered an average temperature reduction of $4^{\circ} \mathrm{C}$, consistent with the results obtained in a number of outdoor experiments using different types of vegetation. While it did result in an average increased indoor air humidity of $15 \%$, it also offered an aesthetically appealing feature to visitors and contributed to increased indoor air quality.

\subsection{Green Façades Research}

In 2002 Sandifer and Giovini from the University of California at Los Angeles explored the thermal effects of vines on wall temperatures. Having focused objectives, the authors found that their experimental set-up and field measurements generated similar data. They came to the conclusion that vines of approximate thickness of $300 \mathrm{~mm}$ would maintain the surface behind them at the same temperature as ambient air. The same thickness of vine negated the effect of wall colour and proportionally, the most important surface temperature reductions were observed on West facing walls. The authors concluded that within a fully vine-covered pergola, the wall surface temperature was identical to the one of vine-covered walls.

In 2008 Köhler from the University of Applied Sciences of Neubrandenburg in Germany offered a in depth review of the body of knowledge accumulated by German researchers on the 
topic of exterior green walls. Going beyond the energy management properties, he highlighted the numerous benefits such as dust and particulate reduction, noise reduction, rain water management, food production and visual environment enhancement. Of note, some of his reviews indicated that non-deciduous exterior green walls created a thermal buffer over the winter months resulting in a wall surface temperature which was on average $3^{\circ} \mathrm{C}$ higher then the outer leaf layer.

In 2009 Eumorfopoulou and Kontoleon, both from the Aristotle University of Thessaloniki in Greece, explored the contribution of plant-covered walls to the thermal behaviour of building envelopes. They conducted a comparative study in which the thermal conditions of two different floors of a residential building (one being vegetated and the other not) are analysed. He presented results very similar to the ones obtained by Tilley with regards to the impact of the plants on thermal flux. In effect, the study he conducted showed that the plants reduced the exterior surface temperature by an average of $5.7^{\circ} \mathrm{C}$. Of interest, the authors highlighted that in addition to plant transpiration, a number of other physiological mechanisms contribute to the dissipation of solar energy. Plants converted solar energy into nutrients through photosynthesis, plant metabolism sustaining growth and respiration.

In 2010 Ip, Lam and Miller from the University of Brighton, UK studied the use of plants instead to replace artificial shading devices. The experiment saw a stainless steel trellis and planter box used to grow Virginia creeper as seasonal window shading devices. These devices were very effective at reducing indoor room temperature, achieving peak reductios of 4 to $6{ }^{\circ} \mathrm{C}$. Notwithstanding the cooling effects, the authors outlined that issues relating to the view of the outdoors being completely obscured and near complete reduction of natural ventilation from the windows were key, from a design perspective. The same issues were relevant in the use of Green Façade where the decision to cover or not windows dramatically changed the impact on both energy performance and human factors. The study provided a time variable bioshading coefficient which allowed incorporating the increasing and decreasing plant cover into an annual dynamic thermal model. Of note, this coefficient would only be valid in the southern United Kingdom, but nonetheless provides a reference point. 
In 2010 Jeffrey Price completed his thesis at the University of Maryland by conducting research on the energy flow and balances associated to Green Façades. He based his work on the same experiment as Tilley's, but used data recorded prior to its conclusion. In it, the author used the thermal data to derive the impact of a Green Façade on the cooling energy use. Given the small size of the experimental buildings, the data was applied to hypothetical models representing more realistic settings such as internal gains, windows and occupancy. The results indicated, that with a high window to wall ratio and without covering windows, the Green Façade had a modest effect, of up to $3.4 \%$. In the case of walls being completely covered, the reduction would be more significant: up to $28.4 \%$. Given that windows would not typically be covered with vegetation, as it negates the purpose of a window, the author concluded that the effect on the whole building cooling load could not be considered significant. From an emergy perspective, when including maintenance emergy, one could expect a return ratio of not more than 1 for 1 .

In 2011 Pérez et al. from the Univerity of Lleida in Spain studied the behaviour of Green Facades in the Mediterranean climate, offering insights into the non-residential use of the modular trellis technology on a community building. The study focused on light transmission and on the hygro thermal properties of the space between the building and the exterior green wall during all seasons, identifying the annual impacts. This space was subject to lower temperatures and higher relative humidity. Of note, the study offered comparison between the shading factor generated by the exterior green wall and other unvegetated commercially available solar barriers. The lowest level of light transmission factor was 0.04 when the green walls saw their foliage fully developed.

In 2011 Perini et al. from the Universtity of Genoa in Italy and University of Delft in the Nertherlands studied the effect of air flow and temperature on the building envelope with Green Façades. They provided a specific understanding of fluid dynamics resulting from the interaction between the Green Façades and wind. This study recommended either direct wall growth or an offset distance of between $400-600 \mathrm{~mm}$ as the optimal distance from the wall surface to create a more stagnant air layer and, consequently, enhance the performance of the exterior green wall. Interestingly, measurements taken of the surface temperature showed almost no temperature 
differential between covered and uncovered sections of walls being measured. Authors suggest that since the measurements were taken in the fall with low ambiant temperatures and diffused sky radiation, the cooling mechanisms of the exterior Green Façades were not active. As such, this highlights the benefits of an adaptative and responsive living building material.

In 2011, Sunakorn and Yimprayoon from the Kasetsart University in Bangkok studied the thermal performance of Green Façades combined with natural ventilation in a tropical climate. The experiment focused on the difference between indoor and outdoor air temperature and the effect of wind velocity on the performance of the vegetated screen. The conclusions showed the authors' findings that vegetated screens actually increased the velocity of air through natural ventilation. They found that the best results were obtained when air velocity was highest, as this drew the air cooled by the plants indoor at a higher flow rate. As such, they found that they could achieve a maximal reduction of almost $10^{\circ} \mathrm{C}$ between indoor and outdoor air and a maximal difference of $5^{\circ} \mathrm{C}$ between the indoor temperature of the reference room and the vegetated screen room. The authors also recommended using the Green Façade as a means of pre-cooling outdoor air.

In 2012 David Tilley et al. from the University of Maryland presented the results of their study of the thermal and growth properties of Green Façades. This study was the main experimental reference for this research project. The experiment consisted of 4 small light woodframe buildings built solely for the purpose of measuring a number of thermal variables. One building was left un-vegetated to serve as a reference and the remainder saw Green Façades installed on their East, South and West façades. The results obtained indicated that exterior green walls reduced thermal flux across the envelope of the test buildings by $43 \%$. In those unconditioned buildings, this translated to an average reduction of ambient air temperature of $4^{\circ} \mathrm{C}$. Peak values indicated that the surface temperature behind the vegetated wall section could be up to $14^{\circ} \mathrm{C}$ cooler than the bare wall surface. The duplication and validation of an energy model is based on this study.

In 2013, Perini et al., from the Universtity of Genoa in Italy and University of Delft in the Nertherlands proposed a decision making process for Green Façades and Living Walls. The 
article presented the different possible options to vegetate a building envelope and highlighted the benefits and drawbacks of each approach. Notably, they found that the environmental impacts of the Green Façade, when considering embodied carbon in the material (steel) is considerable and often not considered when making decisions about which type of vegetated wall to choose. The study identified that for temperate climates, a living wall system offers important benefits for both heating and cooling. Interestingly, all types of greenery offered very comparable cooling benefits.

\subsection{Simulation}

In 1989 Holm, from the University of Pretoria studied thermal gain management by means of Leaf Cover on External Walls using a thermal simulation model. While his study excluded the consideration of evaporative cooling, Holm does consider all other parameters relevant to the thermal effect of vegetated walls and validated his model on vegetated walls, finding the correlation coefficient to be over 0.93. Remarkably, his simulation results indicated an average of $5^{\circ} \mathrm{C}$ of reduction for the interior temperature of the simulated buildings. The limitations of his simulation became apparent when he concluded that vegetated walls would be almost ineffective in Mediterranean climates. His simulation was conducted on a series of DEROB (dynamic energy response of buildings) system of programs which required the use of a mainframe computer.

In 1998, Bruse and Fleer form the Climatology research group at the University of the Ruhr in Germany studied simulated surface-plant-air interactions inside urban environments with a three dimensional numerical model. A highly detailed work of mathematics and physics, this article presented a very useful differentiation between two often confused or assumed identical cooling mechanisms of plants: evaporation and transpiration. Evaporation is defined as phase change to vapour, of liquid water on the surface of vegetation, whereas transpiration is phase change through the leaves. As such, their models took into account different energy impacts of dew on the surface of plants and of water within the plant having to overcome stomatal resistance to vapour diffusion. The model also took into account the upwards or downwards direction of the incoming short wave and long wave thermal radiation fluxes. Finally, turbulence caused by the shearing of air flow by vegetation and thermal stratification is defined as is its dissipation. 
In 1999, Liao and Niu from the Hong Kong Polytechnic University studied the thermal function of ivy covered walls and presented the key factors which modulated the influence vegetation can have on the surface behind it. This mathematical method modelled the impact of the density of the greenery, the ratio of vegetation area to wall surface and the geometrical characteristics of the supporting material. While the model is simplified, the results of the simulation indicated that ivy coverings on walls can significantly reduce the heat flux through the walls they cover. In addition to being conclusive and providing indication about the way forward, it offers a detailed list of variables relevant to a detailed heat balance equation for the leaf and the surrounding air.

In 2000, Takakura, Kitade and Goto from the Nagasaki University and the University of Tokyo explored the cooling effect of greenery cover over a building. They presented the results of the development and validation of a simulation model and discussed its accuracy in comparison to measured results. It was a one-dimensional non-steady state model developed on CSMP software and was very simplified compared to other simulation models. While it did predict quite well the thermal behaviour of the reference section which was not vegetated, it was only somewhat satisfactory in predicting the behavior of the vegetated model. The correct trends where observed, but the effect of evaporative cooling was overestimated by the authors. Nonetheless, this field-validated simulation model did allow the authors to confirm the leaf area index, which ultimately equates to the shading ratio of the surface and evaporative cooling as the most important cooling mechanisms affecting their model. The authors concluded that increased refinement of variables, like some of the others studies mentioned, would yield more accurate prediction.

Bass and Baskaran from Environment Canada and the National Research Council, respectively, evaluated rooftop and vertical gardens as an adaptation strategy for urban areas in 2003. In it, experiments on vertical shading used shrubs to create a screen rather than a vine façade. The shrubs kept the wall surface behind it at an average of $26.8{ }^{\circ} \mathrm{C}$ while the bare wall saw average temperatures of $43^{\circ} \mathrm{C}$. In a separate chapter, the authors then used the software Visual DOE (DOE-2.IE-W83) to develop an approximate energy model allowing them to quantify the impact on cooling energy use. Given that the software did not allow them to 
directly input a green roof and a green wall as a feature, they used alternative inputs to represent the vegetation. As such, they increased the R-Values of the envelope and increased the shading factor, but they could not replicate evaporative cooling. Results showed even without evaporative cooling, cooling energy could be reduced by $23 \%$.

In 2004, Carver, Unger and Parks from the Southern Illinois University used energy modeling to quantify savings from urban shade trees. The software studied only uses the shading effect of trees based on their dimensions and foliage density, effectively ignoring evaporative cooling. Nonetheless, the study presented useful references which indicated that shading an airconditioning unit's evaporator is very advantageous and that shading on the west side of a home is preferential. In the case of mature trees, the validation of the simulation software showed that it produced results that were accurate within 19\%. Oddly enough, the authors explained that the software under-predicted the influence of young trees by $96 \%$ because they could not accurately identify the size of the canopies and as such used over-conservative estimates.

In 2005, Stec, Van Paassen and Mariaz form the Technical University of Delft in the Netherlands took a different approach to integrating vegetation in building façade in which they modelled a double skin façade with plants inside of it. The double skin was not green, but rather made of glass and the reference building used blinds to control the illumination and heat transmission levels. However, the mathematical model in the experiment saw plants (a creeping vine species) being installed within the double skin façades cavity instead of the blinds to perform the same functions. The results of the validated model offered striking similarities to Green Facades in terms of temperature reduction. Effectively, while the blinds would reach a temperature of over $55^{\circ} \mathrm{C}$, the temperature of the plants would never exceed $35^{\circ} \mathrm{C}$. Interestingly, the plant's capacity to dissipate solar radiation resulted in a reduction of cooling capacity of approximately $20 \%$ and a reduction of cooling energy consumption of also $20 \%$.

In 2008 Eleftheria and Jones from Cardiff University used energy modeling to quantify the temperature decrease in urban canyons due to green walls and green roofs in a number of diverse climates. They built and programmed in $\mathrm{C}++$ two dimensional, dynamic micro-scale models to represent and quantify the thermal activity of urban canyons. Of interest, the authors 
created a different number of canyons with variations based on urban geometry, orientation and levels of vegetation covering. They applied each of those models to 9 different climates from around the world. Their findings indicated that cooling load reductions of between 32-100\% are possible. Those findings assumed that the buildings were entirely covered with vegetation, which is unrealistic. The results for urban canyons also assumed those conditions when presenting optimal reductions and indicated that in hot-arid climates, a reduction of up to $11.3^{\circ} \mathrm{C}$ at ground level. Beyond the lack of realism, the results did show trends and patterns which indicated what climates and canyon geometry can benefit the most from vegetative cover on the walls and roofs.

In 2009, Wong et al. from the National University of Singapore presented findings focusing on the impact of vegetated walls on indoor radiant temperature and also on energy consumption of building cooling systems. While the study was specific to Singapore and also focused on a single type of building, it is one of the only studies based on an energy model developed using software called TAS from EDSL. The software was used to grossly determine the impact of the vegetation based on shading and on the reduced conductance of the assembly. The vertical greenery system used in the model was based on a living wall design. The results predicted that significant cooling energy savings, on the magnitude of $74 \%$, were achievable when the entirety of the building was covered. While it fell short of being a comprehensive and field-validated study, it nonetheless quantified the theoretical impact.

In 2010, Kontoleon and Eumorfopoulou, from the Aristotle University of Thessaloniki in Greece explored the effect of the orientation and proportion of a plant-covered wall layer on the indoor thermal conditions. The authors wanted to refine the understanding the two parameters found in the title by using a thermal-network model to conduct simulation and comparison of different configurations. The article was essentially a mathematical demonstration of the conclusions generated by a number of field studies. Of interest, the authors assigned a U-Value of $2 \mathrm{~W} / \mathrm{m}^{2} \cdot \mathrm{K}$ to the foliage once it is fully developed. As well, the authors greatly simplified the interactions between incident short wave solar radiation and the vegetation. As such, they concluded that in general terms about $20 \%$ of the solar energy was reflected while the remaining $80 \%$ was deemed absorbed and dissipated by the plant's biological mechanism. The authors 
included photosynthesis, evaporation, transpiration and breathing of the plants in the absorbed value used in their model.

\section{IES-VE}

The software, which was the main vehicle for this work, is called Virtual Environment, referred to as IES-VE. It was created and is being further developed by Integrated Environmental Solution Ltd in the United Kingdom. Understanding its functionality is necessary to provide context to the methodology used to replicate Green Façades.

In effect, IES-VE allows for the creation of models of buildings in which the physical characteristics and properties of materials and mechanical systems are specified. The software uses input for weather data, internal gains, macro and micro airflow and solar shading values to produce detailed outputs about internal air and thermal conditions and a myriad of energy use data. The advantage of this integrated software is that it allows for quantifying the impact of almost any design feature in isolation. It also allows for direct comparisons between models featuring different designs. As such, it provides the ideal platform to quantify the specific thermal energy impact of a Green Façade on a whole building's energy profile. The software is, according to the user manual:

A powerful integrated suite of applications linked by a Common User Interface (CUI) and a single Integrated Data Model (IDM). This means that all the applications have a consistent "look and feel" and that data input for one application can be used by the others.

IES-VE models are scaled three-dimensional representations of buildings, very similar to products such as Sketchup from Google or Revit from Autodesck. However, given that the software's purpose is to quantify energy and other indoor conditions, it does not have features which allow for creating buildings based on the three-dimensional assembly of materials. Instead, the building geometry is created by defining the outer perimeter/volume of the building and then subdividing all the rooms or by assembling the rooms one by one until the building is complete. The rooms are typically defined by simple lines which form planes, representing the walls, ceilings, floors, doors and windows. IES-VE then allows for specifying the construction details of each plane created, meaning listing the materials layered to form the building part (i.e. 
wall, roof, etc.) be they homogenous or composite. IES calculates the properties of the assembly assigned to the plane, such as its U-Value and its thermal mass and it also allows for specification of the solar absorptivity of those planes.

IES will allow the inclusion of objects within a model, such as household or office furniture or outdoor objects like street lights, trees or park benches. Those objects are taken into account for lighting and shading and also for macro and micro flow analysis but are not included for thermal analysis. While such objects do have a thermal effect, those are taken into account differently. As such, the effects of furniture with regards to thermal mass are accounted for in a specific dialog box, not through the placement of objects. The same is true for the heat gain impact of office equipment or refrigerators: these must be specified in a dialog box, not by placement in the model. Also, since IES-VE is focused on the interior energy dynamics of a building, it simplifies exterior conditions by assuming that exterior air conditions are homogenous around the building. Of note, topographical shades or adjacent buildings are taken into account for shading and radiative heat exchange.

IES-VE is powerful software capable of quantifying many parameters by integrating nonsteady state thermal dynamics within a building. It is very flexible in terms of possible building geometry and contains a extensive library of materials that enable the specification of just about any conventional building material and technique. However, it does have limits at the micro level. It computes how an ensemble of plane surfaces (i.e. walls, ceilings, floors, windows, etc...) with fixed physical, thermal and geometrical properties modulate thermal fluxes and other indoor air and moisture conditions. A Green Façade made of plants does not have fixed properties such as air permeability, homogenous thermal conductance and water vapour permeance. Moreover, being a living organism, the plant cover has irregular geometry and also performs biological functions such as food production, growth, respiration and transpiration. IES does not have features which can duplicate irregular geometry at the scale of a plant and it does not allow specifying energy absorption to biological functions. 


\section{Methodology}

\subsection{Conceptual framework}

The experimental method set forth to meet the research objective is based on a three phased approach. The first two phases will see models created and then validated against experimental data. In this case, the particularity lies in the fact that the experimental data that will be used to validate the models has already been collected. Because Tilley's experiments and report delivered in 2012 offers the required basis for comparison from field data, the models will be built based on the details provided in his paper, which is the simplest and most logical approach to validate.

The first phase will consequently reference the experimental building used by Tilley et al. replicated in IES-VE. A simulation will then be run with weather data specific to the site of the experiment sourced from the American Society of Heating, Refrigerating and Air-Conditioning Engineers, Inc. (ASHRAE) weather database. The simulation will have dates identical to the data samples reported by Tilley et al. in 2012. The results generated by the simulation, focusing on the indoor temperature of the reference model, will be analysed comparatively to the measured indoor temperature of the actual reference building over 24 hour cycles and cumulatively for the period of one week. This will allow for the basis of the conclusion in which the indoor temperature of the model follows trends similar to the actual measured indoor temperature of the reference building. All this while also considering that the reference model will be subject to different weather inputs then those recorded for the reference building. The aim of this phase is to determine the reference model's validity.

The second phase will see a technique developed to incorporate the effects of a Green Façade on a model built in IES-VE. To create a viable technique which ultimately replicates the accurate effects of a Green Façade, the method will need to incorporate all of the Green Façade's thermal properties and behaviours coherently within the framework and operating logic of IESVE. To verify and validate the proposed technique, it will be applied to a model identical to the reference model, which will create a vegetated model. Of note, two different techniques will be devised and have the same meteorological data as was used in the previous phase. This data will 
then be inputted and a simulation will be run for the same time period as the reference model. The results will then be processed and analysed to quantify the reduction in indoor temperature generated for each technique. The reductions will be compared proportionally to the reduction obtained by Tilley in 2012 between his reference building and his vegetated buildings. Again, the difference in weather inputs will be taken into account. The aim of this second phase is to develop a valid technique to replicate the effect of a Green Façade.

Finally, using the reference model and the optimal vegetated model with the same inputs as the previous simulations, another series of simulations will be run. In this third phase, the reference and vegetated models will be conditioned to a set point temperature. This will allow quantifying the amount of energy required to meet the set point and quantify the impact a Green Façade can have over the period of a week. This will also allow for the examination of specific changes in density of the thermal fluxes migrating into the room of the vegetated model through its walls, ceiling and floor in comparison to the cooled reference model.

\subsection{Reference model}

As mentioned previously, a valid reference model is a necessary baseline in order to have an accurate comparison between a building model with and without a Green Façade. As such, to determine the validity of the reference model built in IES-VE, its thermal behaviour will be compared to that of Tilley's reference building. The reference model will be built to the exact dimensions and using the same materials and techniques as the one used by Tilley et al. in 2012 (his description of the construction details can be found in the appendix, Fig. A.1.). Fig. 4 and 5 show the actual reference building and the reference model. Although Tilley's experiment was summarized in the literature review, to highlight, he and his research assistants built 4 small light wood frame buildings. These were insulated but not conditioned. One was left bare to serve as the reference building and the others had Green Façades constructed on their East, South and West walls. They used 3 buildings in order to test different types of structures (Steel trellis, manila rope, etc.) and different types of creeping plants. For the results produced, no significant difference can be attributed to the support system or the species of plant.

The relevant properties affecting the thermal impact of the façade are Leaf-Area Index (LAI) and the thickness/density of the vegetative cover, which are related to growing conditions 
such as nutrients, water and solar radiation exposure. In this experiment, all of the growing conditions where optimised. The buildings were instrumented to capture all thermally-relevant weather data and to record temperature on the surface of the walls, within the walls and finally in the main room of the small buildings (The other cavity in the building is the attic, between the roof and the ceiling). Table 1 provides the dimensions of the different building parts (floor, walls, etc...) and table 2 provides the construction details of the building parts and relevant thermal properties of both reference buildings.

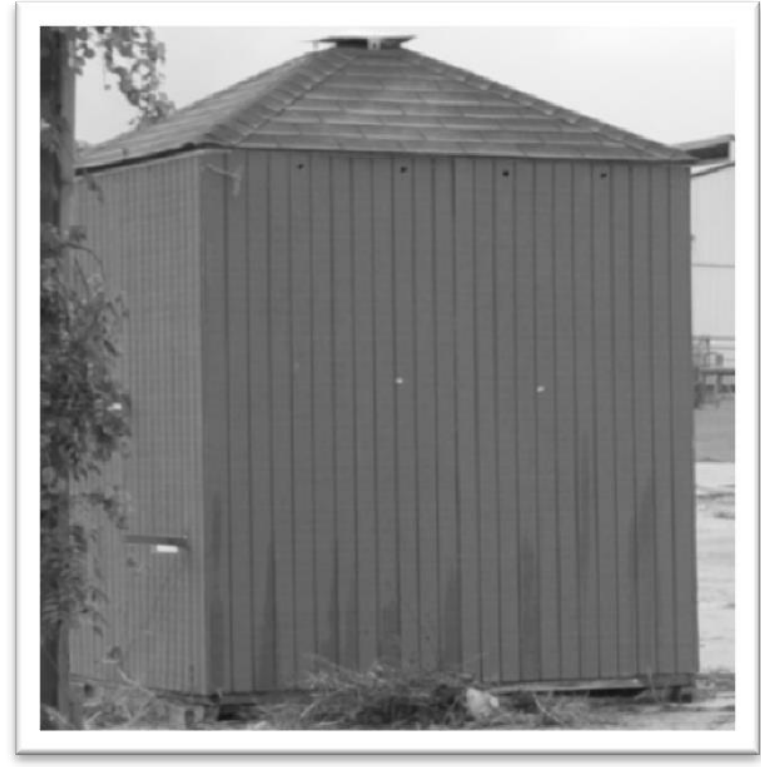

Figure 4 Reference Building (Tilley, Price, \& Marrow, 2012)

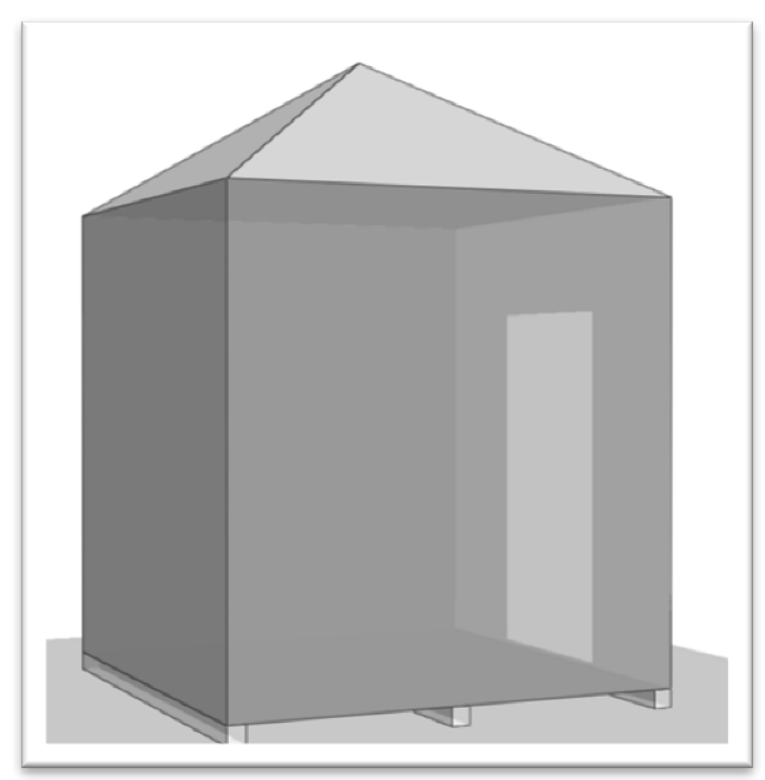

Figure 5 Model Reference Building

Table 1 Dimensions and construction details of the actual and model reference buildings

\begin{tabular}{|l|l|l|}
\hline & $\begin{array}{l}\text { Dimension of } \\
\text { building parts in mm }\end{array}$ & $\begin{array}{l}\text { Construction \& materials (from exterior to } \\
\text { interior, frame and insulation at the same plane) }\end{array}$ \\
\hline Floor area & $5.73 \mathrm{~m}^{2}$ & \\
\hline Inner volume & $14.33 \mathrm{~m}^{3}$ & Main room only \\
\hline Timber blocks & $50 \times 50$ & Solid timber \\
\hline Floor & $2500 \times 2500$ & $\begin{array}{l}139.7 \mathrm{~mm} \text { Joists } \\
88.9 \mathrm{~mm} \text { Fiberglass batts } \\
\end{array}$ \\
& & $12.7 \mathrm{~mm}$ OSB \\
\hline Walls & $2500 \times 2500$ & $14.68 \mathrm{~mm}$ Exterior plywood siding \\
& & $88.9 \mathrm{~mm}$ Studs \\
& & $88.9 \mathrm{~mm}$ Fiberglass batts \\
& & $12.7 \mathrm{~mm}$ Gypsum wall board \\
\hline
\end{tabular}




\begin{tabular}{|l|l|l|}
\hline Door (North Wall) & $1000 \times 2000$ & Insulated steel door \\
\hline Ceiling & $2500 \times 2500$ & $88.9 \mathrm{~mm}$ Studs \\
& & $\begin{array}{l}88.9 \mathrm{~mm} \text { Fiberglass batts } \\
12.7 \mathrm{~mm} \text { Gypsum wall board }\end{array}$ \\
\hline Roof & $2500 \times 2500$ & $4 \mathrm{~mm}$ asphalt Shingles \\
& & $12.7 \mathrm{~mm}$ OSB \\
& & $88.9 \mathrm{~mm}$ Studs \\
\hline
\end{tabular}

Table 2 U-Value of building parts and solar absorptivity coefficient

\begin{tabular}{|l|c|c|}
\hline & U-Value in $/ \mathrm{m}^{2} \cdot \mathrm{K}$ & Solar Absorptivity Coefficient \\
\hline Timber blocks & 3.797 & 0.70 \\
\hline Floor & 0.441 & N/A \\
\hline Walls & 0.491 & 0.85 \\
\hline Door & 1.021 & 0.25 \\
\hline Ceiling & 0.520 & N/A \\
\hline Roof & 3.146 & 0.90 \\
\hline
\end{tabular}

To obtain theses values, IES-VE runs calculations in the background, based on the methods specified in ASHRAE 90.1. Those calculations take into account the physical properties of the material used each layer and they also takes into account the different thermal properties of composite wall layers to derive a U-Value. The solar absorptivity values are attributed according to the properties of the exposed material based on the values found in table 3 .

Table 3 Color-reflectivity classification for opaque building materials (Reagan \& Acklam, 1979)

\begin{tabular}{|l|l|l|}
\hline Color & Solar reflectivity & Solar Absorptivity \\
\hline Very Light & 0.75 & 0.25 \\
\hline Light & 0.65 & 0.35 \\
\hline Medium & 0.45 & 0.55 \\
\hline Dark & 0.25 & 0.75 \\
\hline Very Dark & 0.10 & 0.90 \\
\hline
\end{tabular}

\begin{tabular}{|l|l|}
\hline Very Light & $\begin{array}{l}\text { Smooth building material surfaces covered with a fresh or clean stark white } \\
\text { paint or coating. }\end{array}$ \\
\hline Light & $\begin{array}{l}\text { Masonry, textured, rough wood, or gravel (roof) surfaces covered with a } \\
\text { white paint or coating. }\end{array}$ \\
\hline
\end{tabular}




\begin{tabular}{|l|l|}
\hline Medium & $\begin{array}{l}\text { Off-white, cream, buff or other light colored brick, concrete block, or painted } \\
\text { surfaces and white-chip marble covered roofs. }\end{array}$ \\
\hline Dark & $\begin{array}{l}\text { Brown, red or other dark colored brick, concrete block, painted or natural } \\
\text { wood walls and roofs with gravel, red tile, stone, or tan to brown shingles. }\end{array}$ \\
\hline Very Dark & $\begin{array}{l}\text { Dark brown, dark green or other very dark colored painted, coated, or } \\
\text { shingled surfaces. }\end{array}$ \\
\hline
\end{tabular}

Of note, the U-values found in table 2 are different from the ones that can be determined based on the R-values found in Tilley's report. For example, he provides a U-Value of 0.408 $\left(\mathrm{W} / \mathrm{m}^{2} \cdot \mathrm{K}\right)$ for the floor while the results of the calculation for the reference model provides a value of $0.441\left(\mathrm{~W} / \mathrm{m}^{2} \cdot \mathrm{K}\right)$. Tilley provided the calculations made by his assistant supporting the values in his report. In the case of the floor, while the student took into account the proportion of lumber to insulation, he used the full $139.7 \mathrm{~mm}$ of the floor joists to determine its specific resistance. The insulation being only $88.9 \mathrm{~mm}$, the boundary conditions are not homogenous across the full thickness of the joists. The R-values assigned to his building can be found on page A.1.

\subsection{Simulation inputs for the Reference Model}

In order to verify the accuracy of the reference model, a simulation was run on IES-VE to quantify its interior temperature over a one week period. To perform the simulation, the thermal conditions and properties of the model must be specified. As such, the first set of thermal parameters is defined by the weather data file. The one used for this simulation was sourced from the fourth version of the database created by ASHRAE. It is of the Baltimore/Washington International Thurgood Marshall Airport, Baltimore, MD, USA. The airport is located at a distance of approximately 23 kilometres due east of the experimental site location, which is in Clarksville, MD, USA. IES-VE uses the standard profiles and provides hourly values for the purpose of thermal calculations. The parameters of input are dry-bulb and wet-bulb temperature, direct normal and horizontal diffuse solar radiation, solar altitude and azimuth, wind speed and direction, cloud cover and, finally, atmospheric pressure.

The second and final thermal parameter relevant for the simulation is the rate at which external air is naturally drawn into the building. In this case, the air exchange, happens in the form of infiltration through the building envelope. This occurs due to differential pressures 
generated by wind flow around the building and due to the stack effect induced mainly by the temperature difference between the interior and exterior air (Straube \& Burnett, 2005). The air leakage will be influenced by the availability of pathways for air to enter and escape. Studies indicate that the average rate for modern built residential homes is of 0.25 air changes per hour, or ACH (Chang, Nazaroff, Price, Sohn, \& Gadgil, 2005). Given the reduced size of the building, the minimal number of penetrations through the envelope, the absence of a mechanical ventilation system and the absence of an interior space rim joist and windows, the air change rate potential is deemed low and the value assigned is of $0.10 \mathrm{ACH}$.

Typically, buildings will have internal thermal gains and IES-VE also allows for specifying them. In this case, given that the building was continually unoccupied and without any equipment, no internal gains where specified. Of note, no conditioning of the actual or model reference building took place as such, no HVAC system was specified and the room conditions were not controlled during the simulation. In the present case, the indoor temperature profile was influenced by the five meteorological factors specified by IES-VE in the weather data file and the ACH. Consequently, IES-VE took into account the interaction between all of the weather parameters, $\mathrm{ACH}$, the geometry of the building and the thermal properties assigned to the different surfaces/parts of the building as previously described to generate results indicating the hourly interior temperature.

\subsection{Result interpretation for the reference model}

To determine the validity of the thermal behaviour of the reference model, a simplified comparison between it and the reference building being examined is conducted. This comparison aims at establishing a relationship between their respective interior temperatures in relation to two meteorological factors. Those are the outdoor air temperature and incident solar radiation, which are the two main drivers of heat gain for both the reference buildings and model. Since the comparison is done for identical date ranges and at nearly identical locations, the solar angle and azimuth are deemed to be identical. The following series of figures presents the results obtained from the simulation ran on IES-VE and compares them the actual measurements taken by Tilley et al. during the summer of 2011 for the week of 11-17 July on an hourly basis. Fig. 6 presents the exterior temperatures fluctuations and Fig. 7 presents the incident solar radiation fluctuations. 


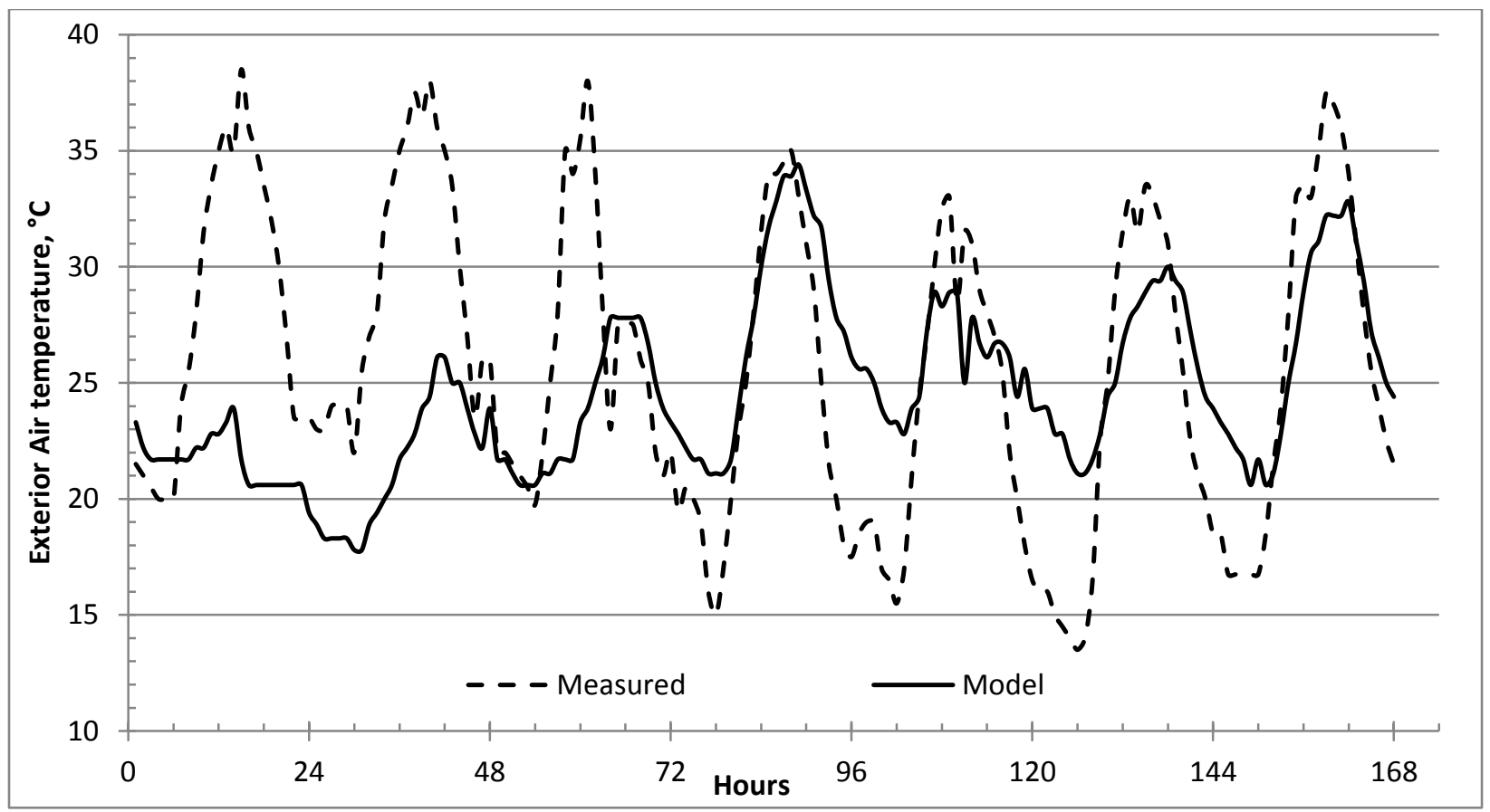

Figure 6 Exterior temperature fluctuations in ${ }^{\circ} \mathrm{C}$ over hours, 11-17 July.

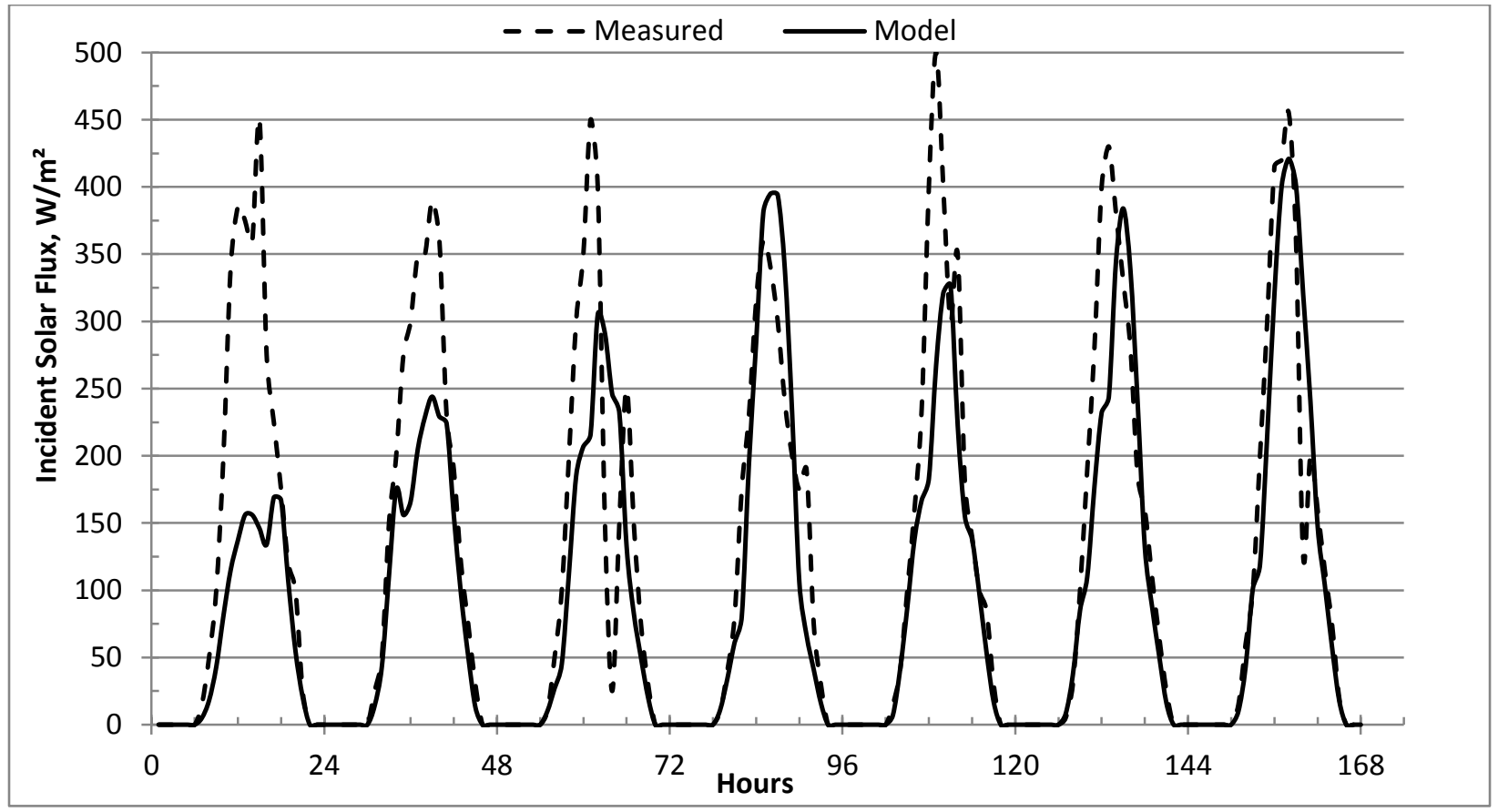

Figure 7 Incident Solar Radiation on South Façade in Watts per square meters over hours, 11-17 July. 


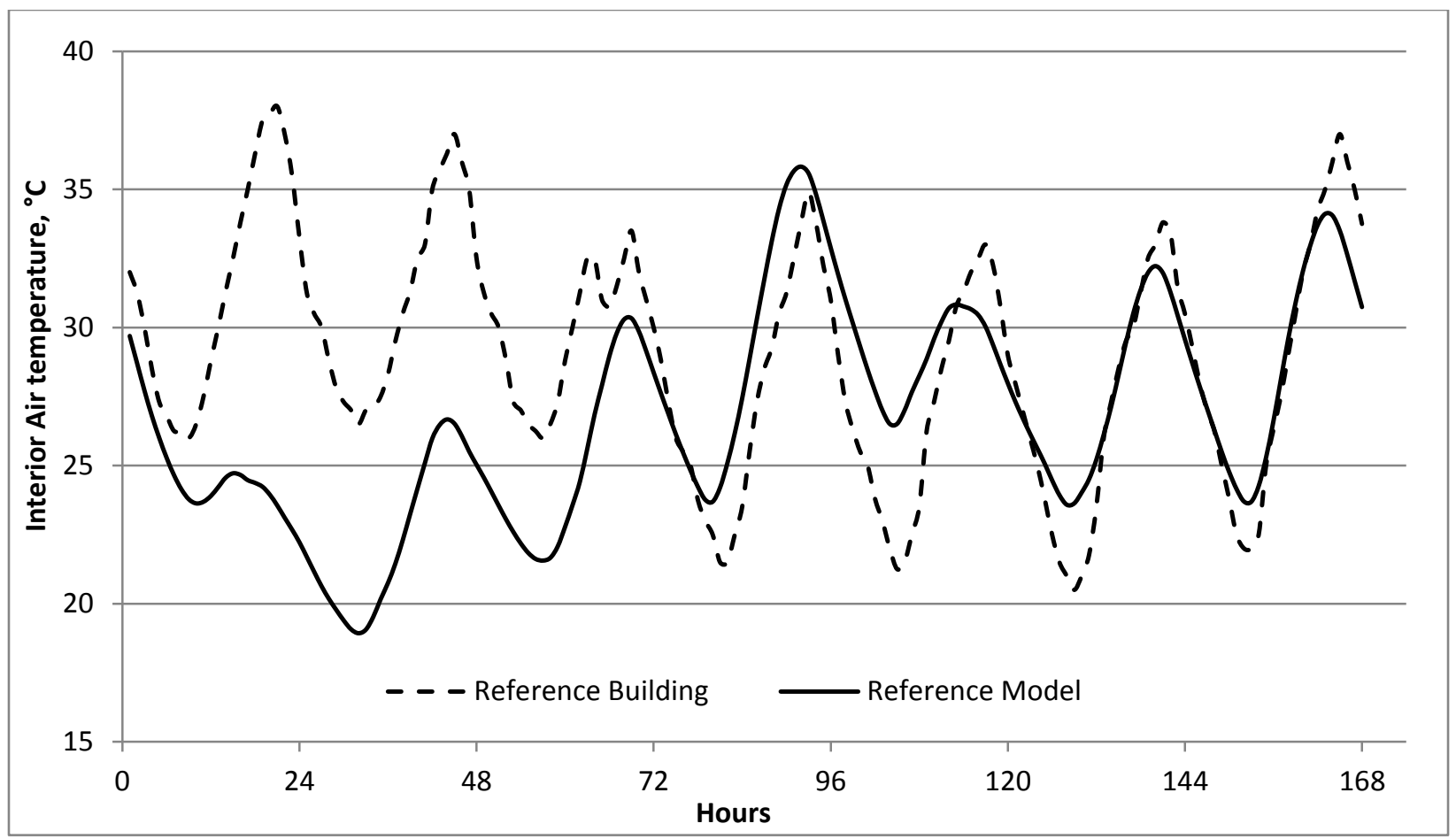

Figure 8 Interior temperature fluctuations in ${ }^{\circ} \mathrm{C}$ over hours, 11-17 July.

Fig. 8 shows the fluctuation of the indoor air temperature of both the reference buildings and the reference model. Looking at Fig. 6 and 7, the correlation between the exterior thermal conditions and interior temperature can be observed. While this is visually useful, it does not necessarily allow for the clear visualisation of the relationship between indoor temperature and exterior thermal conditions. The graph found in Fig. 9 is a representation of this relationship and is based on the following equations, which allows for the determination of the numerical difference, expressed as deltas, between the exterior and interior conditions.

$$
\Delta T_{\text {ext }}=T_{\text {ext }}-T_{\text {ext }}^{\prime}
$$

where:

$T_{\text {ext }}$ is the exterior temperature as measured by Tilley.

$T_{\text {ext }}^{\prime}$ is the exterior temperature value assigned in IES-VE.

$\Delta T_{\text {ext }}$ is the difference between both values. 


$$
\Delta T_{\text {int }}=T_{\text {int }}-T_{\text {int }}^{\prime}
$$

where:

$T_{\text {int }}$ is the interior temperature as measured by Tilley.

$T_{i n t}^{\prime}$ is the interior temperature value as generated by IES-VE.

$\Delta T_{\text {int }}$ is the difference between both values.

$$
\Delta \gamma=\gamma-\gamma^{\prime}
$$

where:

$\gamma$ is the incident solar radiation on the south wall as measured by Tilley.

$\gamma^{\prime}$ is the incident solar radiation assigned in IES-VE.

$\Delta \gamma$ is the difference between both values.

Of note, the result of the equations, based on the specific actual and model values is often negative. All negative values are irrelevant and have been converted to positive, given that the indicator sought after is the absolute numerical delta. 


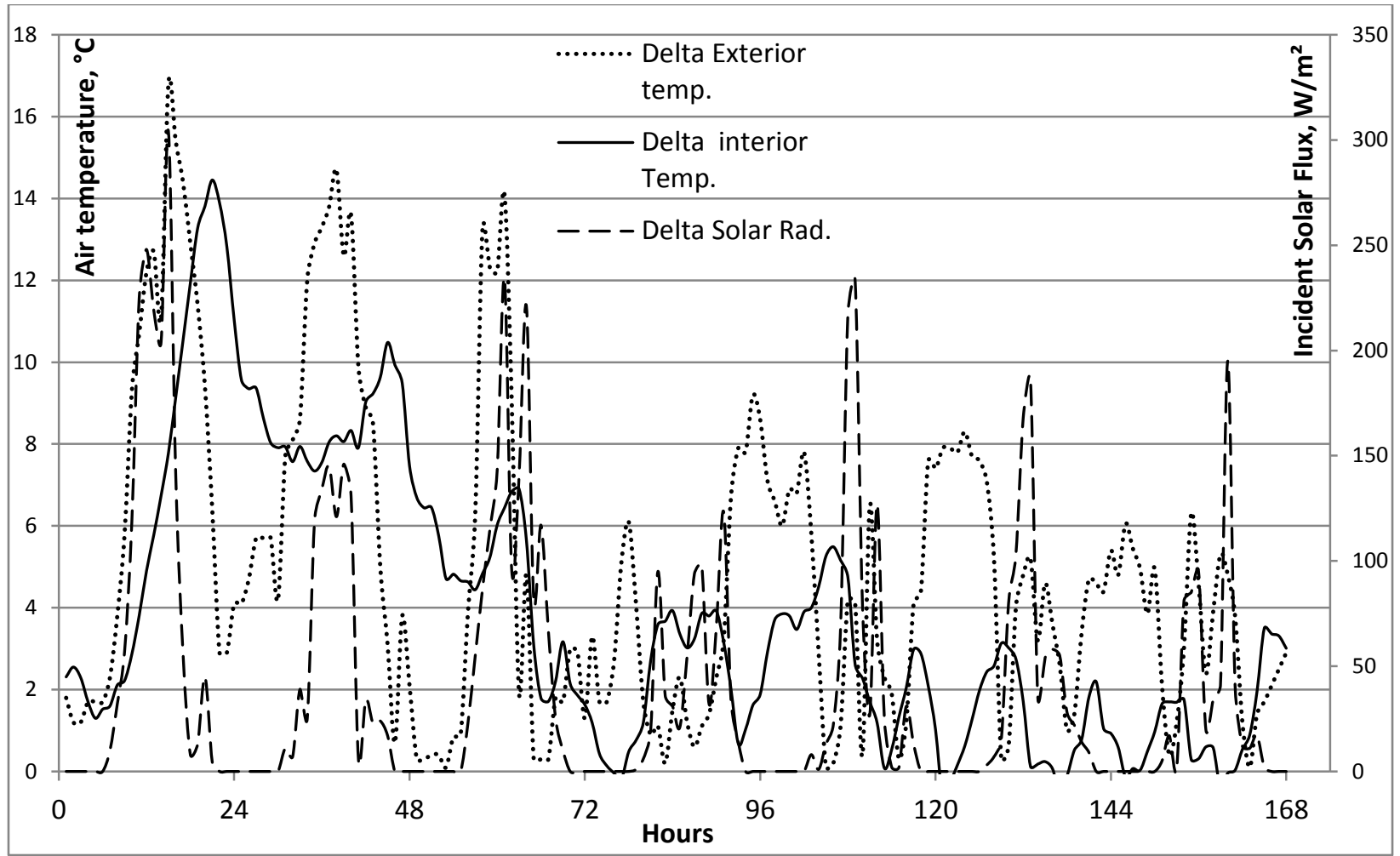

Figure 9 Integrated Deltas for thermal conditions, in ${ }^{\circ} \mathrm{C}$ and Watts per square meters over hours, 11-17 July.

The interior temperature difference between the reference building and the reference model can now be visually related to the difference in the exterior thermal conditions between the two. The result indicates that when both exterior temperature and solar radiation are very different between actual measurements and the model, the indoor temperature is also very different. One can also see that when the temperature difference is high and the solar radiation is low, the indoor temperature delta will tend to be more moderate.

Of course, while the relationship is apparent in many instances, it is far less visible in others. The limitations associated with a relationship model which is not comprehensive are significant. The precise moderating influence of the building envelope on non-steady state heat flux density is not quantified in this model. One can see in Fig. 9 that a constant lag in temperature variation is present for indoor conditions. However, this lag is not consistent over time. Higher deltas in exterior thermal conditions seem to indicate a shorter time lag. In addition, one must consider that the impact of solar radiation on each face of the building is different given the solar angle and azimuth. As such, an interruption due to cloud cover of the solar 
radiation on the southern face at noon might not be as influential as an interruption on the west façade in late afternoon. Also, wind speed is not considered in this comparison, which can account for lower thermal gains even under important radiation fluxes and accelerated cooling under passing cloud cover. Finally, one should note that the data, both for the model inputs and for the actual model, has been simplified to hourly readings, which when considering the highly variable nature of meteorological condition in the North-Eastern USA, can also leave much of the actual total thermal input unaccounted for. Considering those limitations inherent to the validation approach, allows understanding of the irregularities in the data figures.

While the limitations of the comparative model are tangible considering the narrow and simplified parameters, it nonetheless provides clear indications of trends and behaviours within the reference model. Comparing Fig. 6 with 8 shows similar patterns of rise and fall of temperature. The indoor temperature generally peaks at a similar time and lags behind the exterior thermal conditions in a similar fashion. Fig. 9 illustrates the coherent thermal behaviour of the reference model relative the difference in exterior conditions. As such and for the purpose of this research, the reference model offers a very sound basis for the comparison of the effect of a Green Façade. Regardless of the exact behaviour of the model, it provides a robust reference point in order to quantify the effects of a simulated Green Façade on an external wall.

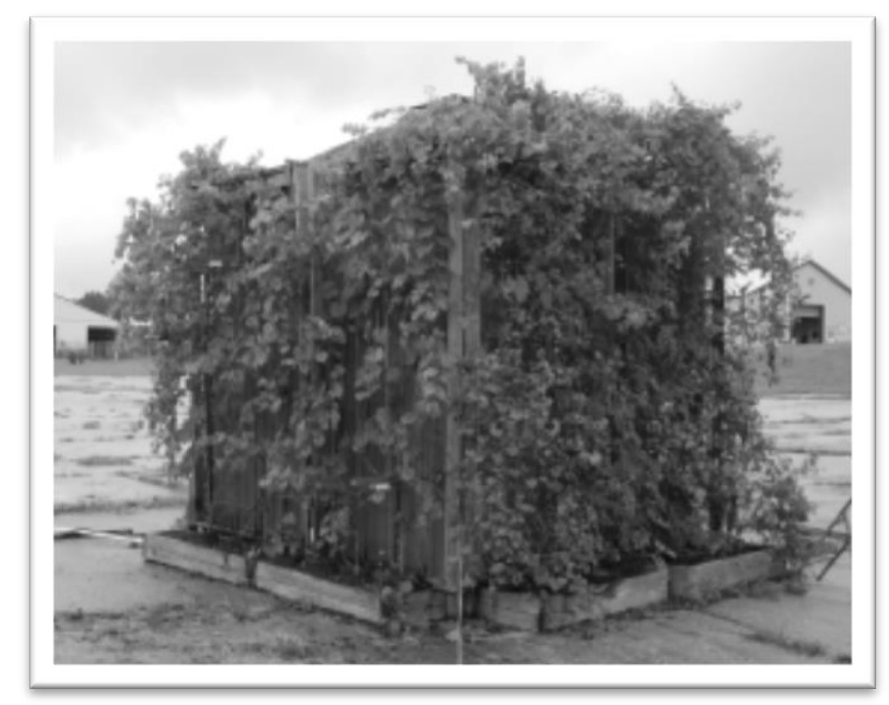

Figure 10 Tilley et al.'s vegetated experimental building with a Green Façades in 2011. 


\subsection{Green Façade replication}

Replicating the impact of a Green Façade using software with limited flexibility outside the realm of conventional construction techniques and materials, was a challenge in balancing simplification and accuracy. While custom built energy models can account for a number of vegetative variables in a very detailed fashion in a non-steady state, IES-VE cannot. As such, the challenge is to devise a technique which can replicate the effects of a living organism on buildings, such as seen above in Fig. 10, which shows Tilley et al.'s vegetated experimental building, using parameters which are functional within IES-VE.

Given how the software processes energy and other indoor conditions over time, the possibilities for taking into account the thermal effects of a Green Façade are limited to one option. The façade must be geometrically represented as a room integral to the building such as shown in Fig. 11. Since the room is meant to represent a Green Façade, it will be referred to specifically as the Green Room. For this Green Room, now part of the building, IES-VE will process how heat, air and moisture behave within inner volumes and across the planes defining the volumes. This processing, based on the various properties of the planes representing a Green Façade, allows for the generation of a broad number of outputs for each surface and space, while integrating those into a whole building energy model. 


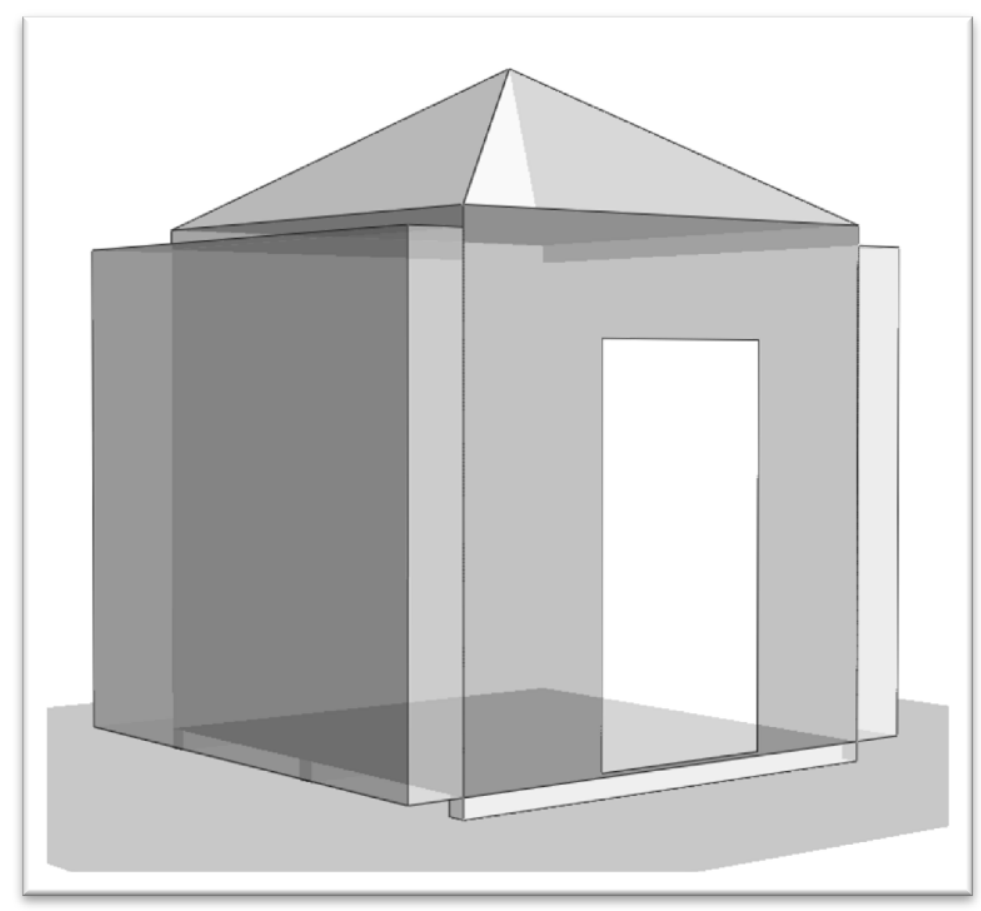

Figure 11 Green room rendering, looking from the North-East.

In order to soundly create a green room which replicates a Green Façade, it needs to be in accordance with an accepted energy balance for plant behaviour with regards to solar radiation and on accepted thermal properties for a vegetated façade. In addition, it will need to duplicate the cooling mechanisms of Green Façades. Of course, given the limitation of IES-VE with regards to possible geometry and characteristics which can be assigned to assemblies, this means that a number of simplifications are required.

As such, the Green Room should modulate solar energy similarly to a Green Façade. As such, the room needs to shade the wall surface behind it, it needs to dissipate solar energy, provide slight insulation value and create a near-stagnant layer of air between the exterior surface of the building and its inner surface (Pérez, Rincón, Vila, González, \& Cabeza, 2011). A Green Room made of opaque materials can obviously meet the shading requirements. By attributing a $\mathrm{U}-$ Value of $2 \mathrm{~W} / \mathrm{m}^{2}$ to the exterior walls of the green room, which is similar to a Green Façade and by also attributing it a solar absorptivity coefficient of $80 \%$, the slight isolative value is then accounted for and the correct proportions of solar radiation are absorbed and reflected 
(Kontoleon \& Eumorfopoulou, 2010). Table 4 presents the combined geometrical and thermal characteristics of the green room.

Table 4 General Characteristics of the Green Room

\begin{tabular}{|l|c|}
\hline Dimensions & $2.5 \mathrm{~m}$ height, $0.3 \mathrm{~m}$ deep along East, South, West facades \\
\hline Floor area & $2.43 \mathrm{~m}^{2}$ \\
\hline Inner volume & $6.03 \mathrm{~m}^{3}$ \\
\hline U-Value of walls & $2.042 \mathrm{~W} / \mathrm{m}^{2} \cdot \mathrm{K}$ \\
\hline Solar absorptivity coefficient & 0.80 \\
\hline
\end{tabular}

Two important cooling mechanisms still need to be incorporated. While the Green Room can provide a stagnant layer of air over the exterior surface of the walls, in reality there is constant air movement around the façade which allows for the dissipation of the latent energy released by the plants. Also, the façade is near stagnant; there remains low velocity air exchange driven by wind generated pressure differences and air buoyancy in all of the multiple cavities of the Green Façade (Perini, Ottelé, Fraaij, Haas, \& Raiteri, 2011). As such, an air exchange process must be included. Finally, the absorbed solar energy must be dissipated; otherwise the green room would simply become an opaque Double Skin Façade. Given that the plants dissipate solar energy mainly through evaporative cooling, incorporating mechanically induced evaporative cooling offers the possibility of replicating this biological mechanism and generating a cooling effect with a similar behaviour and magnitude as the one generated by the plants.

In fact, mechanically induced evaporative cooling is a very effective way to dissipate sensible thermal energy and it is used in many applications for that exact purpose (ASHRAE Handbook: Heating, Ventilation \& Air-Conditioning Applications, 2007). It leverages the significant amounts of energy that water absorbs and contains, called enthalpy, when changing phase to vapour in an adiabatic exchange with the air in the cooling system. As such, water at $20^{\circ} \mathrm{C}$ will have an enthalpy of $83.9 \mathrm{~kJ} / \mathrm{kg}$ of mass, whereas vapour at the same temperature will have an enthalpy of $2453.5 \mathrm{~kJ} / \mathrm{kg}$ (Hutcheon \& Handegor, 1995). Combined to increasing airflow to improve its effectiveness, its capacity to absorb energy can have important cooling effects as can be seen in Fig. 12. 


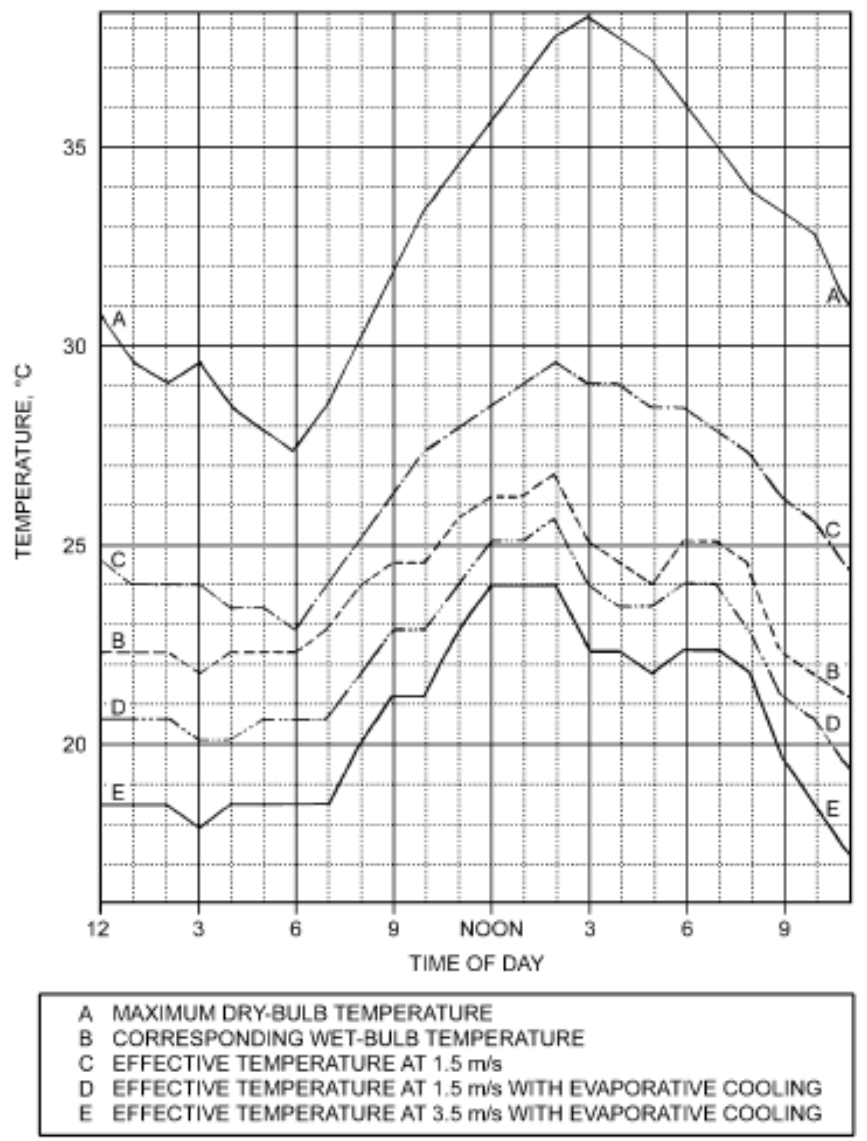

Figure 12 Effective temperature given local peak temperatures in Kansas City, ASHRAE 2007

Considering the above mentioned requirement for both air exchange in and out of the Green Room and the requirement for mechanically induced evaporative cooling, two different configurations are possible. Those options will be presented in detail in the chapters which follow, but in summary, they differ mainly in how they allow for air exchange to occur.

\subsection{Enclosed Green Room Technique}

The first Green Room configuration sees it being fully enclosed, as previously seen in Fig. 11, and assigned an HVAC system. Firstly, that system would be handling the ventilation requirements of the Green Room through a simple loop which sees an external air intake and an exhaust coming in and out of the Green Room. To account for the evaporative cooling, a spray chamber is included after the fresh air intake. The spray chamber has been assigned the default efficiency of $75 \%$. This efficiency refers to the ability of the spray chamber to reduce the sensible heat of the entering air to $75 \%$ of the wet-bulb temperature. Fig. 13 is a diagram of this network. 


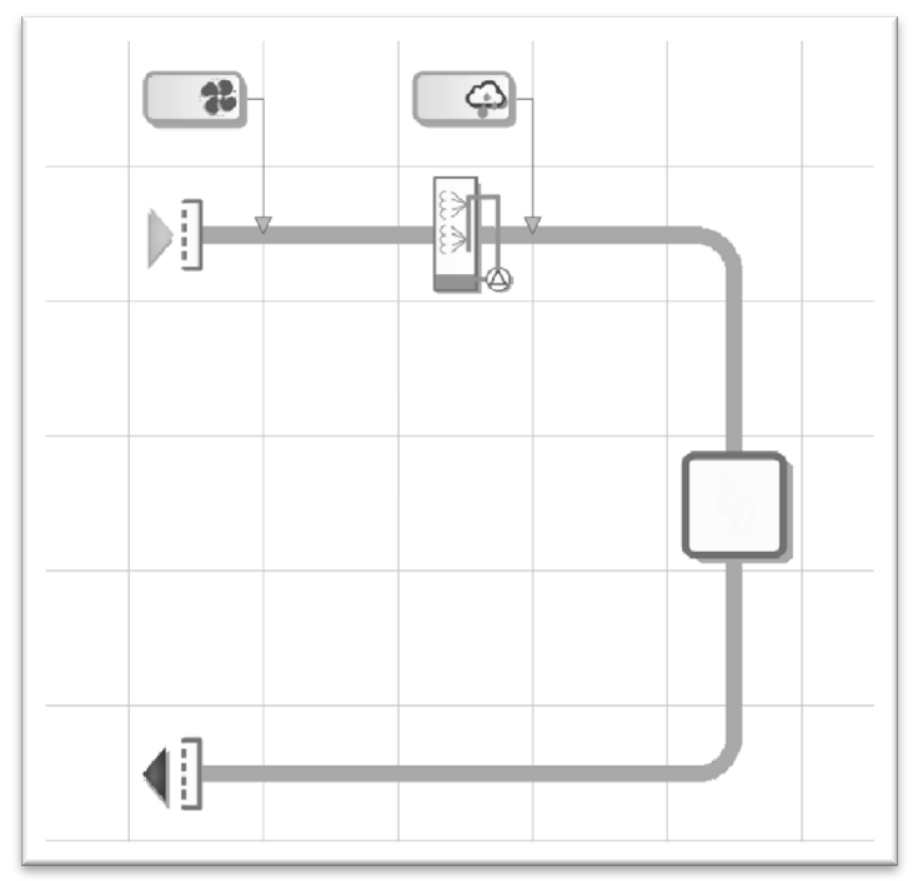

Figure 13 Open loop ventilation and evaporative cooling system

In this case, IES-VE is not concerned about realism. As such, the purpose of the HVAC is to specify simulation inputs in the form of air changes and moisture gain to the Green Room. To this effect, no fans are required, the air flow is modulated through a controller located downstream of the air intake. The spray chamber is also modulated through the use of a controller located downstream. Following a number of iterations, the settings offering the cooling effect which are most similar to that of an actual Green Façade sees the air flow set at 5000 liters per second and the spray chamber completely saturating the air with moisture, reaching a relative humidity of $100 \%$. This system is modulated daily through a timed profile, which activates the air flow and the spray chamber at $0800 \mathrm{hrs}$ and turns it off at $2100 \mathrm{hrs}$.

\subsection{Vented Green Room Technique}

The second configuration takes a slightly different approach and sees the Green Room with $100 \mathrm{~mm}$ high openings at the top and bottom of the Green Room on each face. This variation can be seen in Fig.14. This variation requires a different strategy for managing the air changes of the now open Green Room. Instead of using the mechanical system to handle the air flow in and out of the chamber, the vents are used to allow the displacement of air to occur in a 
less controlled fashion. The expected advantage of this approach is more responsiveness to the effects of wind. In such a small building as the one being used to model, this might not make a significant difference, but for much larger buildings with higher elevations, the impact of the wind would be significantly more important.

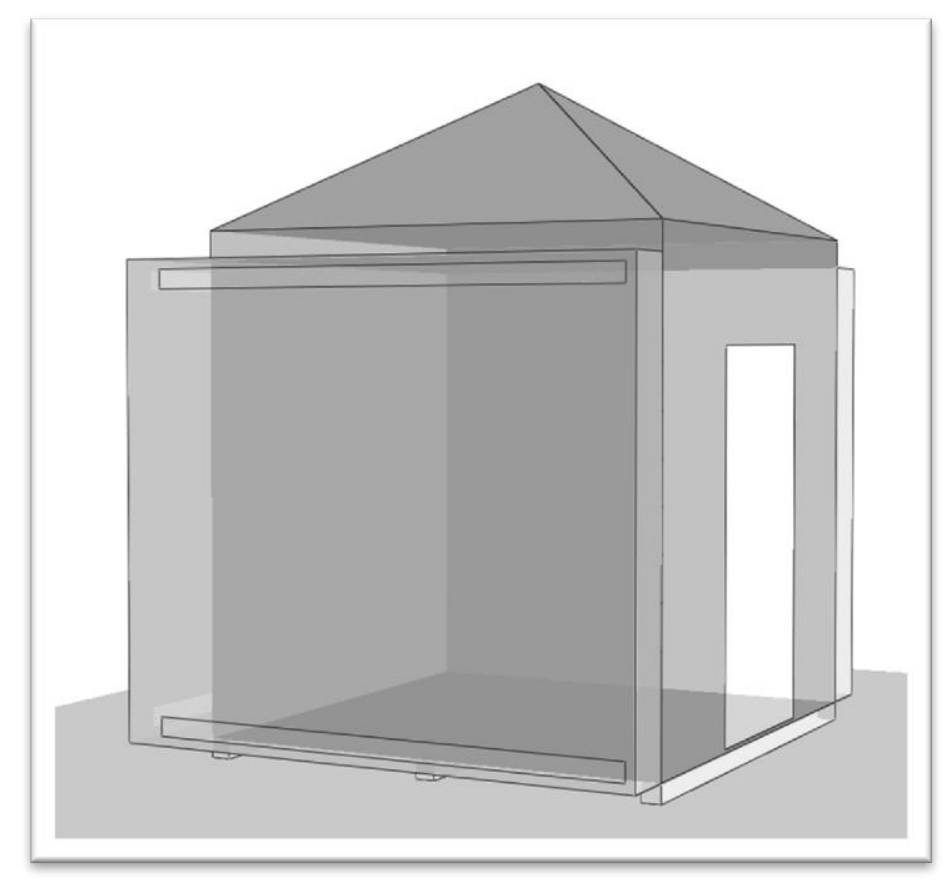

Figure 14 Vented green room rendering, looking from the North-East.

Of course, the need for evaporative cooling is still present and as such, an HVAC system must be assigned. Unlike the system for the closed room, this system would only need to circulate moisture and not draw in fresh air. However, the limitations of IES-VE impose a certain number of characteristics for any HVAC system. Consequently, the system seen in Fig. 15 has both exterior air intake and exhaust which are not required because the Green Room is vented. They are controlled downstream of the air intake in such a way that no air is being taken in or out through them, giving a flow of zero. The remainder of the loop is quite simple and similar to the loop used for the closed room. The loop circulates the air in a closed circuit, taking it out of the Green Room, through the spray chamber and back into the Green Room. Given that the room is open, the air exchange with the exterior occurs naturally through the upper and lower openings. 


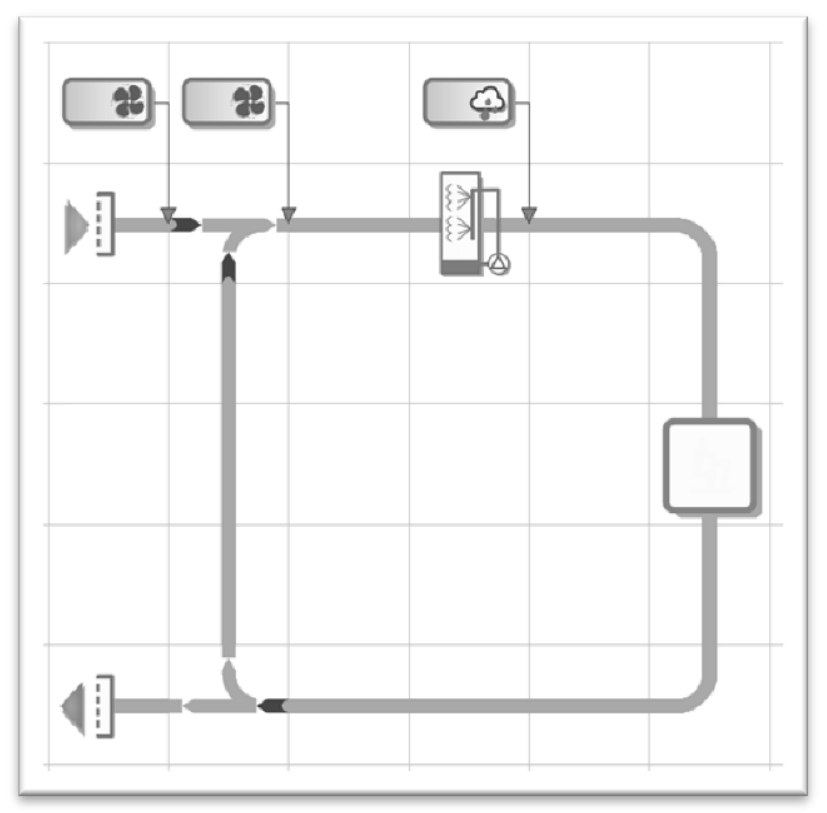

Figure 15 Closed loop ventilation and evaporative cooling system

Similar, to the enclosed room loop, no fans are required, and the air flow is modulated through a controller located downstream of the junction between the air intake and the loop. Again, the spray chamber is modulated through the use of a controller located downstream. In this case as well, a number of iterations were used to determine the settings offering the cooling effect which is most similar to the one of the actual Green Façade. This saw the flow set at 900 000 liters per second and the spray chamber completely saturating the air with moisture, reaching and relative humidity of $100 \%$. While it is understood that such incredibly high flow rate and saturation are simply impossible, those settings must be understood as mathematical instruments, and simply as means to achieve the replication and integration of the thermal effect of Green Façades.

\subsection{Cooled models for energy consumption quantification}

A comparison will be used to determine the impact of a Green Façade on the on the cooling energy a building would consume. To do so, the reference model and the vegetated model will have their main room cooled to a set point of $23.9^{\circ} \mathrm{C}$ for a new series of simulations. Of note, IES-VE allows enabling generic cooling system feature to facilitate comparison of different design strategies and quantify energy consumption. This system specifies to IES-VE to 
calculate how much cooling energy would have to be used to maintain the room temperature below the set point.

This process allows for a comparison of the energy required to cool the main rooms to that set point. The findings will then be used to determine, in percentage terms, the reduction attributable to the Green Room. In addition, the outputs from the simulation will allow quantitative examination of the influence of the Green Room on the conductive thermal fluxes across the different parts of the now cooled room. Given that those fluxes are influenced by the extent of the difference between the thermal conditions on either side of the building parts, the impact is expected to be unambiguous. These results, including average temperature reduction, cooling load reduction, and thermal flux intensity reduction will be compared to the experimental results previously presented in the literature review in order to validate the technique developed. 


\section{Results}

\subsection{Reference building and vegetated building comparison}

Fig.16 compares the measured interior air temperature between conventional (Reference Building) and vegetated building. It indicates the variation over time of the measured interior temperature for both the reference building and the vegetated building from the experiment reported by Tilley et al. in 2012. The Green Façade provides a variable and relative cooling effect, meaning that the reduction in temperature becomes more significant as the external thermal conditions increase. As such, late evening to mid-morning will see a slight reduction in interior temperature whereas mid-day to early evening will see much more pronounced temperature differences.

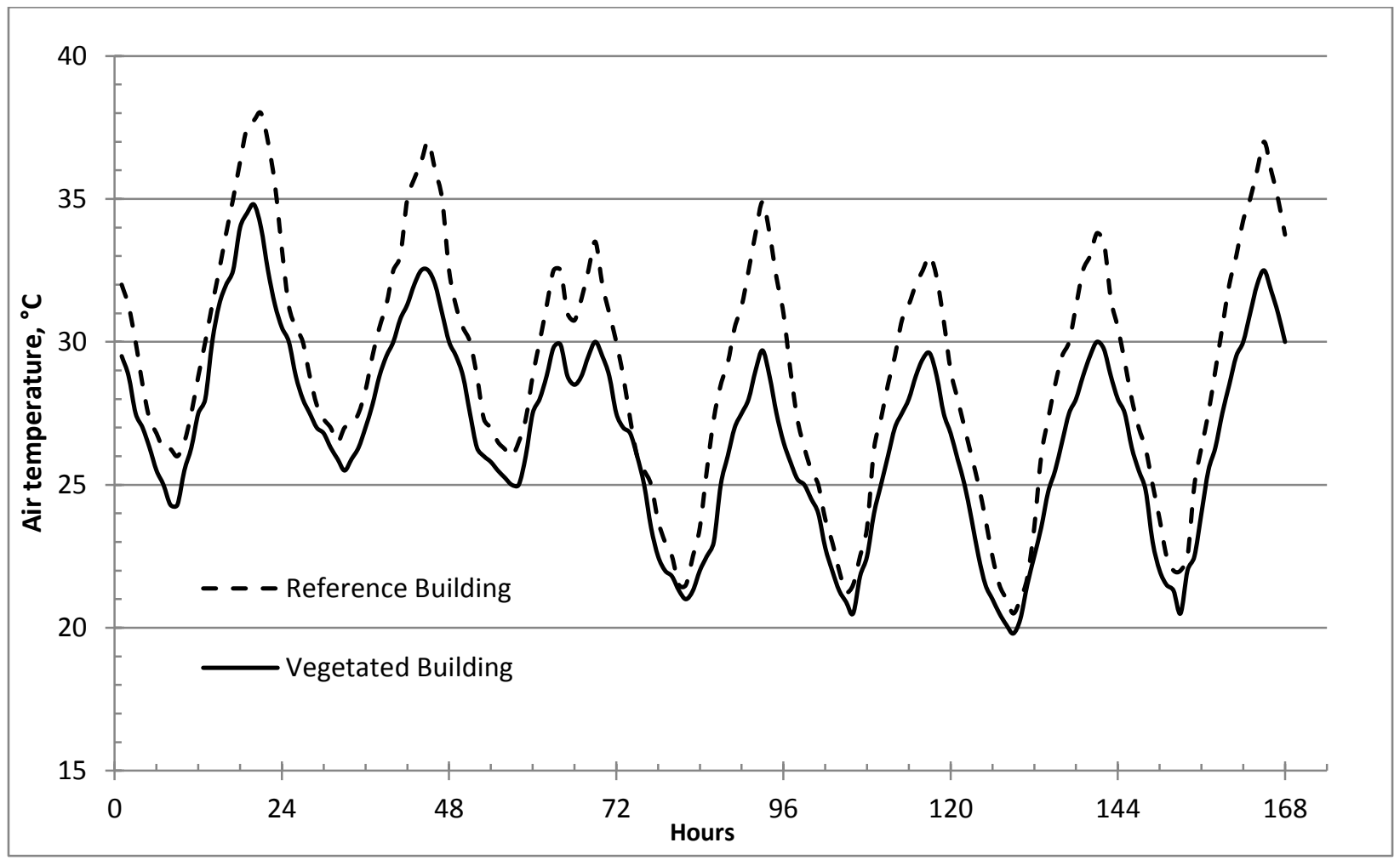

Figure 16 Experimentally measured Interior temperature fluctuations in ${ }^{\circ} \mathrm{C}$ over hours, 11-17 July.

Processed data shows that the reference building had an average interior temperature of $29^{\circ} \mathrm{C}$ over the course of the week from 11-17 July. During the same time period, for the building with a vegetated Green Façade, the average was of $26.8^{\circ} \mathrm{C}$. The average cooling effect was of $2.2^{\circ} \mathrm{C}$ with a maximum of $5.2^{\circ} \mathrm{C}$, the peak time of day being approximately 20:00. In terms of 
proportions, this represents an averaged $7.7 \%$ reduction in indoor temperature between the reference building and the vegetated building.

\subsection{Reference model and enclosed vegetated model comparison}

In the case of the simulation using the enclosed Green Room technique, Fig. 17 below shows the results of the simulation conducted on IES-VE by presenting the variation over time of the calculated interior temperature for both the reference model and the vegetated model. The smoothness of the graph lines compared to the one in Fig. 16 is attributable to the normalized weather data used to generate the model interior temperatures.

In this first IES-VE numerical comparison between reference and vegetated models, the processed data shows that the reference model had an average interior temperature of $26.8{ }^{\circ} \mathrm{C}$ over the course of the week from 11-17 July. For the same time period, the building with a vegetated Green Façade based on an enclosed Green Room, had an average of $25^{\circ} \mathrm{C}$. The average cooling effect was of $1.7^{\circ} \mathrm{C}$ with a maximum of $4.5^{\circ} \mathrm{C}$, the peak time of day being also at approximately 20:00. In terms of proportions, this represents an averaged $6.5 \%$ reduction in indoor temperature between the reference model and the vegetated model.

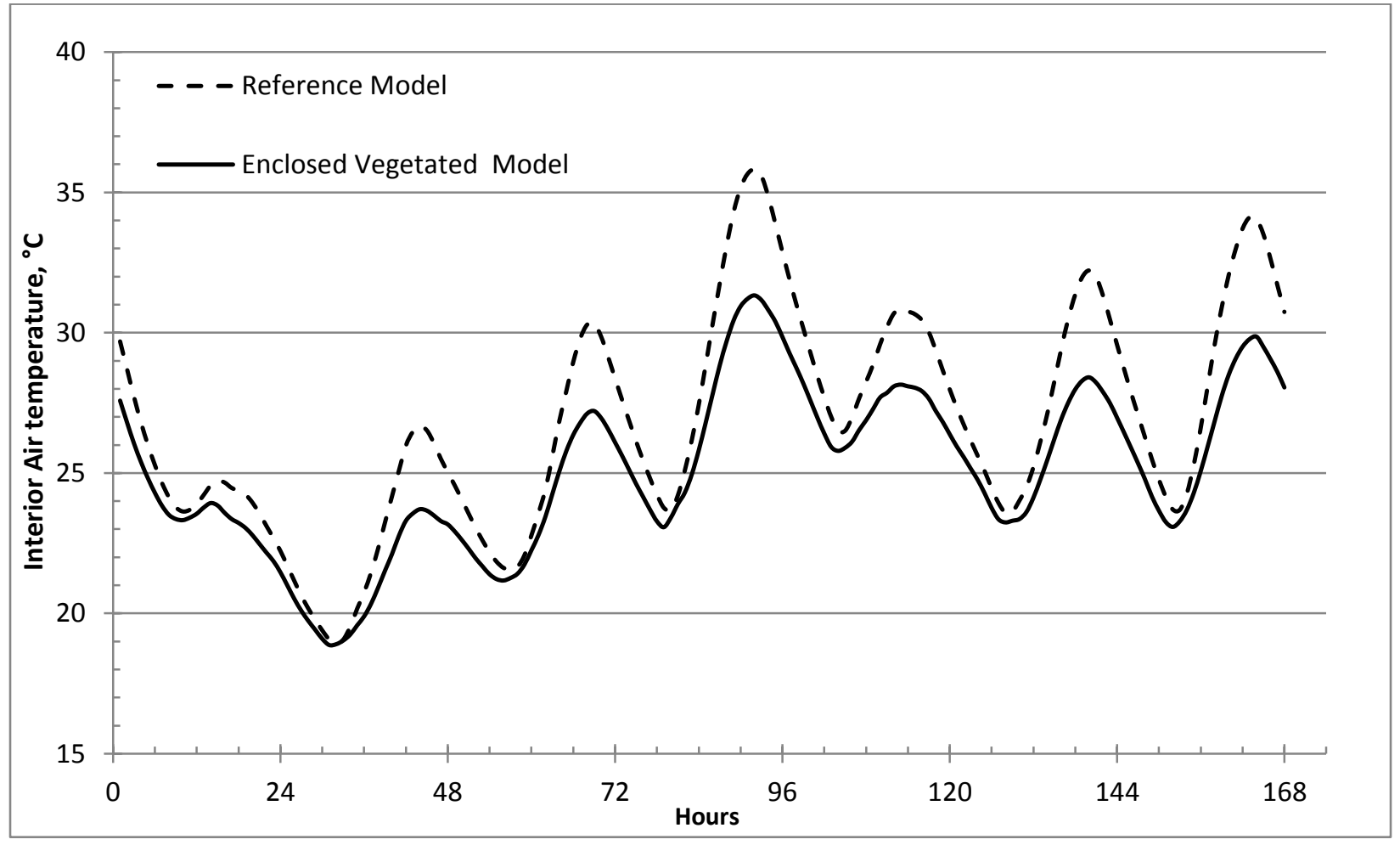

Figure 17 Enclosed technique, IES-VE generated interior temperature fluctuations in ${ }^{\circ} \mathrm{C}$ over hours, 11-17 July. 
Nonetheless, the same patterns of variability in temperature reduction can be clearly observed with corresponding maximal reductions observed when comparing peak interior temperatures. Also, the nesting of both curves for the IES-VE generated model is coherent with the nesting observed in the experimentally measured curves. This is attributable to the thermal buffer behavior of the Green Room. In effect, once the solar gain stops, the room forms a much more coherent stagnant air cavity then a Green Façade would, thus slowing heat loss. Of note, the low values of both curves are closer than observed in the ones observed on the curves based on experimental data.

\subsection{Reference model and vented vegetated model comparison}

In the case of the simulation using the vented Green Room technique, Fig. 18 presents the results of the simulation conducted on IES-VE. The graph shows the variation over time of the interior temperature for both the reference and the vegetated models. The same weather data was used for this simulation, but because this Green Room contains openings to the exterior, it was not influenced by the macro air flows induced by wind. This can be seen in the small irregularities of the graph lines when comparing to Fig. 1.7 Wind generated pressured and air buoyancy altered internal thermal dynamics of the Green Room.

As such, we again have the same average interior temperature of $26.8{ }^{\circ} \mathrm{C}$ for the reference model over the course of the week from 11-17 July. But, for the same time period, the building with a vegetated Green Façade based this time on a vented Green Room, the average was of $24.9^{\circ} \mathrm{C}$. The average cooling effect was of $1.9^{\circ} \mathrm{C}$ with a maximum of $4.2^{\circ} \mathrm{C}$, the peak time of day being also at approximately 20:00 hrs. In terms of proportions, this represents an averaged $7.2 \%$ reduction in indoor temperature between the reference model and the vegetated model. 


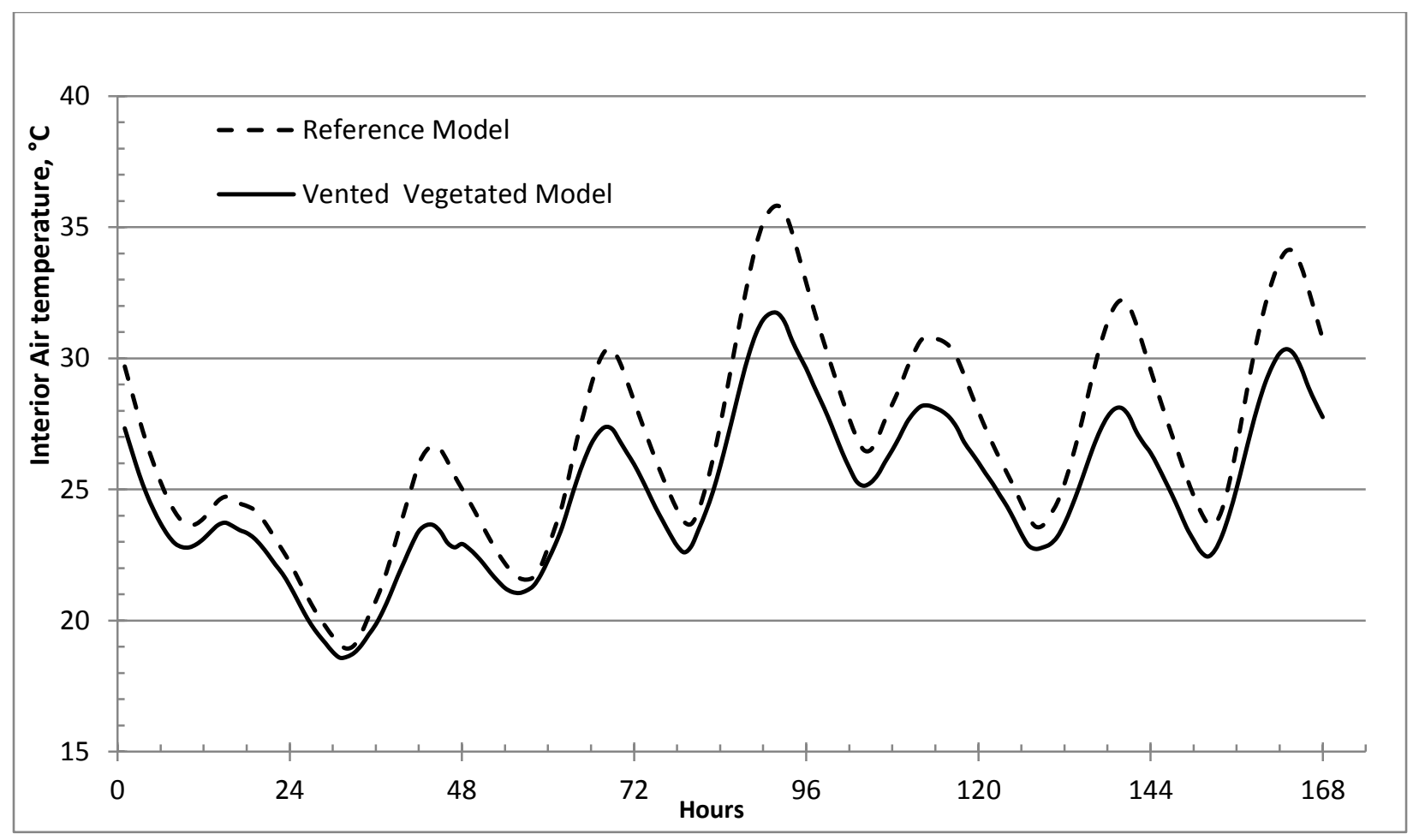

Figure 18 Vented techniques, IES-VE generated interior temperature fluctuations in ${ }^{\circ} \mathrm{C}$ over hours, 11-17 July.

Nevertheless, the same patterns of variability in temperature reduction can be clearly observed with corresponding maximal reductions observed when comparing peak interior temperatures. However, in this case, one can observe that the nesting of both curves, while still very similar, is not identical to the one observed between the enclosed model and the reference model shown in the previous figure. In general, the valleys are slightly lower and the curves tend to be more separated during the late-evening to mid-morning period. This curve separation is not observed to the same extent in the curves generated from experimental data.

\subsection{Comparison between Enclosed and Vented Green Rooms}

While both techniques offer heat gain mitigation comparable to the one of a Green Façade, they differ slightly. In Fig. 19, the interior temperatures resulting from the use of the two techniques are presented. This allows for the observation of the general patterns which differentiates them. As such, the enclosed model prevents the main room from cooling as much as the vented model, which is logical. While both techniques are modulated so that no cooling is taking place past peak heat, the vented room exposes the main room's exterior surface to cooler outdoor air, whereas the enclosed one forms a thermal buffer. 
This thermal buffer effect keeps the indoor temperature slightly higher, which was consistent with both the experimental data and the literature reviewed. This is the only highly consistent difference between both lines; however, one could be lead to conclude that the enclosed model provides a slightly more significant cooling effect observable at or near peak on three occasions during the simulation period of 7 days. All this considered, the analysis of the simulation results for both approaches to the Green Room showed that the technique is perfectly viable to replicate the thermal effects of a Green Façade.

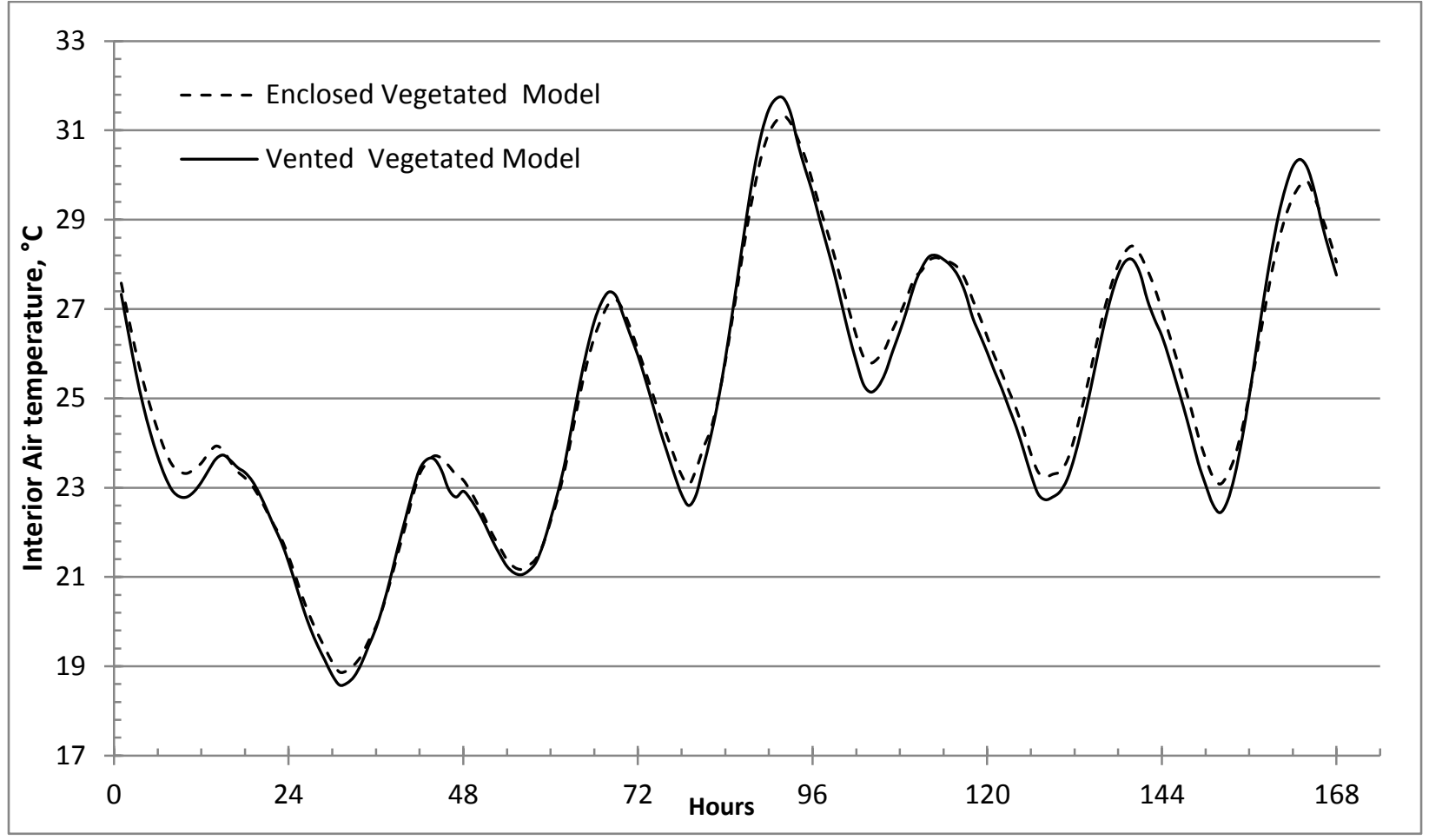

Figure 19 comparative graphs of interior temperature fluctuations for enclosed and vented green room models in ${ }^{\circ} \mathrm{C}$ over hours, 11-17 July.

While the vernacular aim of heat gain mitigation techniques was to provide greater interior thermal comfort to the occupants, today mechanical cooling is the means generally used to achieve this aim. Therefore, a more useful metric for decision makers is to quantify how much of a reduction in cooling energy a Green Façade can offer. In the case of bigger buildings, a reduction in the peak capacity of the cooling system can also mean equipment that is much reduced in size. 


\subsection{Cooling energy reduction}

To quantify the reduction in cooling energy use, now a series of new simulations were conducted. The main room was assigned a cooling system, as described in the methodology. The system was unspecified and simply allowed to keep the room below at or below a maximum set point: in this case $23.9^{\circ} \mathrm{C}$. It also allowed for capturing of how much energy this notional system had to use to meet this condition. The results obtained from the simulation indicated that the total cooling energy consumed to meet the above mentioned set point over the period of the simulation is of $10.7 \mathrm{kWh}$. The same parameters where then applied to the main room of the enclosed vegetated model and of the vented-vegetated model. Results obtained indicated that the total cooling energy consumed for the enclosed vegetated model was of $5.7 \mathrm{kWh}$, which represented a $46 \%$ reduction compared to the reference model. The results also indicated that the vented-vegetated model saw an energy usage of $5.8 \mathrm{kWh}$, representing a $45.9 \%$ reduction compared to the reference model. Fig. 20 below shows the cooling load in $\mathrm{kW}$ over hours of all tree models and allows observing that the slightly more noticeable cooling effect seen in the enclosed-vegetated model translates into a slight cooling load reduction.

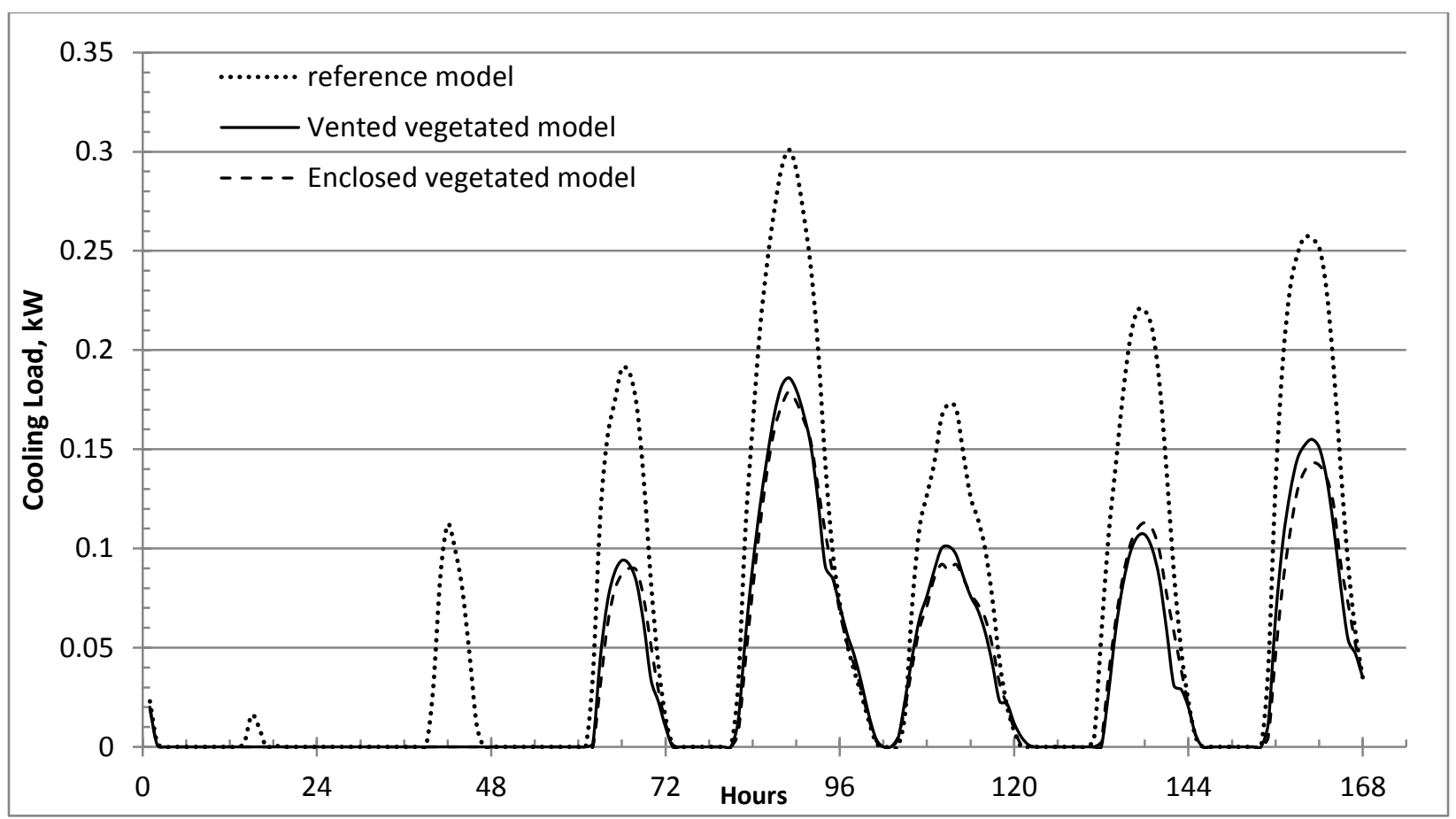

Figure 20 Comparative graph of cooling load to maintain the main room of all models at set point in $\mathrm{kW}$ over hours, 1117 July. 
The enclosed model thus shows a slightly more important cooling effect near peak and a thermal buffer effect at night. In this experiment, these behaviors make it a more accurate replication technique in relation to the overall thermal effects of a Green Façade. Table 5 provides a summary of the thermal effects of a Green Façade as measured experimentally by Tilley et al. in 2012, with results obtained from simulations based on two different techniques.

Table 5 Comparative thermal metrics

\begin{tabular}{|l|r|r|r|}
\hline & \multicolumn{2}{|l|}{$\begin{array}{l}\text { Experimental } \\
\text { buildings }\end{array}$} & \multicolumn{2}{l|}{$\begin{array}{l}\text { Vented } \\
\text { vegetated model }\end{array}$} & $\begin{array}{l}\text { Enclosed vegetated } \\
\text { model }\end{array}$ \\
\hline $\begin{array}{l}\text { Average indoor temperature } \\
\text { of reference buildings/models }\end{array}$ & $29{ }^{\circ} \mathrm{C}$ & $26.8^{\circ} \mathrm{C}$ & $26.8^{\circ} \mathrm{C}$ \\
\hline $\begin{array}{l}\text { Average indoor temperature } \\
\text { of vegetated building/model }\end{array}$ & $26.8^{\circ} \mathrm{C}$ & $24.9^{\circ} \mathrm{C}$ & $25^{\circ} \mathrm{C}$ \\
\hline Peak cooling effect & $5.2^{\circ} \mathrm{C}$ & $4.2^{\circ} \mathrm{C}$ & $4.5^{\circ} \mathrm{C}$ \\
\hline Average cooling effect & $2.2^{\circ} \mathrm{C}$ & $1.9^{\circ} \mathrm{C}$ & $1.7^{\circ} \mathrm{C}$ \\
\hline $\begin{array}{l}\text { Percentage of indoor } \\
\text { temperature reduction }\end{array}$ & $7.7 \%$ & $7.2 \%$ & $6.5 \%$ \\
\hline $\begin{array}{l}\text { Cooling energy use of } \\
\text { reference model main room }\end{array}$ & N/A & $10.7 \mathrm{kWh}$ & $10.7 \mathrm{kWh}$ \\
\hline $\begin{array}{l}\text { Cooling energy use of } \\
\text { Vegetated models }\end{array}$ & N/A & $5.8 \mathrm{kWh}$ & $5.7 \mathrm{kWh}$ \\
\hline $\begin{array}{l}\text { Percentage reduction of } \\
\text { cooling energy use }\end{array}$ & N/A & $45.9 \%$ & $46.4 \%$ \\
\hline
\end{tabular}

\subsection{Thermal Dynamics and Green Facades}

The previous comparison allowed understanding the global thermal impact of a Green Façade on a building. Now, further analysis will allow understanding how the thermal dynamics of a building are altered by it. As such, comparing the total heat fluxes going into the main room from different heat pathways between the reference model and the enclosed-vegetated model can provide insight into the specific thermal dynamics at play. Table 6 presents the comparative data, focusing only on conductive gains and ignoring air infiltration gains. 
Table 6 Comparative conduction gains into main room, 11-17 July

\begin{tabular}{|l|r|r|r|}
\hline & $\begin{array}{l}\text { Conduction gain - } \\
\text { ceiling }(\mathrm{kWh})\end{array}$ & $\begin{array}{l}\text { Conduction gain - } \\
\text { ground floor }(\mathrm{kWh})\end{array}$ & $\begin{array}{l}\text { Conduction gain - walls } \\
(\mathrm{kWh})\end{array}$ \\
\hline Reference model & 2.4 & 0.5 & 7 \\
\hline $\begin{array}{l}\text { Enclosed vegetated } \\
\text { model }\end{array}$ & 2.6 & 0.6 & 1.5 \\
\hline
\end{tabular}

This table shows that while the meteorological data driving heat gain is identical for both models, the addition of a Green Façade altered both the intensity of the heat fluxes and their direction. Heat transfer through conduction increased as the difference in temperature between the separated spaces increased as well (Straube \& Burnett, 2005). As such, given that the main room is cooler in the presence of a Green Façade compared to the reference model, the intensity of the flux showed a slight increase. Most notable is the reduction in heat gain through the walls of the vegetated model, which accounted for the vast majority of the cooling load reduction observed. Fig. 21 and 22 graphically represent the change in the room's heat gain composition.

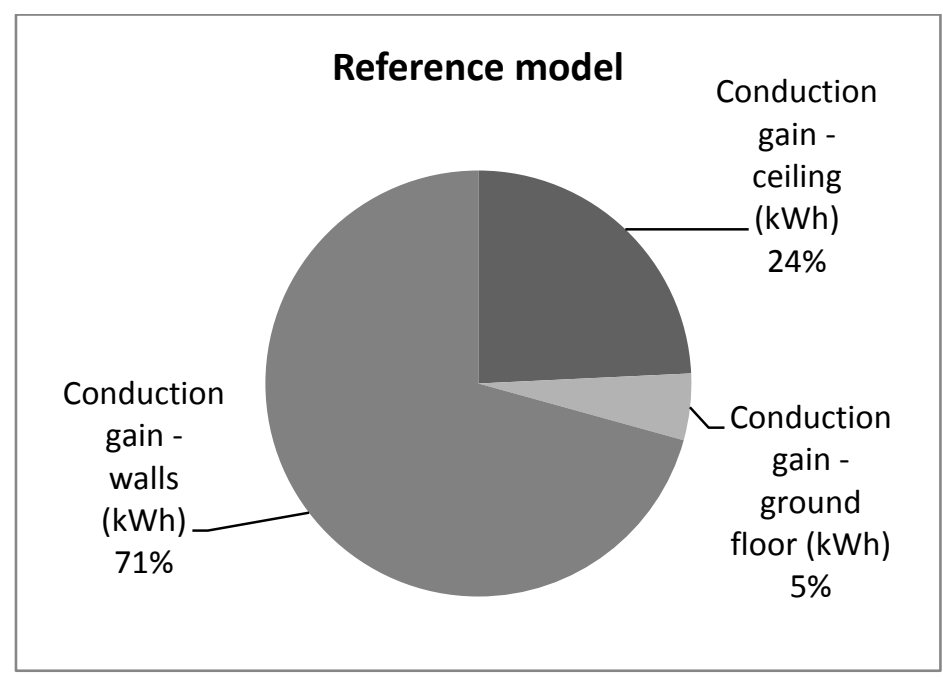

Figure 21 Relative contributions of different thermal pathways to the total heat gain of the main room, 11-17 July. 


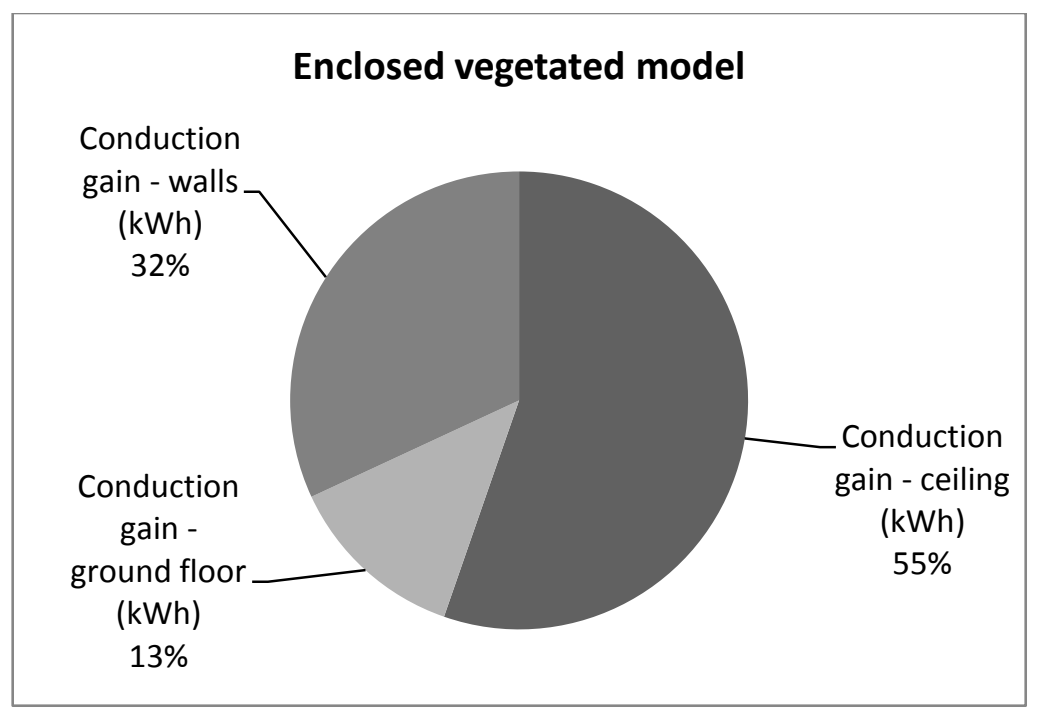

Figure 22 Relative contributions of different thermal pathways to the total heat gain of the vegetated main room, 11-17 July.

The cumulative data allows understanding the impact over time but does not allow discerning the dynamic impact of a Green Façade over the duration of a simulation period. Fig. 23 shows the gain or loss of thermal energy through the walls of the main room. It can be observed that the Green Room significantly reduced the thermal gain from late morning to midevening. This period of time is where the energy transferred within the Green Room was sufficient for the phase change of water to vapour to occur, absorbing important amounts of energy while not seeing an increase of temperature. Interestingly, the vegetated model showed slightly higher thermal loses from midnight to early morning. This was likely due to the fact that the exterior walls saw condensation (dew) occur on their surface, which released a minute amount of heat, slowing the heat loss to the exterior. In the case of the vegetated model, the Green Room shielded the exterior walls of the building from this effect of condensation. 


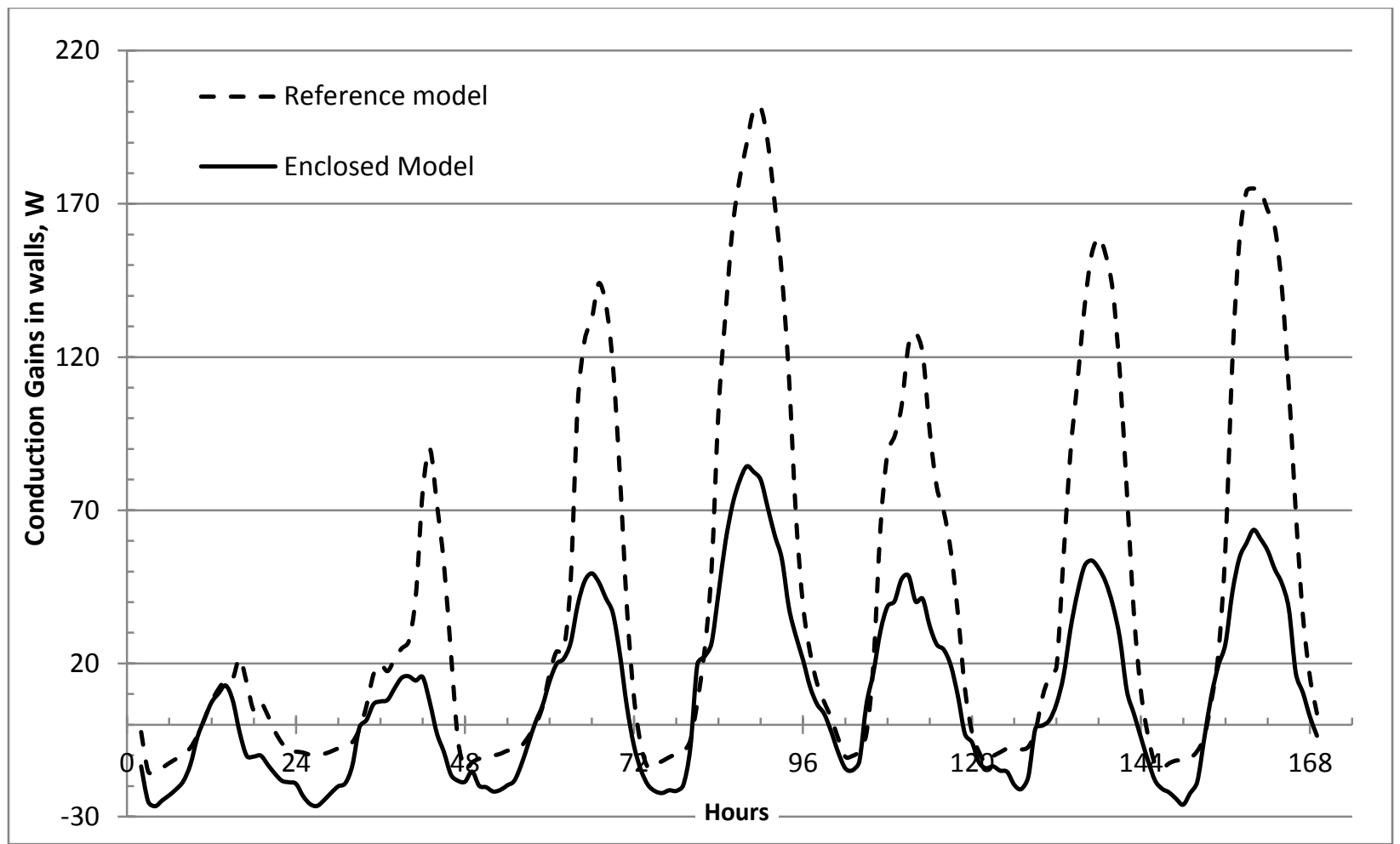

Figure 23 Comparative graph of heat transfer across the walls of the main room in $\mathrm{kW}$ over hours, 11-17 July 


\section{Conclusion}

The literature review has shown that a substantial body of knowledge on Green Façades is available to designers and decision makers, which can allow them to understand the thermal effects of such structures. However, the usefulness to a specific project entails that the thermal effects of Green Façade need to be quantified precisely in relation to a whole building energy model. Such a model must account for the specific size and location on the building of the Green Façade, in order to allow for the quantifying of its impact as accurately as possible. The challenge rests in the fact that for software purposely built to create whole building energy models, a feature to incorporate the Green Façade is not yet available. Consequently, this limits the ability to present the many qualitative advantages for the use of Green Façades as well the quantitative justification many building owners want to have available during their decision making process.

Consequently, the objective of this research was to develop a technique which would allow incorporating a Green Façade into a whole building energy model in IES-VE. Prior to developing such a technique, a valid reference model in IES-VE was required. The 2012 report from the experiment conducted by Tilley et al. in Clarksville, MD, USA, offered the details required to create such a reference building and also offered the quantitative data required to validate the thermal behaviour of the reference model. As such, the reference model is an exact replica of the reference building built and instrumented by Tilley et al. with the same thermal properties, materials and geometry specified. The reference model was then used to conduct a simulation based on meteorological data sourced from ASHRAE. In order to validate the behaviour of the reference model, the results of the simulation were analysed. This analysis illustrated the response of the indoor temperature of both reference building and reference model in relation to exterior thermal conditions. The reference model did behave similarly to the reference building showing high and low indoor temperature peaks at corresponding times of day, similar to the temperature fluctuation patterns and temperature ranges proportional to the exterior conditions.

With a valid reference model, a technique to incorporate a Green Façade was developed based on the operating characteristics of IES-VE and based on the thermal properties and effects 
of a Green Façade. The Green Room technique sees the thermal properties of a Green Façade attributed to the exterior wall of a room which forms a cloak over the reference building, over the same area as a planned Green Façade. It also uses mechanical means to dissipate the thermal energy of solar radiation in quantities similar to that of a Green Façade. A simulation was run for a building identical to the reference building with a Green Room created aiming to replicate the effects of a Green Façade using the same meteorological inputs as the reference model. Results showed that the interior temperature reduction was, in terms of relative percentage, nearly identical to the reduction measured by Tilley et al. between their reference and vegetated buildings.

It can therefore be concluded that the Green Room method offers a valid avenue to incorporate Green Façades in a whole building energy model. This technique now enables, on an approximate basis, to quantify the impact of a Green Façade on the cooling loads of a building and on the peak capacity required of the cooling system. This ultimately translates into the ability to quantify, using a more holistic approach, the costs and savings attributable to a Green Façade. Finally, it enables the experimentation of different configurations and placement options, to determine the optimal use of a Green Façade for a specific building.

In order for this method to be replicable, future work is required to adapt it to a wide variety of buildings. Firstly, a method to determine the air flow settings of the HVAC loop in IES-VE is required. Green Rooms of different sizes, and consequently of different inner volumes will not have the same requirements. Determining the optimal spray chamber efficiency setting, which works in combination with the airflow to remove heat from the Green Room, is also required. Secondly, Fig. 24 illustrates the added complexity of replicating Green Façade where glazing is left uncovered. Identifying how openings for glazing can be most accurately integrated into a Green Room is likely to be challenging. Thirdly, the vented Green Room approach requires the determination of the optimal ratio for the size of the opening given the wall surface area. Finally, a set of criteria specifying under what set of conditions which approach to the Green Room method is more accurate is required. Much research is still required, as all these elements are necessary to the accuracy and reliability of the Green Room Method. 


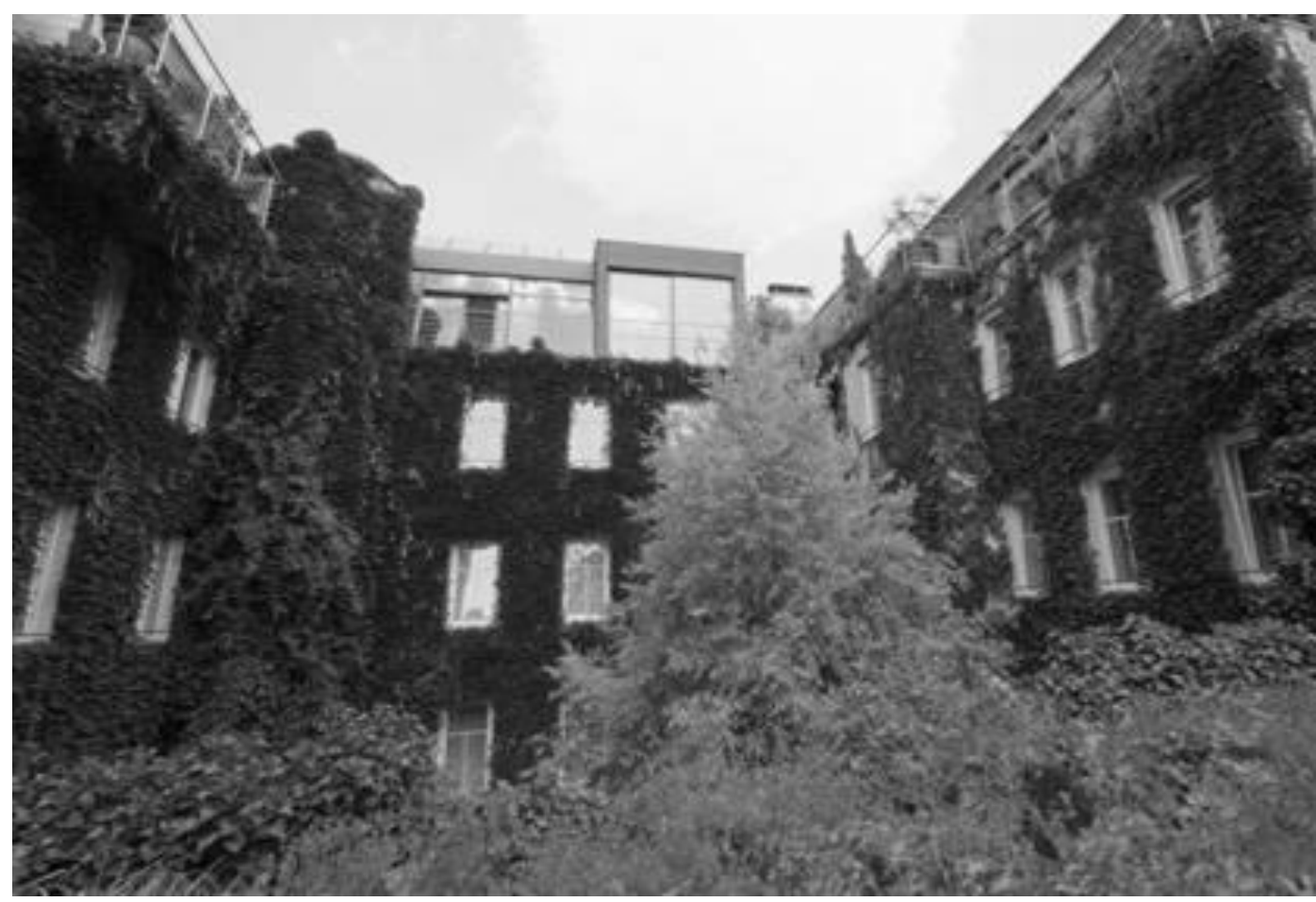

Figure 24 Hotel Stadthalle, Vienna. the world's first city centre hotel with a zero energy balance (Burklein, 2012)

Looking ahead, this technique could be very advantageously adapted to different whole building energy modeling software such as Energy Plus. Most interestingly, the Green Room method can serve as the foundation to develop refined Green Façade application techniques tailored specifically to climatic zones/regions with very different thermal conditions, wind patterns and meteorological normal. Indeed, the use of models allows for the acceleration of the traditional experimentation process by facilitating rapid iteration at low cost, leading to faster design evolution. For designers, manufacturers and owners, this method can translate theories and qualities supporting a design feature into a tangible quantitative argument. In the same way R-Value changed the understanding of heat transfer for the general public, Green Façades can go from being building ornaments to becoming building performance enhancement tools. 


\section{Appendices}

Description of Tilley et al.'s experimental building construction

Four buildings of dimensions 2.5 meters $(8 \mathrm{ft})$ long by 2.5 meters $(8 \mathrm{ft})$ wide by 3.5 meters (11 ft) high were constructed (Figure 10.1a) and placed on a concrete pad at the University of Maryland Central Research and Education Center in Clarksville, MD (approx. 30 $\mathrm{km}$ north of Washington, D.C.) on July 8th, 2009. The buildings consisted of a 4-sided squarehip 4/12 pitch roof with three-tab charcoal asphalt shingles (GAF Materials Corporation) and 5 $\mathrm{cm} \times 15 \mathrm{~cm}$ (2x6 in.) wood rafters, a ceiling hung from $5 \mathrm{~cm} \times 10 \mathrm{~cm}(2 \times 4$ in.) joists, $5 \mathrm{~cm} \mathrm{x} 10$ $\mathrm{cm}(2 \times 4$ in.) wood framed walls, and a $5 \mathrm{~cm} \times 15 \mathrm{~cm}(2 \times 6 \mathrm{in}$.) wood floor all at a $40 \mathrm{~cm}(16 \mathrm{in})$. center spacing. R-13 fiberglass insulation (CertainTeed Corporation), $9 \mathrm{~cm}$ (3-1/2 in.) thick, was installed on the ceiling, walls and floor. The interior walls and ceiling were covered with $1.6 \mathrm{~cm}$ (5/8 in.) thick gypsum drywall. The buildings were wrapped in a vapor barrier material (DuPont Tyvek Home Wrap) and then sided with Georgia-Pacific T1-11 1.5cm (19/32 in.) thick pine wood siding. The buildings were spray painted blue-grey slate (Glidden Premium Latex Exterior Paint-Flat) in May 2010 for the growing season (Figure 10.1b). The buildings had no windows and a single door was installed on the wall opposite the vegetation. The buildings were neither cooled nor heated during any part of the experiment.

Table A.1 Composite insulation of Tilley et al.'s experimental building

\begin{tabular}{|l|l|}
\hline Building Surface & $\begin{array}{l}\text { Composite Insulation Rating (R-Value) } \mathrm{m}^{2} \cdot \mathrm{K}^{-} \cdot \mathrm{W}^{-1}\left(\mathrm{ft}^{2} \cdot\right. \\
\left.{ }^{\circ} \mathrm{F} \cdot \mathrm{h} \cdot \mathrm{Btu}-1\right)\end{array}$ \\
\hline Walls without door & $2.27(12.9)$ \\
\hline Wall with door & $1.72(9.77)$ \\
\hline Roof & $3.21(18.2)$ \\
\hline Floor & $2.45(13.9)$ \\
\hline
\end{tabular}


Table A. 2 Comparative exterior air temperature data, reference building and reference model

\begin{tabular}{|c|c|c|c|}
\hline Date & Time & $\begin{array}{l}\text { Actual dry-bulb } \\
\text { temperature }\left({ }^{\circ} \mathrm{C}\right) \\
\text { Exterior Air }\end{array}$ & $\begin{array}{l}\text { Model dry-bulb } \\
\text { temperature }\left({ }^{\circ} \mathrm{C}\right) \\
\text { Exterior Air }\end{array}$ \\
\hline \multirow[t]{24}{*}{ 11-Jul } & $0: 00$ & 21.5 & 23.3 \\
\hline & $1: 00$ & 21 & 22.2 \\
\hline & $2: 00$ & 20.5 & 21.7 \\
\hline & 3:00 & 20 & 21.7 \\
\hline & $4: 00$ & 20 & 21.7 \\
\hline & $5: 00$ & 20 & 21.7 \\
\hline & $6: 00$ & 24 & 21.7 \\
\hline & $7: 00$ & 25.5 & 21.7 \\
\hline & $8: 00$ & 28 & 22.2 \\
\hline & $9: 00$ & 31.5 & 22.2 \\
\hline & $10: 00$ & 33.5 & 22.8 \\
\hline & $11: 00$ & 35 & 22.8 \\
\hline & $12: 00$ & 36 & 23.3 \\
\hline & $13: 00$ & 35 & 23.9 \\
\hline & $14: 00$ & 38.5 & 21.7 \\
\hline & $15: 00$ & 36 & 20.6 \\
\hline & $16: 00$ & 35 & 20.6 \\
\hline & $17: 00$ & 33.5 & 20.6 \\
\hline & $18: 00$ & 32 & 20.6 \\
\hline & 19:00 & 30 & 20.6 \\
\hline & 20:00 & 27 & 20.6 \\
\hline & 21:00 & 23.5 & 20.6 \\
\hline & $22: 00$ & 23.5 & 20.6 \\
\hline & $23: 00$ & 23.5 & 19.4 \\
\hline \multirow[t]{24}{*}{ 12-Jul } & $0: 00$ & 23 & 18.9 \\
\hline & $1: 00$ & 23 & 18.3 \\
\hline & $2: 00$ & 24 & 18.3 \\
\hline & $3: 00$ & 24 & 18.3 \\
\hline & $4: 00$ & 24 & 18.3 \\
\hline & $5: 00$ & 22 & 17.8 \\
\hline & $6: 00$ & 25.5 & 17.8 \\
\hline & $7: 00$ & 27 & 18.9 \\
\hline & $8: 00$ & 28 & 19.4 \\
\hline & $9: 00$ & 32 & 20 \\
\hline & $10: 00$ & 33.5 & 20.6 \\
\hline & $11: 00$ & 35 & 21.7 \\
\hline & $12: 00$ & 36 & 22.2 \\
\hline & $13: 00$ & 37.5 & 22.8 \\
\hline & $14: 00$ & 36.5 & 23.9 \\
\hline & $15: 00$ & 38 & 24.4 \\
\hline & $16: 00$ & 36 & 26.1 \\
\hline & $17: 00$ & 35 & 26.1 \\
\hline & $18: 00$ & 33.5 & 25 \\
\hline & 19:00 & 30 & 25 \\
\hline & $20: 00$ & 27 & 23.9 \\
\hline & 21:00 & 23.5 & 22.8 \\
\hline & $22: 00$ & 26 & 22.2 \\
\hline & $23: 00$ & 26 & 23.9 \\
\hline \multirow[t]{8}{*}{ 13-Jul } & $0: 00$ & 22 & 21.7 \\
\hline & $1: 00$ & 22 & 21.7 \\
\hline & $2: 00$ & 21.5 & 21.1 \\
\hline & $3: 00$ & 21 & 20.6 \\
\hline & $4: 00$ & 20.5 & 20.6 \\
\hline & $5: 00$ & 19.75 & 20.6 \\
\hline & $6: 00$ & 22 & 21.1 \\
\hline & $7: 00$ & 25 & 21.1 \\
\hline
\end{tabular}




\begin{tabular}{|c|c|c|c|}
\hline & $8: 00$ & 28 & 21.7 \\
\hline & 9:00 & 35 & 21.7 \\
\hline & $10: 00$ & 34 & 21.7 \\
\hline & $11: 00$ & 35.5 & 23.3 \\
\hline & $12: 00$ & 38 & 23.9 \\
\hline & $13: 00$ & 34 & 25 \\
\hline & $14: 00$ & 28 & 26.1 \\
\hline & $15: 00$ & 23 & 27.8 \\
\hline & $16: 00$ & 27.5 & 27.8 \\
\hline & $17: 00$ & 27.5 & 27.8 \\
\hline & $18: 00$ & 27.5 & 27.8 \\
\hline & $19: 00$ & 26 & 27.8 \\
\hline & $20: 00$ & 25 & 26.7 \\
\hline & 21:00 & 22 & 25 \\
\hline & $22: 00$ & 21 & 23.9 \\
\hline & 23:00 & 22 & 23.3 \\
\hline \multirow[t]{24}{*}{ 14-Jul } & 0:00 & 19.5 & 22.8 \\
\hline & $1: 00$ & 20.5 & 22.2 \\
\hline & $2: 00$ & 20 & 21.7 \\
\hline & $3: 00$ & 19 & 21.7 \\
\hline & $4: 00$ & 16 & 21.1 \\
\hline & $5: 00$ & 15 & 21.1 \\
\hline & $6: 00$ & 17 & 21.1 \\
\hline & 7:00 & 20 & 21.7 \\
\hline & $8: 00$ & 23 & 23.9 \\
\hline & 9:00 & 25 & 26.1 \\
\hline & $10: 00$ & 28 & 27.8 \\
\hline & $11: 00$ & 31.5 & 30 \\
\hline & $12: 00$ & 34 & 31.7 \\
\hline & $13: 00$ & 34 & 32.8 \\
\hline & $14: 00$ & 34.5 & 33.9 \\
\hline & $15: 00$ & 35 & 33.9 \\
\hline & $16: 00$ & 33 & 34.4 \\
\hline & $17: 00$ & 31 & 33.3 \\
\hline & $18: 00$ & 29 & 32.2 \\
\hline & $19: 00$ & 25 & 31.7 \\
\hline & 20:00 & 21.5 & 29.4 \\
\hline & $21: 00$ & 20 & 27.8 \\
\hline & $22: 00$ & 18 & 27.2 \\
\hline & 23:00 & 17.5 & 26.1 \\
\hline \multirow[t]{23}{*}{ 15-Jul } & $0: 00$ & 18.5 & 25.6 \\
\hline & $1: 00$ & 19 & 25.6 \\
\hline & $2: 00$ & 19 & 25 \\
\hline & $3: 00$ & 17 & 23.9 \\
\hline & $4: 00$ & 16.5 & 23.3 \\
\hline & $5: 00$ & 15.5 & 23.3 \\
\hline & $6: 00$ & 17 & 22.8 \\
\hline & 7:00 & 21 & 23.9 \\
\hline & $8: 00$ & 24.5 & 24.4 \\
\hline & $9: 00$ & 27 & 27.2 \\
\hline & $10: 00$ & 30 & 28.9 \\
\hline & $11: 00$ & 32.5 & 28.3 \\
\hline & $12: 00$ & 33 & 28.9 \\
\hline & $13: 00$ & 28.5 & 28.9 \\
\hline & $14: 00$ & 31.5 & 25 \\
\hline & $15: 00$ & 31 & 27.8 \\
\hline & $16: 00$ & 29 & 26.7 \\
\hline & $17: 00$ & 28 & 26.1 \\
\hline & $18: 00$ & 27 & 26.7 \\
\hline & $19: 00$ & 25.5 & 26.7 \\
\hline & $20: 00$ & 22 & 26.1 \\
\hline & $21: 00$ & 20 & 24.4 \\
\hline & $22: 00$ & 18 & 25.6 \\
\hline
\end{tabular}




\begin{tabular}{|c|c|c|c|}
\hline & 23:00 & 16.5 & 23.9 \\
\hline \multirow[t]{24}{*}{ 16-Jul } & 0:00 & 16 & 23.9 \\
\hline & $1: 00$ & 16 & 23.9 \\
\hline & $2: 00$ & 15 & 22.8 \\
\hline & $3: 00$ & 14.5 & 22.8 \\
\hline & $4: 00$ & 14 & 21.7 \\
\hline & $5: 00$ & 13.5 & 21.1 \\
\hline & $6: 00$ & 14 & 21.1 \\
\hline & 7:00 & 16.5 & 21.7 \\
\hline & $8: 00$ & 22.5 & 22.8 \\
\hline & $9: 00$ & 25 & 24.4 \\
\hline & $10: 00$ & 29 & 25 \\
\hline & $11: 00$ & 31.5 & 26.7 \\
\hline & $12: 00$ & 33 & 27.8 \\
\hline & $13: 00$ & 31.5 & 28.3 \\
\hline & $14: 00$ & 33.5 & 28.9 \\
\hline & $15: 00$ & 33 & 29.4 \\
\hline & $16: 00$ & 32 & 29.4 \\
\hline & $17: 00$ & 31 & 30 \\
\hline & $18: 00$ & 28 & 29.4 \\
\hline & 19:00 & 25.5 & 28.9 \\
\hline & 20:00 & 22.5 & 27.2 \\
\hline & 21:00 & 21 & 25.6 \\
\hline & $22: 00$ & 20 & 24.4 \\
\hline & $23: 00$ & 18.5 & 23.9 \\
\hline \multirow[t]{24}{*}{ 17-Jul } & 0:00 & 18.5 & 23.3 \\
\hline & $1: 00$ & 16.75 & 22.8 \\
\hline & $2: 00$ & 16.75 & 22.2 \\
\hline & $3: 00$ & 16.75 & 21.7 \\
\hline & 4:00 & 16.75 & 20.6 \\
\hline & $5: 00$ & 16.75 & 21.7 \\
\hline & $6: 00$ & 18.5 & 20.6 \\
\hline & $7: 00$ & 21.5 & 21.1 \\
\hline & $8: 00$ & 24 & 22.8 \\
\hline & $9: 00$ & 28 & 25 \\
\hline & $10: 00$ & 33 & 26.7 \\
\hline & $11: 00$ & 33.5 & 28.9 \\
\hline & $12: 00$ & 33 & 30.6 \\
\hline & $13: 00$ & 35 & 31.1 \\
\hline & $14: 00$ & 37.5 & 32.2 \\
\hline & $15: 00$ & 37 & 32.2 \\
\hline & $16: 00$ & 36 & 32.2 \\
\hline & $17: 00$ & 34 & 32.8 \\
\hline & $18: 00$ & 31 & 31.1 \\
\hline & 19:00 & 28 & 29.4 \\
\hline & 20:00 & 25.5 & 27.2 \\
\hline & 21:00 & 24 & 26.1 \\
\hline & 22:00 & 22.5 & 25 \\
\hline & $23: 00$ & 21.5 & 24.4 \\
\hline
\end{tabular}

Table A. 3 Comparative solar radiation data, reference building and reference model

\begin{tabular}{|r|r|l|lr|}
\hline Date & \multicolumn{1}{|l|}{ Time } & $\begin{array}{l}\text { Actual Ext Surface } \\
\text { incident solar flux }\left(\mathrm{W} / \mathrm{m}^{2}\right)\end{array}$ & $\begin{array}{l}\text { Model Ext surface } \\
\text { incident solar flux }\left(\mathrm{W} / \mathrm{m}^{2}\right) \\
\text { External wall }\end{array}$ \\
\hline & $0: 00$ & 0 & 0 \\
\hline & $1: 00$ & 0 & 0 \\
\hline & $2: 00$ & 0 & 0 \\
\hline & $3: 00$ & 0 & 0 \\
\hline & $4: 00$ & 0 & 0 \\
\hline & $5: 00$ & 0 & 5 \\
\hline
\end{tabular}




\begin{tabular}{|c|c|c|c|}
\hline \multirow[t]{17}{*}{ 11-Jul } & $7: 00$ & 50 & 18 \\
\hline & $8: 00$ & 100 & 43 \\
\hline & 9:00 & 200 & 81 \\
\hline & $10: 00$ & 340 & 115 \\
\hline & $11: 00$ & 385 & 137 \\
\hline & $12: 00$ & 375 & 156 \\
\hline & $13: 00$ & 360 & 156 \\
\hline & $14: 00$ & 450 & 146 \\
\hline & $15: 00$ & 275 & 134 \\
\hline & $16: 00$ & 225 & 169 \\
\hline & $17: 00$ & 175 & 167 \\
\hline & $18: 00$ & 120 & 107 \\
\hline & 19:00 & 100 & 55 \\
\hline & 20:00 & 25 & 20.5 \\
\hline & 21:00 & 0 & 0 \\
\hline & $22: 00$ & 0 & 0 \\
\hline & $23: 00$ & 0 & 0 \\
\hline \multirow[t]{24}{*}{ 12-Jul } & $0: 00$ & 0 & 0 \\
\hline & $1: 00$ & 0 & 0 \\
\hline & $2: 00$ & 0 & 0 \\
\hline & $3: 00$ & 0 & 0 \\
\hline & $4: 00$ & 0 & 0 \\
\hline & $5: 00$ & 0 & 0 \\
\hline & $6: 00$ & 25 & 14 \\
\hline & $7: 00$ & 50 & 43 \\
\hline & $8: 00$ & 150 & 111 \\
\hline & $9: 00$ & 200 & 175 \\
\hline & $10: 00$ & 275 & 156 \\
\hline & $11: 00$ & 300 & 166 \\
\hline & $12: 00$ & 350 & 205 \\
\hline & $13: 00$ & 350 & 229 \\
\hline & $14: 00$ & 390 & 244 \\
\hline & $15: 00$ & 360 & 229 \\
\hline & $16: 00$ & 230 & 224 \\
\hline & $17: 00$ & 190 & 156 \\
\hline & 18:00 & 120 & 97 \\
\hline & 19:00 & 75 & 51 \\
\hline & $20: 00$ & 30 & 13 \\
\hline & 21:00 & 0 & 0 \\
\hline & $22: 00$ & 0 & 0 \\
\hline & $23: 00$ & 0 & 0 \\
\hline \multirow[t]{22}{*}{ 13-Jul } & $0: 00$ & 0 & 0 \\
\hline & $1: 00$ & 0 & 0 \\
\hline & $2: 00$ & 0 & 0 \\
\hline & $3: 00$ & 0 & 0 \\
\hline & $4: 00$ & 0 & 0 \\
\hline & $5: 00$ & 0 & 0 \\
\hline & $6: 00$ & 10 & 10 \\
\hline & $7: 00$ & 50 & 27 \\
\hline & $8: 00$ & 100 & 45 \\
\hline & $9: 00$ & 200 & 113 \\
\hline & $10: 00$ & 300 & 185 \\
\hline & $11: 00$ & 350 & 207 \\
\hline & $12: 00$ & 450 & 216 \\
\hline & $13: 00$ & 400 & 305 \\
\hline & $14: 00$ & 150 & 291 \\
\hline & $15: 00$ & 25 & 246 \\
\hline & $16: 00$ & 150 & 232 \\
\hline & $17: 00$ & 250 & 133 \\
\hline & $18: 00$ & 150 & 83 \\
\hline & $19: 00$ & 75 & 50 \\
\hline & 20:00 & 30 & 20 \\
\hline & 21:00 & 0 & 0 \\
\hline
\end{tabular}




\begin{tabular}{|c|c|c|c|}
\hline & $22: 00$ & 0 & 0 \\
\hline & $23: 00$ & 0 & 0 \\
\hline \multirow[t]{24}{*}{ 14-Jul } & $0: 00$ & 0 & 0 \\
\hline & $1: 00$ & 0 & 0 \\
\hline & $2: 00$ & 0 & 0 \\
\hline & $3: 00$ & 0 & 0 \\
\hline & $4: 00$ & 0 & 0 \\
\hline & $5: 00$ & 0 & 0 \\
\hline & $6: 00$ & 10 & 11 \\
\hline & $7: 00$ & 40 & 34 \\
\hline & $8: 00$ & 80 & 61 \\
\hline & 9:00 & 175 & 80 \\
\hline & $10: 00$ & 230 & 194 \\
\hline & $11: 00$ & 315 & 284 \\
\hline & $12: 00$ & 360 & 381 \\
\hline & $13: 00$ & 340 & 395 \\
\hline & $14: 00$ & 300 & 394 \\
\hline & $15: 00$ & 240 & 338 \\
\hline & $16: 00$ & 200 & 232 \\
\hline & $17: 00$ & 175 & 106 \\
\hline & $18: 00$ & 190 & 66.7 \\
\hline & $19: 00$ & 75 & 41 \\
\hline & $20: 00$ & 30 & 16 \\
\hline & $21: 00$ & 0 & 0 \\
\hline & $22: 00$ & 0 & 0 \\
\hline & $23: 00$ & 0 & 0 \\
\hline \multirow[t]{24}{*}{ 15-Jul } & $0: 00$ & 0 & 0 \\
\hline & $1: 00$ & 0 & 0 \\
\hline & $2: 00$ & 0 & 0 \\
\hline & $3: 00$ & 0 & 0 \\
\hline & $4: 00$ & 0 & 0 \\
\hline & $5: 00$ & 0 & 0 \\
\hline & $6: 00$ & 15 & 7 \\
\hline & $7: 00$ & 40 & 41 \\
\hline & $8: 00$ & 100 & 87 \\
\hline & 9:00 & 160 & 138 \\
\hline & $10: 00$ & 235 & 167 \\
\hline & $11: 00$ & 400 & 183 \\
\hline & $12: 00$ & 500 & 267 \\
\hline & $13: 00$ & 400 & 321 \\
\hline & $14: 00$ & 300 & 327 \\
\hline & $15: 00$ & 350 & 223 \\
\hline & $16: 00$ & 180 & 155 \\
\hline & $17: 00$ & 140 & 138 \\
\hline & $18: 00$ & 100 & 98 \\
\hline & $19: 00$ & 85 & 54 \\
\hline & $20: 00$ & 30 & 17 \\
\hline & $21: 00$ & 0 & 0 \\
\hline & $22: 00$ & 0 & 0 \\
\hline & $23: 00$ & 0 & 0 \\
\hline \multirow[t]{13}{*}{ 16-Jul } & $0: 00$ & 0 & 0 \\
\hline & $1: 00$ & 0 & 0 \\
\hline & $2: 00$ & 0 & 0 \\
\hline & $3: 00$ & 0 & 0 \\
\hline & $4: 00$ & 0 & 0 \\
\hline & $5: 00$ & 0 & 0 \\
\hline & $6: 00$ & 5 & 8 \\
\hline & $7: 00$ & 30 & 37 \\
\hline & $8: 00$ & 100 & 85 \\
\hline & $9: 00$ & 190 & 110 \\
\hline & $10: 00$ & 280 & 177 \\
\hline & $11: 00$ & 400 & 232 \\
\hline & $12: 00$ & 430 & 244 \\
\hline
\end{tabular}




\begin{tabular}{|c|c|c|c|}
\hline & $13: 00$ & 380 & 345 \\
\hline & $14: 00$ & 330 & 384 \\
\hline & $15: 00$ & 280 & 338 \\
\hline & $16: 00$ & 185 & 240 \\
\hline & $17: 00$ & 160 & 132 \\
\hline & $18: 00$ & 110 & 88 \\
\hline & 19:00 & 65 & 51 \\
\hline & 20:00 & 25 & 16 \\
\hline & 21:00 & 0 & 0 \\
\hline & $22: 00$ & 0 & 0 \\
\hline & $23: 00$ & 0 & 0 \\
\hline \multirow[t]{24}{*}{ 17-Jul } & $0: 00$ & 0 & 0 \\
\hline & $1: 00$ & 0 & 0 \\
\hline & $2: 00$ & 0 & 0 \\
\hline & 3:00 & 0 & 0 \\
\hline & $4: 00$ & 0 & 0 \\
\hline & $5: 00$ & 0 & 0 \\
\hline & $6: 00$ & 15 & 10 \\
\hline & $7: 00$ & 60 & 43 \\
\hline & $8: 00$ & 100 & 101 \\
\hline & $9: 00$ & 200 & 119 \\
\hline & $10: 00$ & 300 & 215 \\
\hline & $11: 00$ & 415 & 320 \\
\hline & $12: 00$ & 420 & 400 \\
\hline & $13: 00$ & 455 & 421 \\
\hline & $14: 00$ & 360 & 401 \\
\hline & $15: 00$ & 125 & 320 \\
\hline & $16: 00$ & 200 & 241 \\
\hline & $17: 00$ & 160 & 148 \\
\hline & $18: 00$ & 115 & 104 \\
\hline & $19: 00$ & 75 & 58 \\
\hline & 20:00 & 20 & 18 \\
\hline & $21: 00$ & 0 & 0 \\
\hline & 22:00 & 0 & 0 \\
\hline & 23:00 & 0 & 0 \\
\hline
\end{tabular}

Table A. 4 Comparative interior temperature data for reference building and reference model

\begin{tabular}{|r|r|r|r|r|}
\hline Date & \multicolumn{1}{|l|}{ Time } & Reference Building $\left({ }^{\circ} \mathrm{C}\right)$ & \multicolumn{2}{r|}{ Reference Model $\left.{ }^{\circ} \mathrm{C}\right)$} \\
\hline & & 32 & 29.69 \\
\hline 11-Jul & $0: 00$ & 31.25 & 28.7 \\
\hline & $1: 00$ & 30 & 27.71 \\
\hline & $2: 00$ & 28.5 & 26.8 \\
\hline & $3: 00$ & 27.3 & 26 \\
\hline & $4: 00$ & 26.8 & 25.28 \\
\hline & $5: 00$ & 26.25 & 24.65 \\
\hline & $6: 00$ & 26.25 & 24.14 \\
\hline & $7: 00$ & 26 & 23.78 \\
\hline & $8: 00$ & 26.5 & 23.63 \\
\hline & $10: 00$ & 27.5 & 23.69 \\
\hline & $11: 00$ & 28.8 & 23.9 \\
\hline & $12: 00$ & 30 & 24.22 \\
\hline & $13: 00$ & 31.3 & 24.56 \\
\hline & $14: 00$ & 32.5 & 24.72 \\
\hline & $15: 00$ & 33.8 & 24.66 \\
\hline $16: 00$ & 35 & 24.47 \\
\hline & $17: 00$ & 36.3 & 24.37 \\
\hline & $18: 00$ & 37.5 & 24.23 \\
\hline & $19: 00$ & 37.75 & 23.94 \\
\hline & & 38 & 23.55 \\
\hline
\end{tabular}




\begin{tabular}{|c|c|c|c|}
\hline & $21: 00$ & 37 & 23.11 \\
\hline & $22: 00$ & 35.5 & 22.68 \\
\hline & 23:00 & 33.25 & 22.22 \\
\hline \multirow[t]{24}{*}{ 12-Jul } & $0: 00$ & 31.25 & 21.69 \\
\hline & 1:00 & 30.5 & 21.15 \\
\hline & $2: 00$ & 30 & 20.63 \\
\hline & $3: 00$ & 28.8 & 20.17 \\
\hline & $4: 00$ & 27.8 & 19.77 \\
\hline & $5: 00$ & 27.3 & 19.39 \\
\hline & $6: 00$ & 27 & 19.07 \\
\hline & 7:00 & 26.5 & 18.93 \\
\hline & $8: 00$ & 27 & 19.06 \\
\hline & $9: 00$ & 27.1 & 19.52 \\
\hline & $10: 00$ & 27.5 & 20.16 \\
\hline & $11: 00$ & 28.3 & 20.75 \\
\hline & $12: 00$ & 29.5 & 21.45 \\
\hline & $13: 00$ & 30.5 & 22.3 \\
\hline & $14: 00$ & 31.3 & 23.24 \\
\hline & $15: 00$ & 32.5 & 24.17 \\
\hline & $16: 00$ & 33 & 25.09 \\
\hline & $17: 00$ & 35 & 25.98 \\
\hline & $18: 00$ & 35.7 & 26.47 \\
\hline & $19: 00$ & 36.3 & 26.67 \\
\hline & $20: 00$ & 37 & 26.52 \\
\hline & $21: 00$ & 36 & 26.07 \\
\hline & $22: 00$ & 35 & 25.51 \\
\hline & $23: 00$ & 32.5 & 25.03 \\
\hline \multirow[t]{24}{*}{ 13-Jul } & 0:00 & 31.25 & 24.56 \\
\hline & $1: 00$ & 30.5 & 24.06 \\
\hline & $2: 00$ & 30 & 23.55 \\
\hline & $3: 00$ & 28.8 & 23.05 \\
\hline & $4: 00$ & 27.3 & 22.59 \\
\hline & $5: 00$ & 27 & 22.18 \\
\hline & $6: 00$ & 26.5 & 21.84 \\
\hline & 7:00 & 26.25 & 21.62 \\
\hline & $8: 00$ & 26 & 21.56 \\
\hline & $9: 00$ & 26.5 & 21.66 \\
\hline & $10: 00$ & 27.3 & 22.07 \\
\hline & $11: 00$ & 28.8 & 22.78 \\
\hline & $12: 00$ & 30 & 23.56 \\
\hline & $13: 00$ & 31.25 & 24.41 \\
\hline & $14: 00$ & 32.5 & 25.6 \\
\hline & $15: 00$ & 32.5 & 26.85 \\
\hline & $16: 00$ & 31 & 27.91 \\
\hline & $17: 00$ & 30.75 & 28.96 \\
\hline & $18: 00$ & 31.5 & 29.79 \\
\hline & $19: 00$ & 32.5 & 30.29 \\
\hline & $20: 00$ & 33.5 & 30.33 \\
\hline & $21: 00$ & 32 & 29.86 \\
\hline & $22: 00$ & 31 & 29.14 \\
\hline & $23: 00$ & 30 & 28.37 \\
\hline \multirow[t]{12}{*}{ 14-Jul } & $0: 00$ & 28.8 & 27.61 \\
\hline & $1: 00$ & 27.3 & 26.87 \\
\hline & $2: 00$ & 26 & 26.14 \\
\hline & $3: 00$ & 25.5 & 25.46 \\
\hline & $4: 00$ & 25 & 24.82 \\
\hline & 5:00 & 23.75 & 24.23 \\
\hline & $6: 00$ & 23 & 23.76 \\
\hline & 7:00 & 22.5 & 23.69 \\
\hline & $8: 00$ & 21.5 & 24.2 \\
\hline & 9:00 & 21.5 & 25.09 \\
\hline & $10: 00$ & 22.5 & 26.17 \\
\hline & $11: 00$ & 23.5 & 27.43 \\
\hline
\end{tabular}




\begin{tabular}{|c|c|c|c|}
\hline & $12: 00$ & 25.5 & 28.86 \\
\hline & $13: 00$ & 27.3 & 30.32 \\
\hline & $14: 00$ & 28.5 & 31.74 \\
\hline & $15: 00$ & 29.25 & 33.11 \\
\hline & $16: 00$ & 30.5 & 34.3 \\
\hline & $17: 00$ & 31.25 & 35.17 \\
\hline & $18: 00$ & 32.5 & 35.66 \\
\hline & $19: 00$ & 33.8 & 35.82 \\
\hline & $20: 00$ & 34.9 & 35.58 \\
\hline & 21:00 & 33.8 & 34.83 \\
\hline & $22: 00$ & 32.25 & 33.87 \\
\hline & $23: 00$ & 31 & 32.88 \\
\hline \multirow[t]{24}{*}{ 15-Jul } & $0: 00$ & 29 & 31.92 \\
\hline & $1: 00$ & 27.3 & 31.01 \\
\hline & $2: 00$ & 26.3 & 30.15 \\
\hline & $3: 00$ & 25.5 & 29.3 \\
\hline & $4: 00$ & 25 & 28.47 \\
\hline & $5: 00$ & 23.8 & 27.7 \\
\hline & $6: 00$ & 23 & 27 \\
\hline & 7:00 & 22 & 26.51 \\
\hline & $8: 00$ & 21.25 & 26.51 \\
\hline & 9:00 & 21.5 & 26.99 \\
\hline & $10: 00$ & 22.5 & 27.66 \\
\hline & $11: 00$ & 23.5 & 28.25 \\
\hline & $12: 00$ & 26.25 & 28.86 \\
\hline & $13: 00$ & 27.3 & 29.58 \\
\hline & $14: 00$ & 28.5 & 30.2 \\
\hline & $15: 00$ & 29.5 & 30.69 \\
\hline & $16: 00$ & 30.75 & 30.83 \\
\hline & $17: 00$ & 31.3 & 30.76 \\
\hline & $18: 00$ & 32 & 30.66 \\
\hline & $19: 00$ & 32.5 & 30.45 \\
\hline & $20: 00$ & 33 & 30.02 \\
\hline & 21:00 & 32.25 & 29.37 \\
\hline & $22: 00$ & 30.75 & 28.66 \\
\hline & 23:00 & 29 & 27.98 \\
\hline \multirow[t]{24}{*}{ 16-Jul } & 0:00 & 28 & 27.33 \\
\hline & $1: 00$ & 27 & 26.73 \\
\hline & $2: 00$ & 26 & 26.16 \\
\hline & $3: 00$ & 25 & 25.62 \\
\hline & $4: 00$ & 23.8 & 25.07 \\
\hline & $5: 00$ & 22.5 & 24.47 \\
\hline & $6: 00$ & 21.5 & 23.93 \\
\hline & $7: 00$ & 21 & 23.58 \\
\hline & $8: 00$ & 20.5 & 23.63 \\
\hline & $9: 00$ & 21 & 24.02 \\
\hline & $10: 00$ & 21.75 & 24.5 \\
\hline & $11: 00$ & 23.5 & 25.21 \\
\hline & $12: 00$ & 26 & 26.12 \\
\hline & $13: 00$ & 27.3 & 27.12 \\
\hline & $14: 00$ & 28.5 & 28.26 \\
\hline & $15: 00$ & 29.5 & 29.43 \\
\hline & $16: 00$ & 30 & 30.5 \\
\hline & $17: 00$ & 31.25 & 31.36 \\
\hline & $18: 00$ & 32.5 & 31.98 \\
\hline & 19:00 & 33 & 32.22 \\
\hline & 20:00 & 33.8 & 31.98 \\
\hline & 21:00 & 33.5 & 31.31 \\
\hline & $22: 00$ & 31.5 & 30.45 \\
\hline & 23:00 & 30.5 & 29.57 \\
\hline \multirow[t]{3}{*}{ 17-Jul } & 0:00 & 29.3 & 28.71 \\
\hline & $1: 00$ & 28 & 27.87 \\
\hline & $2: 00$ & 27 & 27.07 \\
\hline
\end{tabular}




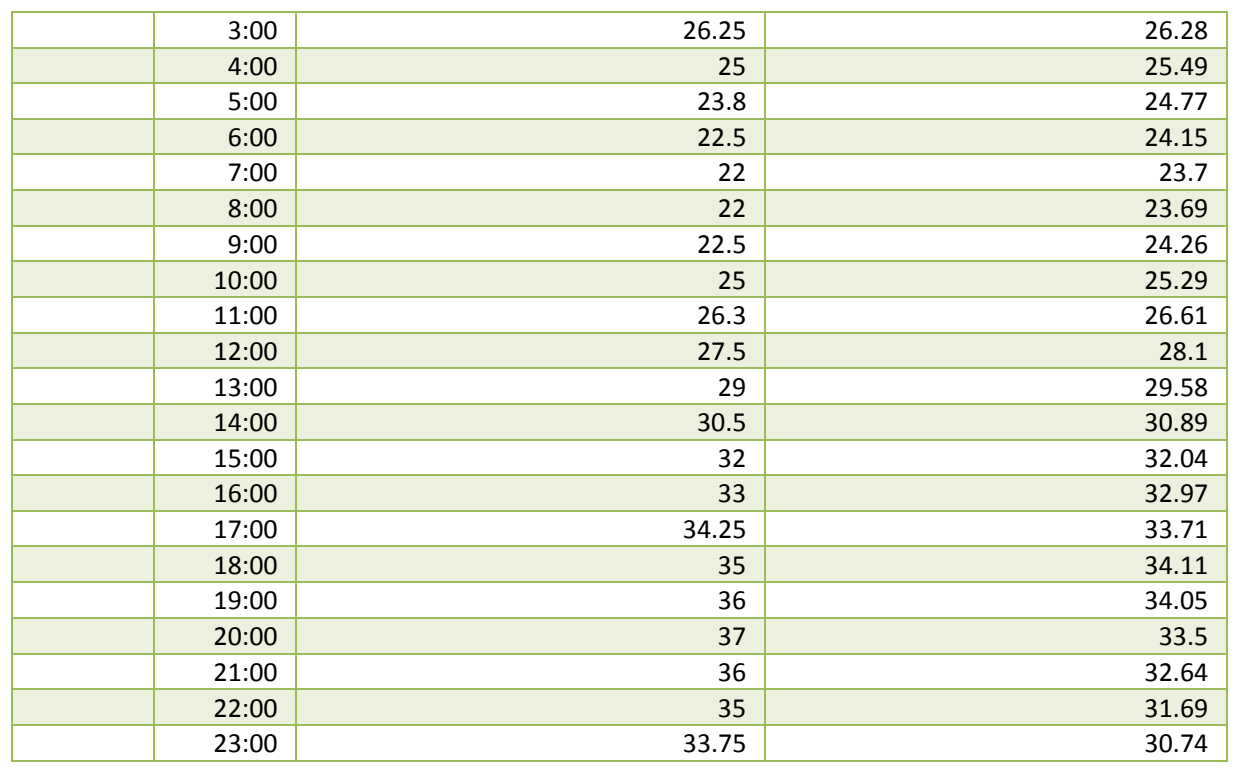

Table A. 5 Difference between reference building and reference model condition, post simulation.

\begin{tabular}{|c|c|c|c|c|}
\hline Date & Time & $\begin{array}{l}\text { Delta }\left({ }^{\circ} \mathrm{C}\right) \\
\text { Exterior temps }\end{array}$ & $\begin{array}{l}\text { Delta }\left({ }^{\circ} \mathrm{C}\right) \\
\text { interior Temps }\end{array}$ & $\begin{array}{l}\text { Delta (W) Solar } \\
\text { Radiation }\end{array}$ \\
\hline \multirow[t]{24}{*}{ 11-Jul } & $0: 00$ & -1.8 & 1.71 & 0 \\
\hline & $1: 00$ & -1.2 & 1.72 & 0 \\
\hline & $2: 00$ & -1.2 & 1.31 & 0 \\
\hline & $3: 00$ & -1.7 & 0.62 & 0 \\
\hline & $4: 00$ & -1.7 & 0.15 & 0 \\
\hline & 5:00 & -1.7 & 0.32 & 0 \\
\hline & $6: 00$ & 2.3 & 0.37 & 10 \\
\hline & 7:00 & 3.8 & 0.91 & 32 \\
\hline & $8: 00$ & 5.8 & 1.09 & 57 \\
\hline & 9:00 & 9.3 & 1.83 & 119 \\
\hline & $10: 00$ & 10.7 & 2.9 & 225 \\
\hline & $11: 00$ & 12.2 & 4.09 & 248 \\
\hline & $12: 00$ & 12.7 & 5.1 & 219 \\
\hline & $13: 00$ & 11.1 & 6.12 & 204 \\
\hline & $14: 00$ & 16.8 & 7.15 & 304 \\
\hline & $15: 00$ & 15.4 & 8.45 & 141 \\
\hline & $16: 00$ & 14.4 & 9.86 & 56 \\
\hline & $17: 00$ & 12.9 & 11.31 & 8 \\
\hline & $18: 00$ & 11.4 & 12.6 & 13 \\
\hline & $19: 00$ & 9.4 & 13.1 & 45 \\
\hline & 20:00 & 6.4 & 13.7 & 4.5 \\
\hline & $21: 00$ & 2.9 & 13.13 & 0 \\
\hline & $22: 00$ & 2.9 & 12.06 & 0 \\
\hline & 23:00 & 4.1 & 10.22 & 0 \\
\hline \multirow[t]{11}{*}{ 12-Jul } & 0:00 & 4.1 & 8.68 & 0 \\
\hline & $1: 00$ & 4.7 & 8.44 & 0 \\
\hline & $2: 00$ & 5.7 & 8.44 & 0 \\
\hline & $3: 00$ & 5.7 & 7.69 & 0 \\
\hline & $4: 00$ & 5.7 & 7.1 & 0 \\
\hline & 5:00 & 4.2 & 6.98 & 0 \\
\hline & $6: 00$ & 7.7 & 7.04 & 11 \\
\hline & $7: 00$ & 8.1 & 6.8 & 7 \\
\hline & $8: 00$ & 8.6 & 7.34 & 39 \\
\hline & 9:00 & 12 & 7.18 & 25 \\
\hline & $10: 00$ & 12.9 & 7.04 & 119 \\
\hline
\end{tabular}




\begin{tabular}{|c|c|c|c|c|}
\hline & $11: 00$ & 13.3 & 7.35 & 134 \\
\hline & $12: 00$ & 13.8 & 8.06 & 145 \\
\hline & $13: 00$ & 14.7 & 8.38 & 121 \\
\hline & $14: 00$ & 12.6 & 8.39 & 146 \\
\hline & $15: 00$ & 13.6 & 8.76 & 131 \\
\hline & $16: 00$ & 9.9 & 8.5 & 6 \\
\hline & $17: 00$ & 8.9 & 9.65 & 34 \\
\hline & $18: 00$ & 8.5 & 9.76 & 23 \\
\hline & $19: 00$ & 5 & 10.1 & 24 \\
\hline & $20: 00$ & 3.1 & 10.77 & 17 \\
\hline & $21: 00$ & 0.7 & 10.08 & 0 \\
\hline & $22: 00$ & 3.8 & 9.53 & 0 \\
\hline & $23: 00$ & 2.1 & 7.47 & 0 \\
\hline \multirow[t]{24}{*}{ 13-Jul } & $0: 00$ & 0.3 & 6.54 & 0 \\
\hline & $1: 00$ & 0.3 & 6.18 & 0 \\
\hline & $2: 00$ & 0.4 & 6.08 & 0 \\
\hline & $3: 00$ & 0.4 & 5.3 & 0 \\
\hline & $4: 00$ & -0.1 & 4.2 & 0 \\
\hline & $5: 00$ & -0.85 & 4.27 & 0 \\
\hline & $6: 00$ & 0.9 & 4.11 & 0 \\
\hline & $7: 00$ & 3.9 & 4.11 & 23 \\
\hline & $8: 00$ & 6.3 & 3.99 & 55 \\
\hline & 9:00 & 13.3 & 4.48 & 87 \\
\hline & $10: 00$ & 12.3 & 5.05 & 115 \\
\hline & $11: 00$ & 12.2 & 5.98 & 143 \\
\hline & $12: 00$ & 14.1 & 6.49 & 234 \\
\hline & $13: 00$ & 9 & 7.08 & 95 \\
\hline & $14: 00$ & 1.9 & 7.43 & -141 \\
\hline & $15: 00$ & -4.8 & 6.25 & -221 \\
\hline & $16: 00$ & -0.3 & 3.8 & -82 \\
\hline & $17: 00$ & -0.3 & 2.61 & 117 \\
\hline & $18: 00$ & -0.3 & 2.48 & 67 \\
\hline & 19:00 & -1.8 & 2.9 & 25 \\
\hline & 20:00 & -1.7 & 3.65 & 10 \\
\hline & 21:00 & -3 & 2.38 & 0 \\
\hline & $22: 00$ & -2.9 & 1.94 & 0 \\
\hline & $23: 00$ & -1.3 & 1.55 & 0 \\
\hline \multirow[t]{24}{*}{ 14-Jul } & 0:00 & -3.3 & 0.94 & 0 \\
\hline & $1: 00$ & -1.7 & 0.03 & 0 \\
\hline & $2: 00$ & -1.7 & -0.69 & 0 \\
\hline & $3: 00$ & -2.7 & -0.61 & 0 \\
\hline & $4: 00$ & -5.1 & -0.58 & 0 \\
\hline & 5:00 & -6.1 & -1.3 & 0 \\
\hline & $6: 00$ & -4.1 & -1.57 & -1 \\
\hline & $7: 00$ & -1.7 & -1.81 & 6 \\
\hline & $8: 00$ & -0.9 & -3.09 & 19 \\
\hline & $9: 00$ & -1.1 & -3.79 & 95 \\
\hline & $10: 00$ & 0.2 & -3.64 & 36 \\
\hline & $11: 00$ & 1.5 & -3.64 & 31 \\
\hline & $12: 00$ & 2.3 & -2.77 & -21 \\
\hline & $13: 00$ & 1.2 & -2.22 & -55 \\
\hline & $14: 00$ & 0.6 & -2.22 & -94 \\
\hline & $15: 00$ & 1.1 & -2.71 & -98 \\
\hline & $16: 00$ & -1.4 & -2.6 & -32 \\
\hline & $17: 00$ & -2.3 & -2.79 & 69 \\
\hline & $18: 00$ & -3.2 & -2.15 & 123.3 \\
\hline & $19: 00$ & -6.7 & -1.18 & 34 \\
\hline & 20:00 & -7.9 & -0.13 & 14 \\
\hline & 21:00 & -7.8 & -0.82 & 0 \\
\hline & 22:00 & -9.2 & -1.62 & 0 \\
\hline & 23:00 & -8.6 & -2.1 & 0 \\
\hline \multirow[t]{2}{*}{ 15-Jul } & $0: 00$ & -7.1 & -3.33 & 0 \\
\hline & $1: 00$ & -6.6 & -4.29 & 0 \\
\hline
\end{tabular}

A11 


\begin{tabular}{|c|c|c|c|c|}
\hline & $2: 00$ & -6 & -4.59 & 0 \\
\hline & $3: 00$ & -6.9 & -4.7 & 0 \\
\hline & $4: 00$ & -6.8 & -4.49 & 0 \\
\hline & $5: 00$ & -7.8 & -5 & 0 \\
\hline & $6: 00$ & -5.8 & -5.14 & 8 \\
\hline & $7: 00$ & -2.9 & -5.58 & -1 \\
\hline & $8: 00$ & 0.1 & -6.11 & 13 \\
\hline & $9: 00$ & -0.2 & -6.15 & 22 \\
\hline & $10: 00$ & 1.1 & -5.67 & 68 \\
\hline & $11: 00$ & 4.2 & -5.17 & 217 \\
\hline & $12: 00$ & 4.1 & -2.84 & 233 \\
\hline & $13: 00$ & -0.4 & -2.36 & 79 \\
\hline & $14: 00$ & 6.5 & -1.8 & -27 \\
\hline & $15: 00$ & 3.2 & -1.28 & 127 \\
\hline & $16: 00$ & 2.3 & -0.29 & 25 \\
\hline & $17: 00$ & 1.9 & 0.33 & 2 \\
\hline & $18: 00$ & 0.3 & 1.13 & 2 \\
\hline & $19: 00$ & -1.2 & 1.74 & 31 \\
\hline & 20:00 & -4.1 & 2.53 & 13 \\
\hline & $21: 00$ & -4.4 & 2.29 & 0 \\
\hline & $22: 00$ & -7.6 & 1.44 & 0 \\
\hline & 23:00 & -7.4 & 0.27 & 0 \\
\hline \multirow[t]{24}{*}{ 16-Jul } & 0:00 & -7.9 & -0.14 & 0 \\
\hline & $1: 00$ & -7.9 & -0.6 & 0 \\
\hline & $2: 00$ & -7.8 & -1.1 & 0 \\
\hline & $3: 00$ & -8.3 & -1.6 & 0 \\
\hline & $4: 00$ & -7.7 & -2.31 & 0 \\
\hline & $5: 00$ & -7.6 & -3.08 & 0 \\
\hline & $6: 00$ & -7.1 & -3.53 & -3 \\
\hline & 7:00 & -5.2 & -3.58 & -7 \\
\hline & $8: 00$ & -0.3 & -3.92 & 15 \\
\hline & 9:00 & 0.6 & -3.67 & 80 \\
\hline & $10: 00$ & 4 & -3.27 & 103 \\
\hline & $11: 00$ & 4.8 & -1.97 & 168 \\
\hline & $12: 00$ & 5.2 & -0.16 & 186 \\
\hline & $13: 00$ & 3.2 & 0.32 & 35 \\
\hline & $14: 00$ & 4.6 & 0.61 & -54 \\
\hline & $15: 00$ & 3.6 & 0.58 & -58 \\
\hline & $16: 00$ & 2.6 & 0.09 & -55 \\
\hline & $17: 00$ & 1 & 0.5 & 28 \\
\hline & $18: 00$ & -1.4 & 1.11 & 22 \\
\hline & 19:00 & -3.4 & 1.22 & 14 \\
\hline & 20:00 & -4.7 & 2.03 & 9 \\
\hline & 21:00 & -4.6 & 2.16 & 0 \\
\hline & $22: 00$ & -4.4 & 0.85 & 0 \\
\hline & 23:00 & -5.4 & 0.56 & 0 \\
\hline \multirow[t]{17}{*}{ 17-Jul } & 0:00 & -4.8 & 0.06 & 0 \\
\hline & $1: 00$ & -6.05 & -0.56 & 0 \\
\hline & $2: 00$ & -5.45 & -0.89 & 0 \\
\hline & $3: 00$ & -4.95 & -0.98 & 0 \\
\hline & 4:00 & -3.85 & -1.56 & 0 \\
\hline & 5:00 & -4.95 & -2.07 & 0 \\
\hline & $6: 00$ & -2.1 & -2.78 & 5 \\
\hline & 7:00 & 0.4 & -2.77 & 17 \\
\hline & $8: 00$ & 1.2 & -2.53 & -1 \\
\hline & $9: 00$ & 3 & -2.31 & 81 \\
\hline & $10: 00$ & 6.3 & -0.56 & 85 \\
\hline & $11: 00$ & 4.6 & -0.31 & 95 \\
\hline & $12: 00$ & 2.4 & -0.3 & 20 \\
\hline & $13: 00$ & 3.9 & -0.1 & 34 \\
\hline & $14: 00$ & 5.3 & 0.27 & -41 \\
\hline & $15: 00$ & 4.8 & 0.74 & -195 \\
\hline & $16: 00$ & 3.8 & 0.87 & -41 \\
\hline
\end{tabular}

A12 


\begin{tabular}{|r|r|r|r|r|}
\hline & $17: 00$ & 1.2 & 1.4 & 12 \\
\hline & $18: 00$ & -0.1 & 1.6 & 11 \\
\hline & $19: 00$ & -1.4 & 2.44 & 17 \\
\hline & $20: 00$ & -1.7 & 3.69 & 2 \\
\hline & $21: 00$ & -2.1 & 3.32 & 0 \\
\hline & $22: 00$ & -2.5 & 3.07 & 0 \\
\hline & $23: 00$ & -2.9 & 2.58 & 0 \\
\hline
\end{tabular}

Table A. 6 Cooling effect observed between reference building and vegetated building

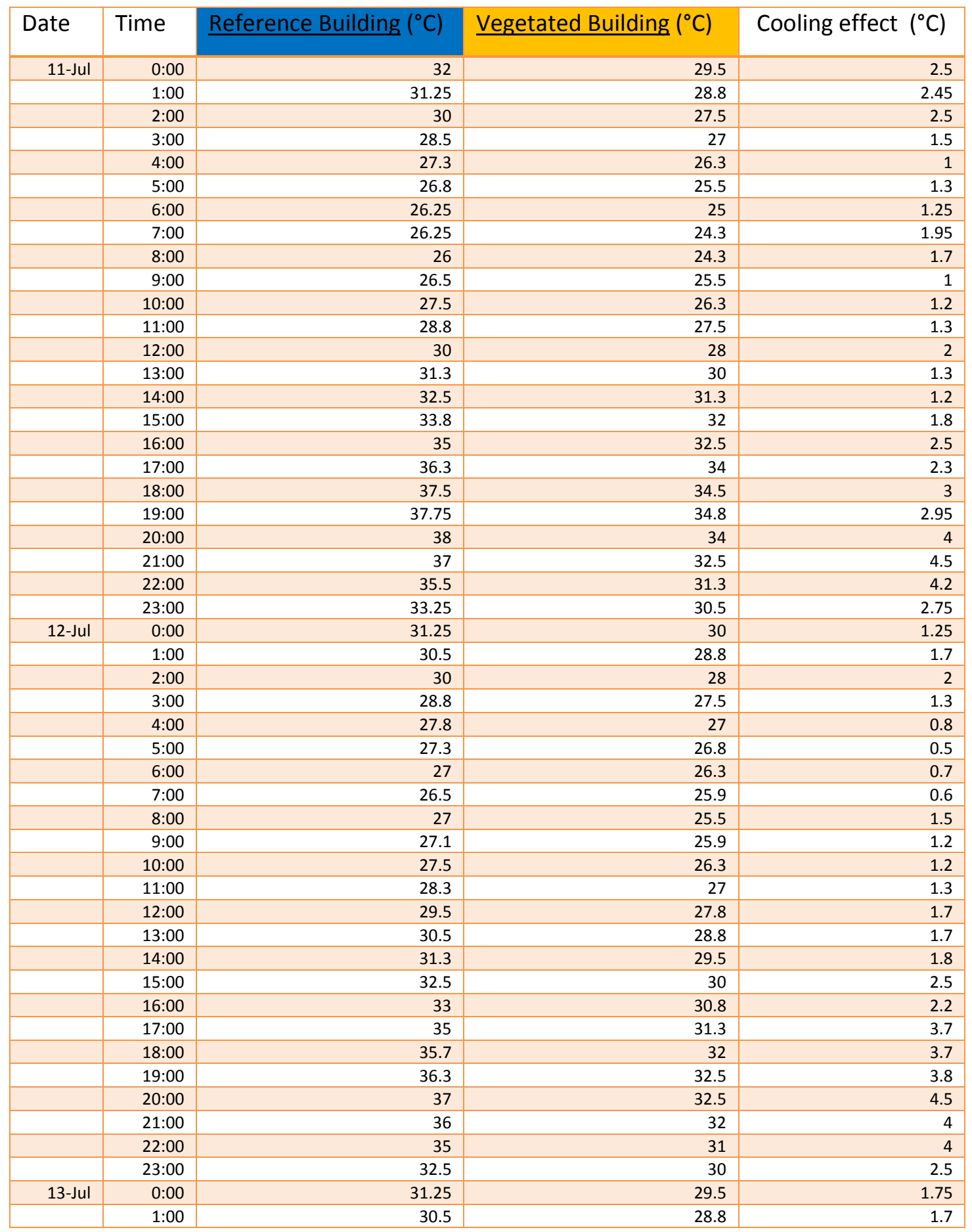

A13 


\begin{tabular}{|c|c|c|c|c|}
\hline & $2: 00$ & 30 & 27.5 & 2.5 \\
\hline & $3: 00$ & 28.8 & 26.3 & 2.5 \\
\hline & $4: 00$ & 27.3 & 26 & 1.3 \\
\hline & $5: 00$ & 27 & 25.8 & 1.2 \\
\hline & $6: 00$ & 26.5 & 25.5 & 1 \\
\hline & $7: 00$ & 26.25 & 25.25 & 1 \\
\hline & 8:00 & 26 & 25 & 1 \\
\hline & $9: 00$ & 26.5 & 25 & 1.5 \\
\hline & $10: 00$ & 27.3 & 26 & 1.3 \\
\hline & $11: 00$ & 28.8 & 27.5 & 1.3 \\
\hline & $12: 00$ & 30 & 28 & 2 \\
\hline & $13: 00$ & 31.25 & 28.8 & 2.45 \\
\hline & $14: 00$ & 32.5 & 29.8 & 2.7 \\
\hline & $15: 00$ & 32.5 & 29.9 & 2.6 \\
\hline & $16: 00$ & 31 & 28.8 & 2.2 \\
\hline & $17: 00$ & 30.75 & 28.5 & 2.25 \\
\hline & $18: 00$ & 31.5 & 28.8 & 2.7 \\
\hline & $19: 00$ & 32.5 & 29.5 & 3 \\
\hline & $20: 00$ & 33.5 & 30 & 3.5 \\
\hline & 21:00 & 32 & 29.5 & 2.5 \\
\hline & $22: 00$ & 31 & 28.8 & 2.2 \\
\hline & $23: 00$ & 30 & 27.5 & 2.5 \\
\hline \multirow[t]{24}{*}{ 14-Jul } & $0: 00$ & 28.8 & 27 & 1.8 \\
\hline & $1: 00$ & 27.3 & 26.8 & 0.5 \\
\hline & $2: 00$ & 26 & 26 & 0 \\
\hline & $3: 00$ & 25.5 & 25 & 0.5 \\
\hline & $4: 00$ & 25 & 23.5 & 1.5 \\
\hline & $5: 00$ & 23.75 & 22.5 & 1.25 \\
\hline & $6: 00$ & 23 & 22 & 1 \\
\hline & $7: 00$ & 22.5 & 21.8 & 0.7 \\
\hline & $8: 00$ & 21.5 & 21.3 & 0.2 \\
\hline & $9: 00$ & 21.5 & 21 & 0.5 \\
\hline & $10: 00$ & 22.5 & 21.3 & 1.2 \\
\hline & $11: 00$ & 23.5 & 22 & 1.5 \\
\hline & $12: 00$ & 25.5 & 22.5 & 3 \\
\hline & $13: 00$ & 27.3 & 23 & 4.3 \\
\hline & $14: 00$ & 28.5 & 25 & 3.5 \\
\hline & $15: 00$ & 29.25 & 26 & 3.25 \\
\hline & $16: 00$ & 30.5 & 27 & 3.5 \\
\hline & $17: 00$ & 31.25 & 27.5 & 3.75 \\
\hline & $18: 00$ & 32.5 & 28 & 4.5 \\
\hline & 19:00 & 33.8 & 29 & 4.8 \\
\hline & $20: 00$ & 34.9 & 29.7 & 5.2 \\
\hline & 21:00 & 33.8 & 28.8 & 5 \\
\hline & $22: 00$ & 32.25 & 27.5 & 4.75 \\
\hline & $23: 00$ & 31 & 26.5 & 4.5 \\
\hline \multirow[t]{17}{*}{ 15-Jul } & $0: 00$ & 29 & 25.8 & 3.2 \\
\hline & $1: 00$ & 27.3 & 25.2 & 2.1 \\
\hline & $2: 00$ & 26.3 & 25 & 1.3 \\
\hline & $3: 00$ & 25.5 & 24.5 & 1 \\
\hline & 4:00 & 25 & 24 & 1 \\
\hline & $5: 00$ & 23.8 & 22.8 & 1 \\
\hline & $6: 00$ & 23 & 22 & 1 \\
\hline & $7: 00$ & 22 & 21.3 & 0.7 \\
\hline & $8: 00$ & 21.25 & 20.9 & 0.35 \\
\hline & $9: 00$ & 21.5 & 20.5 & 1 \\
\hline & $10: 00$ & 22.5 & 21.8 & 0.7 \\
\hline & 11:00 & 23.5 & 22.5 & 1 \\
\hline & $12: 00$ & 26.25 & 24 & 2.25 \\
\hline & $13: 00$ & 27.3 & 25 & 2.3 \\
\hline & $14: 00$ & 28.5 & 26 & 2.5 \\
\hline & $15: 00$ & 29.5 & 27 & 2.5 \\
\hline & $16: 00$ & 30.75 & 27.5 & 3.25 \\
\hline
\end{tabular}

A14 


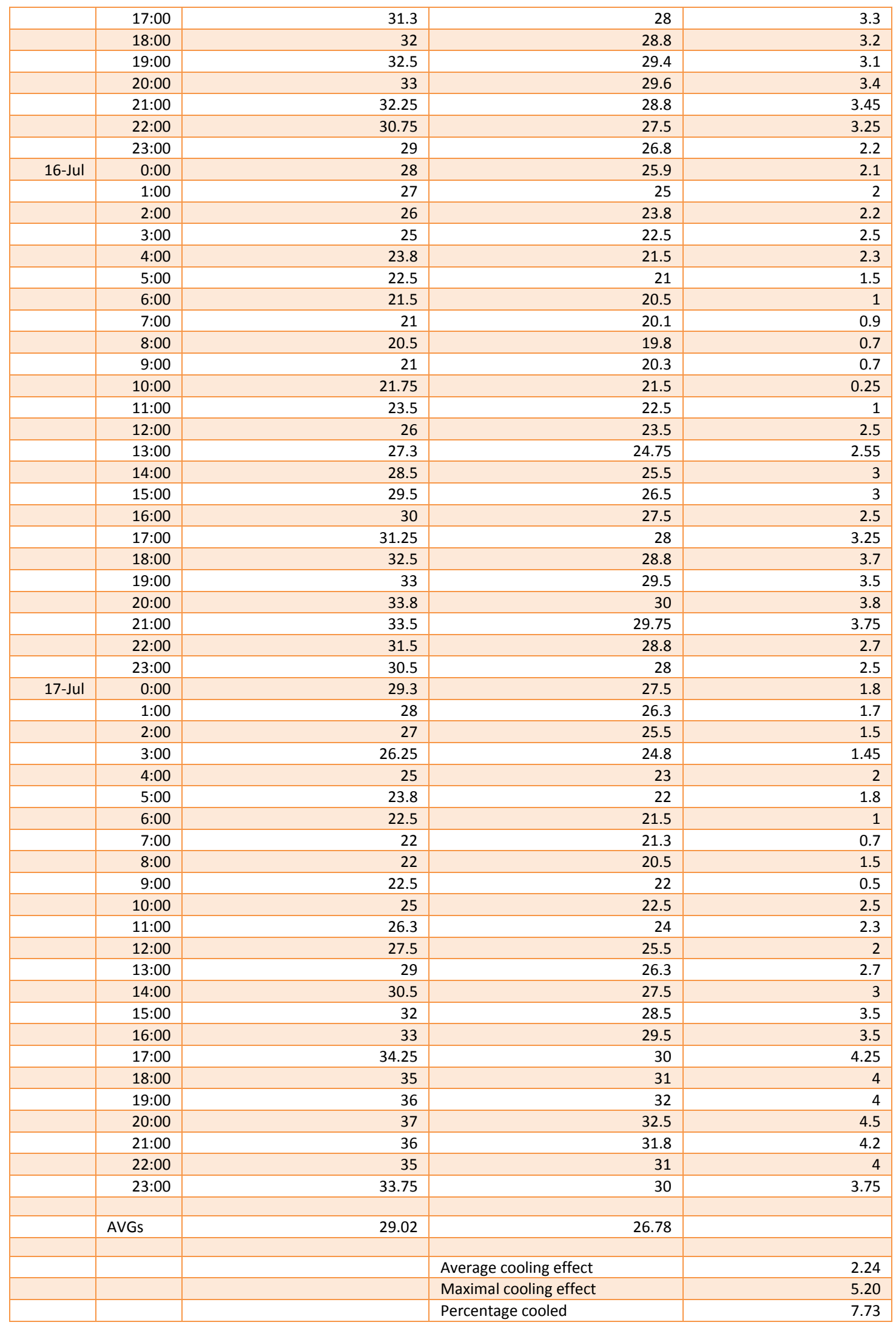

A15 
Table A. 7 Cooling effect observed between reference model and vegetated models

\begin{tabular}{|c|c|c|c|c|c|c|}
\hline Date & Time & $\frac{\text { Reference }}{\text { Model }\left({ }^{\circ} \mathrm{C}\right)}$ & $\frac{\text { Enclosed }}{\text { Vegetated }}$ & cooling at 5k & $\frac{\frac{\text { Vented }}{\text { Vegetated }}}{\text { Model }\left({ }^{\circ} \mathrm{C}\right)}$ & cooling at $900 \mathrm{~K}$ \\
\hline \multirow[t]{24}{*}{$\begin{array}{l}\text { Sun, } \\
11 / J u l\end{array}$} & $0: 30$ & 29.69 & 27.58 & 2.11 & 27.33 & 2.36 \\
\hline & $1: 30$ & 28.7 & 26.8 & 1.9 & 26.45 & 2.25 \\
\hline & $2: 30$ & 27.71 & 26.05 & 1.66 & 25.59 & 2.12 \\
\hline & $3: 30$ & 26.8 & 25.39 & 1.41 & 24.85 & 1.95 \\
\hline & $4: 30$ & 26 & 24.81 & 1.19 & 24.23 & 1.77 \\
\hline & $5: 30$ & 25.28 & 24.29 & 0.99 & 23.7 & 1.58 \\
\hline & $6: 30$ & 24.65 & 23.84 & 0.81 & 23.26 & 1.39 \\
\hline & $7: 30$ & 24.14 & 23.51 & 0.63 & 22.94 & 1.2 \\
\hline & $8: 30$ & 23.78 & 23.36 & 0.42 & 22.8 & 0.98 \\
\hline & $9: 30$ & 23.63 & 23.32 & 0.31 & 22.79 & 0.84 \\
\hline & $10: 30$ & 23.69 & 23.41 & 0.28 & 22.91 & 0.78 \\
\hline & $11: 30$ & 23.9 & 23.55 & 0.35 & 23.12 & 0.78 \\
\hline & $12: 30$ & 24.22 & 23.77 & 0.45 & 23.39 & 0.83 \\
\hline & $13: 30$ & 24.56 & 23.93 & 0.63 & 23.64 & 0.92 \\
\hline & $14: 30$ & 24.72 & 23.84 & 0.88 & 23.73 & 0.99 \\
\hline & $15: 30$ & 24.66 & 23.58 & 1.08 & 23.61 & 1.05 \\
\hline & $16: 30$ & 24.47 & 23.36 & 1.11 & 23.45 & 1.02 \\
\hline & $17: 30$ & 24.37 & 23.22 & 1.15 & 23.34 & 1.03 \\
\hline & $18: 30$ & 24.23 & 23.04 & 1.19 & 23.15 & 1.08 \\
\hline & $19: 30$ & 23.94 & 22.78 & 1.16 & 22.86 & 1.08 \\
\hline & $20: 30$ & 23.55 & 22.47 & 1.08 & 22.51 & 1.04 \\
\hline & $21: 30$ & 23.11 & 22.16 & 0.95 & 22.13 & 0.98 \\
\hline & $22: 30$ & 22.68 & 21.86 & 0.82 & 21.78 & 0.9 \\
\hline & $23: 30$ & 22.22 & 21.46 & 0.76 & 21.33 & 0.89 \\
\hline \multirow[t]{24}{*}{$\begin{array}{l}\text { Mon, } \\
12 / J u l\end{array}$} & $0: 30$ & 21.69 & 20.99 & 0.7 & 20.82 & 0.87 \\
\hline & $1: 30$ & 21.15 & 20.51 & 0.64 & 20.3 & 0.85 \\
\hline & $2: 30$ & 20.63 & 20.09 & 0.54 & 19.84 & 0.79 \\
\hline & $3: 30$ & 20.17 & 19.73 & 0.44 & 19.46 & 0.71 \\
\hline & $4: 30$ & 19.77 & 19.41 & 0.36 & 19.13 & 0.64 \\
\hline & $5: 30$ & 19.39 & 19.09 & 0.3 & 18.8 & 0.59 \\
\hline & $6: 30$ & 19.07 & 18.87 & 0.2 & 18.58 & 0.49 \\
\hline & $7: 30$ & 18.93 & 18.9 & 0.03 & 18.62 & 0.31 \\
\hline & $8: 30$ & 19.06 & 19.03 & 0.03 & 18.77 & 0.29 \\
\hline & $9: 30$ & 19.52 & 19.24 & 0.28 & 19.06 & 0.46 \\
\hline & $10: 30$ & 20.16 & 19.57 & 0.59 & 19.46 & 0.7 \\
\hline & $11: 30$ & 20.75 & 19.89 & 0.86 & 19.85 & 0.9 \\
\hline & $12: 30$ & 21.45 & 20.34 & 1.11 & 20.37 & 1.08 \\
\hline & $13: 30$ & 22.3 & 20.91 & 1.39 & 20.98 & 1.32 \\
\hline & $14: 30$ & 23.24 & 21.52 & 1.72 & 21.65 & 1.59 \\
\hline & $15: 30$ & 24.17 & 22.11 & 2.06 & 22.27 & 1.9 \\
\hline & $16: 30$ & 25.09 & 22.77 & 2.32 & 22.89 & 2.2 \\
\hline & $17: 30$ & 25.98 & 23.3 & 2.68 & 23.41 & 2.57 \\
\hline & $18: 30$ & 26.47 & 23.56 & 2.91 & 23.63 & 2.84 \\
\hline & $19: 30$ & 26.67 & 23.71 & 2.96 & 23.64 & 3.03 \\
\hline & $20: 30$ & 26.52 & 23.66 & 2.86 & 23.39 & 3.13 \\
\hline & $21: 30$ & 26.07 & 23.49 & 2.58 & 22.96 & 3.11 \\
\hline & $22: 30$ & 25.51 & 23.29 & 2.22 & 22.79 & 2.72 \\
\hline & $23: 30$ & 25.03 & 23.17 & 1.86 & 22.92 & 2.11 \\
\hline \multirow[t]{5}{*}{$\begin{array}{l}\text { Tue, } \\
13 / J u l\end{array}$} & $0: 30$ & 24.56 & 22.92 & 1.64 & 22.74 & 1.82 \\
\hline & $1: 30$ & 24.06 & 22.62 & 1.44 & 22.48 & 1.58 \\
\hline & $2: 30$ & 23.55 & 22.3 & 1.25 & 22.17 & 1.38 \\
\hline & $3: 30$ & 23.05 & 21.96 & 1.09 & 21.82 & 1.23 \\
\hline & $4: 30$ & 22.59 & 21.67 & 0.92 & 21.51 & 1.08 \\
\hline
\end{tabular}




\begin{tabular}{|c|c|c|c|c|c|c|}
\hline & $5: 30$ & 22.18 & 21.39 & 0.79 & 21.24 & 0.94 \\
\hline & $6: 30$ & 21.84 & 21.22 & 0.62 & 21.09 & 0.75 \\
\hline & $7: 30$ & 21.62 & 21.17 & 0.45 & 21.05 & 0.57 \\
\hline & $8: 30$ & 21.56 & 21.26 & 0.3 & 21.14 & 0.42 \\
\hline & $9: 30$ & 21.66 & 21.41 & 0.25 & 21.33 & 0.33 \\
\hline & $10: 30$ & 22.07 & 21.74 & 0.33 & 21.74 & 0.33 \\
\hline & $11: 30$ & 22.78 & 22.25 & 0.53 & 22.3 & 0.48 \\
\hline & $12: 30$ & 23.56 & 22.78 & 0.78 & 22.89 & 0.67 \\
\hline & $13: 30$ & 24.41 & 23.44 & 0.97 & 23.58 & 0.83 \\
\hline & $14: 30$ & 25.6 & 24.25 & 1.35 & 24.46 & 1.14 \\
\hline & $15: 30$ & 26.85 & 25.06 & 1.79 & 25.32 & 1.53 \\
\hline & $16: 30$ & 27.91 & 25.78 & 2.13 & 26.08 & 1.83 \\
\hline & $17: 30$ & 28.96 & 26.36 & 2.6 & 26.72 & 2.24 \\
\hline & $18: 30$ & 29.79 & 26.79 & 3 & 27.15 & 2.64 \\
\hline & $19: 30$ & 30.29 & 27.12 & 3.17 & 27.38 & 2.91 \\
\hline & $20: 30$ & 30.33 & 27.21 & 3.12 & 27.29 & 3.04 \\
\hline & $21: 30$ & 29.86 & 26.96 & 2.9 & 26.85 & 3.01 \\
\hline & $22: 30$ & 29.14 & 26.56 & 2.58 & 26.4 & 2.74 \\
\hline & $23: 30$ & 28.37 & 26.09 & 2.28 & 25.96 & 2.41 \\
\hline \multirow[t]{24}{*}{$\begin{array}{l}\text { Wed, } \\
14 / J u l\end{array}$} & $0: 30$ & 27.61 & 25.62 & 1.99 & 25.44 & 2.17 \\
\hline & $1: 30$ & 26.87 & 25.12 & 1.75 & 24.88 & 1.99 \\
\hline & $2: 30$ & 26.14 & 24.62 & 1.52 & 24.31 & 1.83 \\
\hline & $3: 30$ & 25.46 & 24.16 & 1.3 & 23.8 & 1.66 \\
\hline & $4: 30$ & 24.82 & 23.7 & 1.12 & 23.3 & 1.52 \\
\hline & $5: 30$ & 24.23 & 23.28 & 0.95 & 22.85 & 1.38 \\
\hline & $6: 30$ & 23.76 & 23.07 & 0.69 & 22.6 & 1.16 \\
\hline & $7: 30$ & 23.69 & 23.41 & 0.28 & 22.84 & 0.85 \\
\hline & $8: 30$ & 24.2 & 23.89 & 0.31 & 23.47 & 0.73 \\
\hline & 9:30 & 25.09 & 24.3 & 0.79 & 24.14 & 0.95 \\
\hline & $10: 30$ & 26.17 & 24.95 & 1.22 & 24.92 & 1.25 \\
\hline & $11: 30$ & 27.43 & 25.81 & 1.62 & 25.87 & 1.56 \\
\hline & $12: 30$ & 28.86 & 26.8 & 2.06 & 26.93 & 1.93 \\
\hline & $13: 30$ & 30.32 & 27.82 & 2.5 & 28.03 & 2.29 \\
\hline & $14: 30$ & 31.74 & 28.83 & 2.91 & 29.14 & 2.6 \\
\hline & $15: 30$ & 33.11 & 29.7 & 3.41 & 30.14 & 2.97 \\
\hline & $16: 30$ & 34.3 & 30.44 & 3.86 & 30.94 & 3.36 \\
\hline & $17: 30$ & 35.17 & 30.94 & 4.23 & 31.47 & 3.7 \\
\hline & $18: 30$ & 35.66 & 31.21 & 4.45 & 31.71 & 3.95 \\
\hline & $19: 30$ & 35.82 & 31.33 & 4.49 & 31.72 & 4.1 \\
\hline & $20: 30$ & 35.58 & 31.16 & 4.42 & 31.38 & 4.2 \\
\hline & $21: 30$ & 34.83 & 30.8 & 4.03 & 30.7 & 4.13 \\
\hline & $22: 30$ & 33.87 & 30.39 & 3.48 & 30.13 & 3.74 \\
\hline & $23: 30$ & 32.88 & 29.85 & 3.03 & 29.61 & 3.27 \\
\hline \multirow[t]{18}{*}{$\begin{array}{l}\text { Thu, } \\
\text { 15/Jul }\end{array}$} & $0: 30$ & 31.92 & 29.28 & 2.64 & 28.99 & 2.93 \\
\hline & $1: 30$ & 31.01 & 28.75 & 2.26 & 28.4 & 2.61 \\
\hline & $2: 30$ & 30.15 & 28.19 & 1.96 & 27.79 & 2.36 \\
\hline & $3: 30$ & 29.3 & 27.59 & 1.71 & 27.11 & 2.19 \\
\hline & $4: 30$ & 28.47 & 26.98 & 1.49 & 26.43 & 2.04 \\
\hline & $5: 30$ & 27.7 & 26.41 & 1.29 & 25.83 & 1.87 \\
\hline & $6: 30$ & 27 & 25.93 & 1.07 & 25.31 & 1.69 \\
\hline & $7: 30$ & 26.51 & 25.79 & 0.72 & 25.14 & 1.37 \\
\hline & $8: 30$ & 26.51 & 25.9 & 0.61 & 25.26 & 1.25 \\
\hline & 9:30 & 26.99 & 26.12 & 0.87 & 25.57 & 1.42 \\
\hline & $10: 30$ & 27.66 & 26.53 & 1.13 & 26.05 & 1.61 \\
\hline & $11: 30$ & 28.25 & 26.88 & 1.37 & 26.5 & 1.75 \\
\hline & $12: 30$ & 28.86 & 27.28 & 1.58 & 27 & 1.86 \\
\hline & $13: 30$ & 29.58 & 27.69 & 1.89 & 27.54 & 2.04 \\
\hline & $14: 30$ & 30.2 & 27.86 & 2.34 & 27.92 & 2.28 \\
\hline & $15: 30$ & 30.69 & 28.09 & 2.6 & 28.17 & 2.52 \\
\hline & $16: 30$ & 30.83 & 28.15 & 2.68 & 28.2 & 2.63 \\
\hline & $17: 30$ & 30.76 & 28.09 & 2.67 & 28.11 & 2.65 \\
\hline
\end{tabular}




\begin{tabular}{|c|c|c|c|c|c|c|}
\hline & $18: 30$ & 30.66 & 28.04 & 2.62 & 27.97 & 2.69 \\
\hline & $19: 30$ & 30.45 & 27.92 & 2.53 & 27.74 & 2.71 \\
\hline & $20: 30$ & 30.02 & 27.65 & 2.37 & 27.36 & 2.66 \\
\hline & $21: 30$ & 29.37 & 27.21 & 2.16 & 26.81 & 2.56 \\
\hline & $22: 30$ & 28.66 & 26.82 & 1.84 & 26.42 & 2.24 \\
\hline & $23: 30$ & 27.98 & 26.38 & 1.6 & 26.03 & 1.95 \\
\hline \multirow[t]{24}{*}{ Fri, 16/Jul } & $0: 30$ & 27.33 & 25.95 & 1.38 & 25.61 & 1.72 \\
\hline & $1: 30$ & 26.73 & 25.57 & 1.16 & 25.22 & 1.51 \\
\hline & $2: 30$ & 26.16 & 25.16 & 1 & 24.78 & 1.38 \\
\hline & $3: 30$ & 25.62 & 24.76 & 0.86 & 24.35 & 1.27 \\
\hline & $4: 30$ & 25.07 & 24.28 & 0.79 & 23.84 & 1.23 \\
\hline & $5: 30$ & 24.47 & 23.76 & 0.71 & 23.3 & 1.17 \\
\hline & $6: 30$ & 23.93 & 23.35 & 0.58 & 22.86 & 1.07 \\
\hline & $7: 30$ & 23.58 & 23.24 & 0.34 & 22.73 & 0.85 \\
\hline & $8: 30$ & 23.63 & 23.3 & 0.33 & 22.79 & 0.84 \\
\hline & 9:30 & 24.02 & 23.36 & 0.66 & 22.91 & 1.11 \\
\hline & $10: 30$ & 24.5 & 23.61 & 0.89 & 23.19 & 1.31 \\
\hline & $11: 30$ & 25.21 & 24.12 & 1.09 & 23.69 & 1.52 \\
\hline & $12: 30$ & 26.12 & 24.77 & 1.35 & 24.33 & 1.79 \\
\hline & $13: 30$ & 27.12 & 25.47 & 1.65 & 25.05 & 2.07 \\
\hline & $14: 30$ & 28.26 & 26.21 & 2.05 & 25.83 & 2.43 \\
\hline & $15: 30$ & 29.43 & 26.92 & 2.51 & 26.6 & 2.83 \\
\hline & $16: 30$ & 30.5 & 27.51 & 2.99 & 27.26 & 3.24 \\
\hline & $17: 30$ & 31.36 & 27.98 & 3.38 & 27.77 & 3.59 \\
\hline & $18: 30$ & 31.98 & 28.29 & 3.69 & 28.07 & 3.91 \\
\hline & $19: 30$ & 32.22 & 28.41 & 3.81 & 28.1 & 4.12 \\
\hline & $20: 30$ & 31.98 & 28.22 & 3.76 & 27.8 & 4.18 \\
\hline & $21: 30$ & 31.31 & 27.88 & 3.43 & 27.21 & 4.1 \\
\hline & $22: 30$ & 30.45 & 27.48 & 2.97 & 26.77 & 3.68 \\
\hline & $23: 30$ & 29.57 & 26.97 & 2.6 & 26.4 & 3.17 \\
\hline \multirow[t]{29}{*}{$\begin{array}{l}\text { Sat, } \\
17 / J u l\end{array}$} & $0: 30$ & 28.71 & 26.44 & 2.27 & 25.9 & 2.81 \\
\hline & $1: 30$ & 27.87 & 25.9 & 1.97 & 25.35 & 2.52 \\
\hline & $2: 30$ & 27.07 & 25.35 & 1.72 & 24.79 & 2.28 \\
\hline & $3: 30$ & 26.28 & 24.78 & 1.5 & 24.19 & 2.09 \\
\hline & $4: 30$ & 25.49 & 24.16 & 1.33 & 23.56 & 1.93 \\
\hline & $5: 30$ & 24.77 & 23.66 & 1.11 & 23.07 & 1.7 \\
\hline & $6: 30$ & 24.15 & 23.25 & 0.9 & 22.63 & 1.52 \\
\hline & $7: 30$ & 23.7 & 23.08 & 0.62 & 22.44 & 1.26 \\
\hline & $8: 30$ & 23.69 & 23.28 & 0.41 & 22.69 & 1 \\
\hline & $9: 30$ & 24.26 & 23.68 & 0.58 & 23.26 & 1 \\
\hline & $10: 30$ & 25.29 & 24.29 & 1 & 24.07 & 1.22 \\
\hline & $11: 30$ & 26.61 & 25.07 & 1.54 & 25.04 & 1.57 \\
\hline & $12: 30$ & 28.1 & 25.95 & 2.15 & 26.13 & 1.97 \\
\hline & $13: 30$ & 29.58 & 26.85 & 2.73 & 27.22 & 2.36 \\
\hline & $14: 30$ & 30.89 & 27.74 & 3.15 & 28.22 & 2.67 \\
\hline & $15: 30$ & 32.04 & 28.49 & 3.55 & 29.07 & 2.97 \\
\hline & $16: 30$ & 32.97 & 29.07 & 3.9 & 29.72 & 3.25 \\
\hline & $17: 30$ & 33.71 & 29.5 & 4.21 & 30.19 & 3.52 \\
\hline & $18: 30$ & 34.11 & 29.77 & 4.34 & 30.35 & 3.76 \\
\hline & $19: 30$ & 34.05 & 29.86 & 4.19 & 30.16 & 3.89 \\
\hline & $20: 30$ & 33.5 & 29.49 & 4.01 & 29.63 & 3.87 \\
\hline & $21: 30$ & 32.64 & 29.06 & 3.58 & 28.91 & 3.73 \\
\hline & $22: 30$ & 31.69 & 28.6 & 3.09 & 28.31 & 3.38 \\
\hline & $23: 30$ & 30.74 & 28.05 & 2.69 & 27.76 & 2.98 \\
\hline & & 26.78 & 25.04 & & 24.86 & \\
\hline & & & & & & \\
\hline & & & & 1.74 & & 1.93 \\
\hline & & & & 4.49 & & 4.20 \\
\hline & & Percentage cooled & & 6.49 & & 7.19 \\
\hline
\end{tabular}

Table A. 8 Reduction in cooling load observed between reference model and vegetated models 


\begin{tabular}{|c|c|c|c|c|}
\hline Date & Time & $\frac{\text { reference model }}{\text { cooling load }(\mathrm{kW})}$ & $\frac{\text { Vented vegetated }}{\frac{\text { model cooling load }}{(\mathrm{kW})}}$ & $\frac{\text { Enclosed vegetated }}{\frac{\text { model cooling load }}{(\mathrm{kW})}}$ \\
\hline \multirow[t]{25}{*}{ Sun, $11 / J u l$} & $0: 30$ & 0.023 & 0.019 & 0.02 \\
\hline & $1: 30$ & 0.002 & 0.001 & 0.001 \\
\hline & $2: 30$ & 0 & 0 & 0 \\
\hline & $3: 30$ & 0 & 0 & 0 \\
\hline & $4: 30$ & 0 & 0 & 0 \\
\hline & $5: 30$ & 0 & 0 & 0 \\
\hline & $6: 30$ & 0 & 0 & 0 \\
\hline & $7: 30$ & 0 & 0 & 0 \\
\hline & $8: 30$ & 0 & 0 & 0 \\
\hline & $9: 30$ & 0 & 0 & 0 \\
\hline & $10: 30$ & 0 & 0 & 0 \\
\hline & $11: 30$ & 0 & 0 & 0 \\
\hline & $12: 30$ & 0 & 0 & 0 \\
\hline & $13: 30$ & 0.002 & 0 & 0 \\
\hline & $14: 30$ & 0.016 & 0 & 0 \\
\hline & $15: 30$ & 0.01 & 0 & 0 \\
\hline & $16: 30$ & 0 & 0 & 0 \\
\hline & $17: 30$ & 0.001 & 0 & 0 \\
\hline & $18: 30$ & 0 & 0 & 0 \\
\hline & $19: 30$ & 0 & 0 & 0 \\
\hline & $20: 30$ & 0 & 0 & 0 \\
\hline & $21: 30$ & 0 & 0 & 0 \\
\hline & $22: 30$ & 0 & 0 & 0 \\
\hline & $23: 30$ & 0 & 0 & 0 \\
\hline & $0: 30$ & 0 & 0 & 0 \\
\hline \multirow[t]{24}{*}{ Mon, 12/Jul } & $1: 30$ & 0 & 0 & 0 \\
\hline & $2: 30$ & 0 & 0 & 0 \\
\hline & $3: 30$ & 0 & 0 & 0 \\
\hline & $4: 30$ & 0 & 0 & 0 \\
\hline & $5: 30$ & 0 & 0 & 0 \\
\hline & $6: 30$ & 0 & 0 & 0 \\
\hline & $7: 30$ & 0 & 0 & 0 \\
\hline & $8: 30$ & 0 & 0 & 0 \\
\hline & $9: 30$ & 0 & 0 & 0 \\
\hline & $10: 30$ & 0 & 0 & 0 \\
\hline & $11: 30$ & 0 & 0 & 0 \\
\hline & $12: 30$ & 0 & 0 & 0 \\
\hline & $13: 30$ & 0 & 0 & 0 \\
\hline & $14: 30$ & 0 & 0 & 0 \\
\hline & $15: 30$ & 0.029 & 0 & 0 \\
\hline & $16: 30$ & 0.086 & 0 & 0 \\
\hline & $17: 30$ & 0.112 & 0 & 0 \\
\hline & $18: 30$ & 0.1 & 0 & 0 \\
\hline & $19: 30$ & 0.08 & 0 & 0 \\
\hline & $20: 30$ & 0.047 & 0 & 0 \\
\hline & $21: 30$ & 0.011 & 0 & 0 \\
\hline & $22: 30$ & 0 & 0 & 0 \\
\hline & $23: 30$ & 0 & 0 & 0 \\
\hline & $0: 30$ & 0 & 0 & 0 \\
\hline \multirow[t]{8}{*}{ Tue, 13/Jul } & $1: 30$ & 0 & 0 & 0 \\
\hline & $2: 30$ & 0 & 0 & 0 \\
\hline & $3: 30$ & 0 & 0 & 0 \\
\hline & $4: 30$ & 0 & 0 & 0 \\
\hline & $5: 30$ & 0 & 0 & 0 \\
\hline & $6: 30$ & 0 & 0 & 0 \\
\hline & $7: 30$ & 0 & 0 & 0 \\
\hline & $8: 30$ & 0 & 0 & 0 \\
\hline
\end{tabular}




\begin{tabular}{|c|c|c|c|c|}
\hline & $9: 30$ & 0 & 0 & 0 \\
\hline & $10: 30$ & 0 & 0 & 0 \\
\hline & $11: 30$ & 0 & 0 & 0 \\
\hline & $12: 30$ & 0 & 0 & 0 \\
\hline & $13: 30$ & 0.036 & 0.002 & 0 \\
\hline & $14: 30$ & 0.115 & 0.044 & 0.03 \\
\hline & $15: 30$ & 0.156 & 0.073 & 0.061 \\
\hline & $16: 30$ & 0.174 & 0.088 & 0.079 \\
\hline & $17: 30$ & 0.191 & 0.094 & 0.087 \\
\hline & $18: 30$ & 0.189 & 0.092 & 0.09 \\
\hline & $19: 30$ & 0.173 & 0.083 & 0.089 \\
\hline & $20: 30$ & 0.135 & 0.062 & 0.075 \\
\hline & $21: 30$ & 0.083 & 0.034 & 0.051 \\
\hline & $22: 30$ & 0.042 & 0.023 & 0.029 \\
\hline & $23: 30$ & 0.015 & 0.01 & 0.012 \\
\hline & $0: 30$ & 0.001 & 0 & 0.001 \\
\hline \multirow[t]{24}{*}{ Wed, 14/Jul } & $1: 30$ & 0 & 0 & 0 \\
\hline & $2: 30$ & 0 & 0 & 0 \\
\hline & $3: 30$ & 0 & 0 & 0 \\
\hline & $4: 30$ & 0 & 0 & 0 \\
\hline & $5: 30$ & 0 & 0 & 0 \\
\hline & $6: 30$ & 0 & 0 & 0 \\
\hline & $7: 30$ & 0 & 0 & 0 \\
\hline & $8: 30$ & 0 & 0 & 0 \\
\hline & $9: 30$ & 0.031 & 0.013 & 0.007 \\
\hline & $10: 30$ & 0.109 & 0.055 & 0.043 \\
\hline & $11: 30$ & 0.162 & 0.091 & 0.079 \\
\hline & $12: 30$ & 0.21 & 0.121 & 0.111 \\
\hline & $13: 30$ & 0.244 & 0.146 & 0.139 \\
\hline & $14: 30$ & 0.271 & 0.168 & 0.16 \\
\hline & $15: 30$ & 0.292 & 0.182 & 0.172 \\
\hline & $16: 30$ & 0.301 & 0.186 & 0.179 \\
\hline & $17: 30$ & 0.291 & 0.18 & 0.174 \\
\hline & $18: 30$ & 0.269 & 0.168 & 0.165 \\
\hline & $19: 30$ & 0.242 & 0.152 & 0.154 \\
\hline & $20: 30$ & 0.201 & 0.124 & 0.131 \\
\hline & $21: 30$ & 0.143 & 0.091 & 0.108 \\
\hline & $22: 30$ & 0.099 & 0.085 & 0.088 \\
\hline & $23: 30$ & 0.072 & 0.071 & 0.068 \\
\hline & $0: 30$ & 0.052 & 0.057 & 0.052 \\
\hline \multirow[t]{23}{*}{ Thu, 15/Jul } & $1: 30$ & 0.038 & 0.046 & 0.041 \\
\hline & $2: 30$ & 0.026 & 0.032 & 0.028 \\
\hline & $3: 30$ & 0.013 & 0.016 & 0.014 \\
\hline & $4: 30$ & 0.002 & 0.004 & 0.003 \\
\hline & $5: 30$ & 0 & 0 & 0 \\
\hline & $6: 30$ & 0 & 0 & 0 \\
\hline & $7: 30$ & 0 & 0.004 & 0.005 \\
\hline & $8: 30$ & 0.017 & 0.024 & 0.02 \\
\hline & $9: 30$ & 0.073 & 0.046 & 0.041 \\
\hline & $10: 30$ & 0.111 & 0.065 & 0.06 \\
\hline & $11: 30$ & 0.127 & 0.076 & 0.071 \\
\hline & $12: 30$ & 0.143 & 0.089 & 0.085 \\
\hline & $13: 30$ & 0.166 & 0.1 & 0.092 \\
\hline & $14: 30$ & 0.173 & 0.101 & 0.089 \\
\hline & $15: 30$ & 0.171 & 0.097 & 0.092 \\
\hline & $16: 30$ & 0.148 & 0.086 & 0.085 \\
\hline & $17: 30$ & 0.126 & 0.076 & 0.077 \\
\hline & $18: 30$ & 0.115 & 0.069 & 0.072 \\
\hline & $19: 30$ & 0.1 & 0.058 & 0.065 \\
\hline & $20: 30$ & 0.075 & 0.042 & 0.051 \\
\hline & $21: 30$ & 0.043 & 0.023 & 0.032 \\
\hline & $22: 30$ & 0.021 & 0.022 & 0.021 \\
\hline & $23: 30$ & 0.008 & 0.012 & 0.009 \\
\hline
\end{tabular}




\begin{tabular}{|c|c|c|c|c|}
\hline & $0: 30$ & 0 & 0.005 & 0.001 \\
\hline \multirow[t]{24}{*}{ Fri, 16/Jul } & $1: 30$ & 0 & 0.001 & 0 \\
\hline & $2: 30$ & 0 & 0 & 0 \\
\hline & $3: 30$ & 0 & 0 & 0 \\
\hline & $4: 30$ & 0 & 0 & 0 \\
\hline & $5: 30$ & 0 & 0 & 0 \\
\hline & $6: 30$ & 0 & 0 & 0 \\
\hline & $7: 30$ & 0 & 0 & 0 \\
\hline & $8: 30$ & 0 & 0 & 0 \\
\hline & $9: 30$ & 0 & 0 & 0 \\
\hline & $10: 30$ & 0.004 & 0 & 0 \\
\hline & $11: 30$ & 0.056 & 0 & 0.003 \\
\hline & $12: 30$ & 0.106 & 0.027 & 0.036 \\
\hline & $13: 30$ & 0.142 & 0.059 & 0.064 \\
\hline & $14: 30$ & 0.178 & 0.082 & 0.086 \\
\hline & $15: 30$ & 0.206 & 0.098 & 0.102 \\
\hline & $16: 30$ & 0.22 & 0.106 & 0.11 \\
\hline & $17: 30$ & 0.22 & 0.107 & 0.113 \\
\hline & $18: 30$ & 0.211 & 0.1 & 0.11 \\
\hline & $19: 30$ & 0.184 & 0.085 & 0.099 \\
\hline & $20: 30$ & 0.139 & 0.059 & 0.077 \\
\hline & $21: 30$ & 0.088 & 0.031 & 0.058 \\
\hline & $22: 30$ & 0.049 & 0.029 & 0.039 \\
\hline & $23: 30$ & 0.023 & 0.02 & 0.021 \\
\hline & $0: 30$ & 0.005 & 0.006 & 0.006 \\
\hline \multirow[t]{23}{*}{ Sat, $17 / J u l$} & $1: 30$ & 0 & 0 & 0 \\
\hline & $2: 30$ & 0 & 0 & 0 \\
\hline & $3: 30$ & 0 & 0 & 0 \\
\hline & $4: 30$ & 0 & 0 & 0 \\
\hline & $5: 30$ & 0 & 0 & 0 \\
\hline & $6: 30$ & 0 & 0 & 0 \\
\hline & $7: 30$ & 0 & 0 & 0 \\
\hline & $8: 30$ & 0 & 0 & 0 \\
\hline & $9: 30$ & 0 & 0 & 0 \\
\hline & $10: 30$ & 0.04 & 0.012 & 0.005 \\
\hline & $11: 30$ & 0.132 & 0.065 & 0.046 \\
\hline & $12: 30$ & 0.194 & 0.103 & 0.082 \\
\hline & $13: 30$ & 0.231 & 0.128 & 0.108 \\
\hline & $14: 30$ & 0.248 & 0.145 & 0.129 \\
\hline & $15: 30$ & 0.257 & 0.152 & 0.139 \\
\hline & $16: 30$ & 0.256 & 0.155 & 0.143 \\
\hline & $17: 30$ & 0.252 & 0.151 & 0.142 \\
\hline & $18: 30$ & 0.231 & 0.136 & 0.136 \\
\hline & $19: 30$ & 0.191 & 0.111 & 0.122 \\
\hline & $20: 30$ & 0.139 & 0.08 & 0.092 \\
\hline & $21: 30$ & 0.092 & 0.054 & 0.072 \\
\hline & $22: 30$ & 0.058 & 0.047 & 0.052 \\
\hline & $23: 30$ & 0.035 & 0.035 & 0.035 \\
\hline \multicolumn{2}{|c|}{ Summed load in $\mathrm{KwH}$} & 10.701 & 5.792 & 5.736 \\
\hline & & Percentage reduction & 45.87 & 46.40 \\
\hline
\end{tabular}

Table A. 9 Exterior wall specific conduction gain observed between reference model and vegetated models

\begin{tabular}{|c|c|c|c|}
\hline & $\begin{array}{l}\text { Conduction gain - } \\
\text { ceiling (kWh) }\end{array}$ & $\begin{array}{l}\text { Conduction gain - } \\
\text { ground floor (kWh) }\end{array}$ & $\begin{array}{l}\text { Conduction gain - } \\
\text { walls (kWh) }\end{array}$ \\
\hline Reference model & 2.4 & 0.5 & 7 \\
\hline $\begin{array}{l}\text { Enclosed vegetated } \\
\text { model }\end{array}$ & 2.6 & 0.6 & 1.5 \\
\hline
\end{tabular}




\section{Bibliography}

American Society of Heating, Refrigeration and Air-Conditioning Engineers, Inc. (ASHRAE). (2007). ASHRAE Handbook: Heating, Ventilation \& Air-Conditioning Applications. Atlanta: ASHRAE Inc.

American Society of Heating, Refrigeration and Air-Conditioning Engineers, Inc. (ASHRAE). (2009). ASHRAE Handbook: Fundamentals SI edition. Atlanta: ASHRAE Inc.

Bass, B., \& Baskaran, B. (2003). Evaluating rooftop and vertical gardens as an adaptation strategy for urban areas. Ottawa: National Research Counci l- Institute for Research in Construction.

Bruse, M., \& Fleer, H. (1998). Simulating surface-plant-air interactions inside urban environments with a three dimensional numerical model. Environmental Modeling and Software, 373-384.

Burklein, C. (2012, January 9). Sustainable travel: Vienna is home to the first hotel with a zero energy balance. Retrieved from Livegreen: http://www.livegreenblog.com/sustainablearchitecture/sustainable-travel-vienna-is-home-to-the-first-hotel-with-a-zero-energybalance-7449/

Carver, A., Unger, D., \& Parks, C. (2004). Modeling energy savings from urban shade trees: An assessment of the CITYgreen energy conservation module. Environmental Management, 650-655.

Castillo-Garcia, G. B. (2011). Effects of evaporative cooling in the thermal performance of green roofs. Portland: Portland State University.

Chang, W., Nazaroff, W., Price, P., Sohn, M., \& Gadgil, A. (2005). Analyzing a database of residential air leakage in the United States. Atmospheric Environement, 3445-3455.

Cheng, C., Cheung, K., \& Chu, L. (2010). Thermal performance of a vegetated cladding system on façade walls. Building and Environement, 1779-1787.

Christen, A., \& Vogt, R. (2004). Energy and Radiation Balance of a Central European City. International Journal of Climatology, 1395-1421.

Dimoudi, A., \& Nikolopoulou, M. (2003). Vegetation in the urban environment: microclimatic analysis and benefits. Energy and Buildings, 69-76.

Eleftheria, A., \& Jones, P. (2008). Temperature decreases in an urban canyon due to green walls and green roofs in diverse climates. Building and Environment, 480-493.

Eumorfopoulou, E., \& Kontoleon, K. (2009). Experimental approach to the contribution of plantcovered walls to the thermal behaviour of building envelopes. Building and Environement, 1024-1038.

Fernandez-Canero, R., Urrestarazu, L., \& Salas, A. (2012). Assessment of the cooling potential of an indoor living wall using different substrates in a warm climate. Indoor and Built Environment, 642-650.

Hien, W., Yok, T., \& Yu, C. (2007). Study of thermal performance of extensive rooftop greenery systems in the tropical climate. Building and Environment, 25-54.

Hoyano, A. (1988). Climatological uses of plants for solar control and effects on the thermal environment of a building. Energy and Buildings, 181-199.

Hutcheon, N., \& Handegor, G. (1995). Building Science for a Cold Climate. National Reasearch Council of Canada: Institute for Research in Construction.

Integrated Environmental Solutions Limited (IES). (2012). Virtual Environment Pro 2012 V.6.4 User Guides. Glasgow, UK.: IES. 
Ip, K., Lam, M., \& Miller, A. (2010). Shading performance of a vertical deciduous climbing plant. Building and Environement, 81-88.

Köhler, M. (2008, May 28). Green facades, a view back and some visions. Urban Ecosyst, pp. 423-436.

Kontoleon, K., \& Eumorfopoulou, E. (2010). The effect of the orientation and proportion of a plant-covered wall layer on the thermal performance of a building zone. Building and Environment, 1287-1303.

Liao, Z., \& Niu, J. (1999). Study on the thermal function of ivy-covered walls. Hong Kong: The Hong Kong Polytechnic University.

McPherson, G., Herrington, L., \& Heisler, G. (1988). Impacts of Vegetation on Residential Heating and Cooling. Energy and Buildings, 41-51.

Meier, A. (1990). Strategic Landscaping and Air-conditioning Savings: A Literature Review. Energy and Buildings, 479-486.

Pérez, G., Rincón, L., Vila, A., González, J., \& Cabeza, L. (2011, January 6). Behaviour of green facades in Mediterranean Continental climate. Energy Conversion and Management, 1861-1867.

Pérez, G., Rincón, L., Vila, A., González, J., \& Cabeza, L. (2011, June 18). Green vertical systems for buildings as passive systems for energy savings. Applied Energy 88, pp. 4854-4859.

Perini, K., Ottelé, M., Fraaij, A., Haas, E., \& Raiteri, R. (2011). Vertical greening systems and the effect on air flow and temperature on the building envelope. Building and Environement, 2287-2294.

Perini, K., Ottelé, M., Haas, E., \& Raiteri, R. (2013). Vertical greening systems, a process tree for green façades and living walls. Urban Ecosystem, 265-277.

Price, J. W. (2010). Green Façade Energetics. College Park: University of Maryland.

Reagan, J., \& Acklam, D. (1979). Solar Reflectivity of Common Building Materials and its Influence on the Roof Heat Gain of Typical Southwestern U.S.A. Residences. Energy and Buildings, 237-248.

Sandifer, S., \& Givoni, B. (2002). Thermal effects of vines on wall temperatures-comparing laboratory and field collected data. SOLAR 2002 (pp. 451-457). Boulder, Colorado: Proceedings of the Annual Conference of the American Solar Energy Society.

Stec, W., Van Paassen, A., \& Maziarz, A. (2005). Modelling the double skin façade with plants. Energy and Buildings, 419-427.

Straube, J., \& Burnett, E. (2005). Building Science for Building enclosures. Westford, Massachusetts: Building Science Press Inc.

Sunakorn, P., \& Yimprayoon, C. (2011). Thermal performance of biofacade with natural ventilation in the tropical climate. 2011 International Conference on Green Buildings and Sustainable Cities (pp. 34-41). Bologna, Italy: Procedia Engineering.

Taha, H. (1997). Urban climates and heat islands: albedo, evapotranspiration, and anthropogenic heat. Energy and Buildings, 99-103.

Takakura, T., Kitade, S., \& Goto, E. (2000). Cooling effect of greenery cover over a building. Energy and Buildings, 1-6.

Tilley, D., Price, J. M., \& Marrow, B. (2012). Vegetated Walls: Thermal and Growth Properties of Structured Green Façades. Toronto \& College Park: Green Roofs for Healthy Cities \& University of Maryland. 
Wong, N., Tan, A., Tan, P., \& NC, W. (2009). Energy simulation of vertical greenery systems. Energy and Buildings, 1401-1408. 